\title{
Pharmaceutical performance testing of commercially available calcium supplements
}

Jianqing Liu

West Virginia University

Follow this and additional works at: https://researchrepository.wvu.edu/etd

\section{Recommended Citation}

Liu, Jianqing, "Pharmaceutical performance testing of commercially available calcium supplements" (2005). Graduate Theses, Dissertations, and Problem Reports. 4168.

https://researchrepository.wvu.edu/etd/4168

This Thesis is protected by copyright and/or related rights. It has been brought to you by the The Research Repository @ WVU with permission from the rights-holder(s). You are free to use this Thesis in any way that is permitted by the copyright and related rights legislation that applies to your use. For other uses you must obtain permission from the rights-holder(s) directly, unless additional rights are indicated by a Creative Commons license in the record and/ or on the work itself. This Thesis has been accepted for inclusion in WVU Graduate Theses, Dissertations, and Problem Reports collection by an authorized administrator of The Research Repository @ WVU. For more information, please contact researchrepository@mail.wvu.edu. 


\title{
PHARMACEUTICAL PERFORMANCE TESTING OF COMMERCIALLY AVAILABLE CALCIUM SUPPLEMENTS
}

\author{
Jianqing Liu \\ THESIS \\ Submitted to the School of Pharmacy \\ at \\ West Virginia University \\ in partial fulfillment of the requirements \\ for the degree of
}

\section{MASTER OF SCIENCE}

in

Pharmaceutics

Paula J. Stout, Ph.D., Chair

Patrick S. Callery, Ph.D.

Mary Stamatakis, Pharm.D.

Department of Basic Pharmaceutical Sciences

Morgantown, West Virginia

2005 


\section{Abstract \\ PHARMACEUTICAL PERFORMANCE TESTING OF COMMERCIALLY AVAILABLE CALCIUM SUPPLEMENTS \\ Jianqing Liu}

The use of dietary supplements is increasing rapidly. More and more people take one or more types of supplements as a health booster, hoping to satisfy their body's daily nutritional need or even relieve disease. Although most dietary supplement products are used with such health benefit intention, they are still regulated as food, meaning that their assessed quality and effectiveness are not required by law. Therefore, the knowledge of the factors that influence the safety and efficacy of these products has not kept pace with public demand.

Calcium is one of the most widely used supplements, with a confirmed benefit for bone growth and a variety of diseases such as osteoporosis. Its active ingredients are usually different types of calcium salts. The products include traditional and quick dissolving tablets. Early studies showed that the solubility of calcium salt is so low that its bioavailability and effectiveness in health benefit are questioned due to its limited dissolution in vitro. With this concern, the pharmaceutical performance of some commercially available calcium products was tested.

In our research, the quality of a number of calcium supplements was evaluated by their physical properties, disintegration and dissolution profiles. Physical tests confirmed the good uniformity of the products. In the USP required dissolution test, most of those products cannot reach acceptable drug release in the specified time period. While formulation factors and the salt form of calcium supplements can to some extent affect their dissolution pattern, it was ultimately considered that the failure may be related to the poor solubility of the calcium salts. 
Based on the results and the proposed mechanisms in the failure in dissolution, a number of revised dissolution test methodologies were performed differing from the USP in attempts to increase the active ingredient's solubility and improvement of the dissolution test sensitivity. A revised testing criterion was obtained by changing the parameters of agitation, dissolution volume, and dissolution medium. The optimized test enhanced the release percentage of calcium and could discriminate the quality of products. This test was then used to evaluate some quick-dissolving calcium products. The results confirmed the test's improvement in discrimination.

In conclusion, the sensitivity of the current USP standard dissolution test is limited in evaluating less soluble drug release. A revised test method which enhances the dissolution can serve to better examine and characterize the quality of calcium supplements. 


\section{TABLE OF CONTENTS}

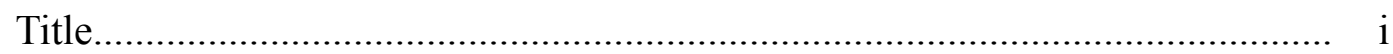

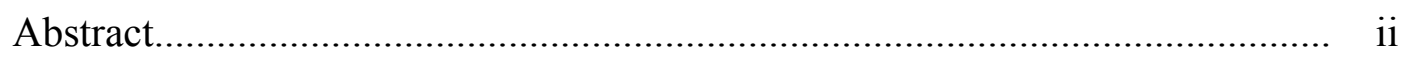

Table of Content.................................................................................. iv

Acknowledgement............................................................................... $\mathrm{V}$

List of Tables................................................................................... vi

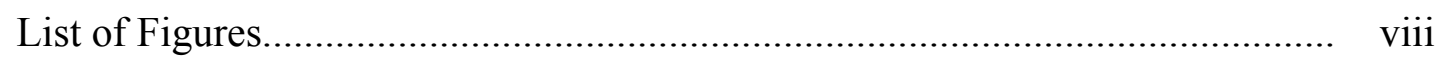

Chapter I - Background and Rationale................................................. 1

References for Chapter I....................................................................... 29

Chapter II - Goals and Objectives........................................................ 50

Chapter III - Materials and methods....................................................... 53

References for Chapter III...................................................................... 75

Chapter IV - Results and Discussion........................................................ 76

References for Chapter IV....................................................................... 104

Chapter V - Summary and Conclusions................................................... 105 


\section{ACKNOWLEDGEMENT}

I would like to thank Dr. Paula Stout who provided constant assistance, confidence in me, and encouragement throughout the project. I would like to thank Dr. Patrick Callery and Dr. Mary Stamatakis who generously gave their time and agreed to serve on my committee. Also, thanks go out to the entire Basic Pharmaceutical, faculty, staff, and students for all their assistance.

I also with to express my appreciation for my loving parents and wife, who through both teaching and example have provided a wonderful home, where the quest of knowledge has always been a pleasurable experience.

Lastly, I would like to thank my friends in Morgantown for all their love, prayer, encouragement and support. 


\section{LIST OF TABLES}

Table 1 Physiological function of calcium.........................................................

Table 2 Recommended Adequate Intake by the IOM for calcium.........................

Table 3 The development of dietary supplements' regulations.......................17-18

Table 4 Dissolution requirement for dietary supplements. ...............................21

Table 5 The comparison of elemental calcium of different calcium salts.............23

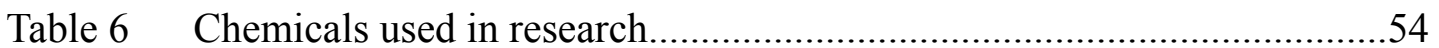

Table 7 Commercial calcium products tested in the research..............................55

Table $8 \quad$ Passing criteria of weight variation test...............................................61

Table 9 The preparation of standard solutions for electrode assessment..............63

Table 10 The preparation of standard solutions for the calibration curve...............64

Table 11 An example of typical readings in calibration......................................65

Table 12 The change of $\mathrm{pH}$ at different surfactant concentrations........................69

Table 13 The composite of surfactant-containing standard solutions for electrode calibration $71-72$

Table 14 Physical properties for each calcium supplement product........................76

Table 15 Length of the tablets and their disintegration in Apparatus A and B.........78

Table 16 Disintegration data of each calcium supplement....................................80

Table 17 The chemical properties of the three calcium salt forms..........................83

Table 18 Calcium supplements' dissolution in surfactant media $50 \mathrm{rpm}$................91

Table 19 Calcium supplements' dissolution in surfactant media 75 rpm................92 
Table 20 NatureMade calcium citrate's dissolution profile in optimized test..........94

Table 21 Major Calcium Carbonate's dissolution profile in optimized test..............95

Table 22 PhosLo Calcium Acetate's dissolution profile in optimized test.........96-97

Table 23 Physical properties of Tums chewable tablets.......................................99

Table 24 Disintegration time for Tums chewable tablets....................................100 


\section{LIST OF FIGURES}

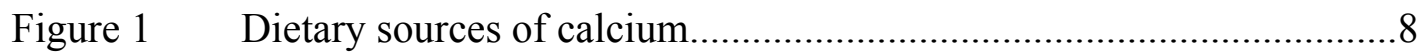

Figure 2 A typical calibration curve with its regression equation......................65

Figure 3 Comparison of disintegration by Apparatus A and B...........................78

Figure 4 Disintegration profile of each calcium supplement...........................80

Figure 5 Calcium supplements' dissolution profiles by USP standard paddle

method .82

Figure 6 Calcium supplements' dissolution profiles in increased speed and larger volume tests. .85

Figure 7 Calcium supplements' dissolution profiles in increased speed and larger volume tests. (without deviation bars) $.86-87$

Figure 8 Calcium supplements' dissolution profiles in phosphate medium..89-90

Figure 9 Calcium supplements' dissolution in containing media $50 \mathrm{rpm}$..........91

Figure 10 Calcium supplements' dissolution in surfactant media 75 rpm...........93

Figure 11 NatureMade Calcium Citrate's dissolution profile in optimized test...94

Figure 12 Major Calcium Carbonate's dissolution profile in optimized test.......96

Figure 13 PhosLo Calcium Acetate's dissolution profile in optimized test.........97

Figure 14 Dissolution profiles of Tums chewable tablets in USP and revised testing method. 101

Figure 15 The comparison of dissolution profiles using optimized and USP conditions. 103 


\section{Chapter I}

\section{Background and Rationale}

\section{Calcium}

Calcium is one of the most abundant minerals in the human body, contributing $1.5 \%$ of the total body weight. ${ }^{1}$ Of all calcium in the body, over $99 \%$ is stored in the bones and teeth to support their structures. The remaining $1 \%$ is found in blood or intercellular fluid, providing other essential functions in nerve conduction, ${ }^{2,3,4}$ muscle contraction, ${ }^{5,6,7}$ secretion of hormones and enzymes, ${ }^{8,9,10,11}$ and blood clotting. ${ }^{12,13,14}$

Without sufficient calcium, a number of related physiological processes will be affected. Furthermore, when there is not sufficient calcium in the blood, calcium stored in the bone will be released to maintain blood calcium levels. This calcium transfer will, in the long run, deteriorate the bone structure, known as osteopenia and osteoporosis. ${ }^{15,16}$ Therefore, it is important to consume sufficient calcium to maintain bone health and other vital body processes as well.

\section{* Calcium's role in disease prevention and health}

Since calcium is involved in many physical reactions and processes, the lack of sufficient calcium can lead to various diseases or health problems. It is now a most widely used dietary supplement for many health concerns. 


\section{a. Osteoporosis and osteopenia}

Bones change throughout life. During childhood and adolescence, bones increase in size and mass. About the age of 30 , bone mass reaches its peak. ${ }^{17}$ Regular weight bearing exercise can contribute to bone strength and density to help prevent osteoporosis. $^{18}$

Osteoporosis means "porous bone". ${ }^{16,17,19}$ Osteoporosis and osteopenia are a condition in which the normal amount of bone mass has decreased. The bone mass is determined by bone mineral density (BMD) tests, which measure the BMD in different parts of the body, hip, wrist, spine, etc. and compare this with an optimal BMD value of a 30 year old healthy adult. Osteopenia is when the so-called T-score is between -1.0 and -2.5 . When below -2.5 , osteoporosis is diagnosed. ${ }^{20,21}$ People with osteoporosis usually have brittle bones, which increases the risk of bone fracture, particularly in the hip, spine, and wrist. ${ }^{22}$

Osteoporosis and osteopenia can result from dietary factors such as:

- chronically low calcium intake in diet

The insufficient calcium intake limits the formation of blood cells and other essential physiological functions. Bone degradation will then take place to satisfy the need to maintain plasma calcium levels. ${ }^{18}$

- low vitamin D intake

Research has proved that Vitamin D can mediate the intestinal absorption of calcium. $^{23,24,25,26}$ Sufficient sunshine can induce Vitamin D formation in the body and thus, increase the calcium absorption. Vitamin D intake from dietary 
supplements has the same effect.

- poor calcium absorption

Besides the lack of vitamin $\mathrm{D}$, other factors that can limit calcium absorption are: a diet high in phytic acid ${ }^{27}$, a sedentary life ${ }^{28}$, and phosphoric acid, as found in soft drinks ${ }^{29}$.

- excess calcium excretion

Excessive calcium excretion can be found in patients with celiac desease. ${ }^{30,31}$ It is also reported that increased sodium intake can result in increased calcium excretion $^{32,33,34}$

There are a number of confirmed factors that increase the risk for osteoporosis. Some of the risk factors cannot be changed, including being female ${ }^{35}$, postmenopausal $^{36,37}$, having a small skeleton ${ }^{38}$, being Caucasian/Asian ${ }^{39,40}$, family history of osteoporosis and fractures ${ }^{41,42}$, and advanced age ${ }^{43,44}$, while many other factors are controllable, such as calcium-consuming medications like steroids (used to treat asthma and arthritis) ${ }^{45}$ and high dosages of thyroid hormone ${ }^{46}$, inadequate or excessive intake of fiber and phosphorous nutrients ${ }^{47}$, excessive exercise ${ }^{48}$, low body weight $^{48}$, cigarette smoking ${ }^{49,50}$ and high alcohol consumption ${ }^{51}$.

Osteoporosis affects people of different races, genders and ethnicities. It is a serious public health problem for more than 10 million Americans. Women are at higher risk and it is estimated that they make up $80 \%$ of all osteoporosis patients. ${ }^{52}$

This public concern led to a special authorization from the FDA in 1993, permitting a health claim for food labels in calcium, saying "adequate calcium intake 
throughout life is linked to reduced risk of osteoporosis through the mechanism of optimizing peak bone mass during adolescence and early adulthood and decreasing bone loss later in life" ${ }^{53}$ This regulation recognized the evidence that insufficient calcium intake can lead to low peak bone mass and is considered a risk factor for osteoporosis.

\section{b. Kidney stones}

Kidney stone disease constitutes a major health care burden for the United States population, causing significant pain, morbidity, and hospitalization. ${ }^{54}$ Recent reports suggest that the incidence of these cases is increasing. Men tend to be affected more frequently than women. Kidney stones are crystallized deposits of calcium and other minerals in the urinary tract. Calcium oxalate is the most common form. ${ }^{54}$

Although calcium oxalate stone disease is a very common health problem among adults in the United States, it is poorly understood at the basic science level. The disease may be caused by many factors. ${ }^{55,56}$ A dietary cause was intensively researched. ${ }^{55,56}$ Patients have been advised to consume low calcium diets to prevent kidney stone formation; however, scientists found later that meeting recommended calcium intake actually reduces the risk. ${ }^{57,58}$ It is thus important for patients to consume appropriate amount of calcium, avoiding deficient or excessive intake. ${ }^{59}$

\section{c. Phosphorus binding}

Hyperphosphataemia plays a key role in the pathogenesis of renal 
osteodystrophy (generalized changes in the bone that resemble osteomalacia and rickets; occurring in those with chronic renal failure), and phosphate-binding agents are required in many chronic dialysis patients. ${ }^{60}$ Calcium acetate is used as a potent phosphate binder to increase gastrointestinal excretion of phosphorus. Research shows it increases fecal excretion of phosphorus by binding both dietary and endogenous phosphorus. Calcium acetate has now taken the place of once commonly used calcium carbonate and become a common treatment. ${ }^{61,62}$ For the most efficient phosphorus binding, calcium dosing with meals is recommended. ${ }^{61}$

\section{d. Acid reflux}

The full name for acid reflux is gastro-oesophageal reflux, which may be caused by heartburn or indigestion. Acid reflux usually occurs after eating a heavy meal, during pregnancy, or as a side effect of constipation. ${ }^{63,64}$ People who are overweight, smokers and heavy drinkers have a higher risk of developing the condition. Acid reflux can also be a symptom of a hiatal hernia. ${ }^{64}$

A most common antacid used is calcium carbonate, which can also be used as a combined formulation with other salts (Calcium Carbonate and Magnesia; Calcium Carbonate, Magnesia, and Simethicone; Calcium and Magnesium Carbonate). Locally, these salts can neutralize excessive acid in the GI tract and thus effectively alleviate symptoms. In the stomach, the carbonate can neutralize the excessive acid and thus relieve the reflux symptom. Some antacids also contain ingredients such as alginates that relieve the symptoms of trapped gas. ${ }^{65,66}$ 


\section{e. Hypertension}

For a long time, research has indicated that a vegetarian diet high in minerals (calcium, magnesium and potassium) and fiber and low in fat, can reduce blood pressure. $^{67}$

In 1997, the National Heart, Lung and Blood Institute of NIH reported their findings in "Dietary Approaches to Stop Hypertension (DASH)". The pattern of increased calcium, decreased blood pressure was confirmed. And a DASH diet of sufficient fruits and vegetables as well as calcium from low fat dairy products was suggested. $^{70}$

In 2003, a large scale survey $(17,030$ participants 20 years or older) confirmed the effect of calcium in lowering blood pressure, and suggested that "If the calcium intake of the general population were to increase to above $1200 \mathrm{mg}$, the incidence of isolated systolic hypertension in the elderly might be decreased."69

The mechanism is still in debate, but this connection has now been proved. ${ }^{70}$

\section{f. Cancer}

The relationship between calcium intake and the risk of colorectal cancer and prostate cancer has been reported. Some observational studies suggest that increased intake of dietary and supplemental calcium is associated with a decrease risk of colorectal cancer. ${ }^{71,72,73}$ Some other published results, however, indicate that such a connection is not clear, both in colorectal cancer ${ }^{74,75,76}$ and colon cancer ${ }^{75,77}$. 


\section{g. Weight management}

It is reported that calcium, especially that from dairy products, can help regulate body fat. ${ }^{78,79}$ For body weight control, low fat dairy products are more beneficial than calcium supplements alone. ${ }^{80}$

A summary of the proven and suggested health benefits of calcium supplementation in the diet is shown below.

\begin{tabular}{|c|l|}
\hline \multicolumn{1}{|c|}{ Rating } & \multicolumn{1}{|c|}{ Health Concerns } \\
\hline & $\begin{array}{l}\text { Gestational hypertension } \\
\text { Lactose intolerance (for preventing deficiency if dairy } \\
\text { products are avoided only) } \\
\text { Osteoporosis } \\
\text { Preeclampsia (for deficiency) } \\
\text { Premenstrual syndrome } \\
\text { Rickets }\end{array}$ \\
\hline Celiac disease (for deficiency only) \\
\hline High blood pressure \\
High cholesterol \\
High triglycerides
\end{tabular}

Table 1. Physiological function of calcium ${ }^{81}$ 


\section{* Recommended intake}

The Institute of Medicine (IOM) of the National Academy of Sciences provides the recommendations for calcium in its Dietary Reference Intakes (DRIs). The Recommended Daily Amount (RDA) recommends the average daily intake that is sufficient to meet the nutrient requirements of nearly all (97-98\%) healthy individuals in each age and gender group. Table 2 shows the current recommendations for calcium for infants, children and adults.

\begin{tabular}{|l|l|l|}
\hline Male and Female Age & Calcium $(\mathbf{m g} /$ day) & Pregnancy \& Lactation \\
\hline \hline 0 to 6 months & 210 & N/A \\
\hline \hline 7 to 12 months & 270 & N/A \\
\hline \hline 1 to 3 years & 500 & N/A \\
\hline \hline 4 to 8 years & 800 & N/A \\
\hline \hline 9 to 13 years & 1300 & N/A \\
\hline 14 to 18 years & 1300 & 1300 \\
\hline 19 to 50 years & 1000 & 1000 \\
\hline $51+$ years & 1200 & N/A \\
\hline
\end{tabular}

Table 2. Recommended Adequate Intake by the IOM for calcium ${ }^{82}$

The National Institute of Health Consensus Conference and the National Osteoporosis Foundation support a higher calcium intake of 1,500 milligrams per day for postmenopausal women not taking estrogen and adults 65 years or older.

It is reported by the Continuing Survey of Food Intakes of Individuals (CSFII 1994-96) that the following percentage of Americans are not meeting their recommended calcium intake.

$44 \%$ boys and $58 \%$ girls ages $6-11$

$64 \%$ boys and $87 \%$ girls ages $12-19$

$55 \%$ men and $78 \%$ of women ages $20+{ }^{83}$ 


\section{Sources of calcium}

In the typical American diet, the major contributors of calcium are milk, yogurt and cheese. ${ }^{84}$ Insufficient intake of these dairy foods leads to a possible deficiency in calcium. The U.S. Department of Agriculture's Food Guide Pyramid recommends that individuals two years and older eat 2-3 servings of dairy products per day. ${ }^{85}$ A serving is equal to: (as shown in Figure 1)

1 cup ( $8 \mathrm{fl} \mathrm{oz})$ of milk

8 oz of yogurt

$1.5 \mathrm{oz}$ of natural cheese (such as Cheddar)

$2.0 \mathrm{oz}$ of processed cheese (such as American)

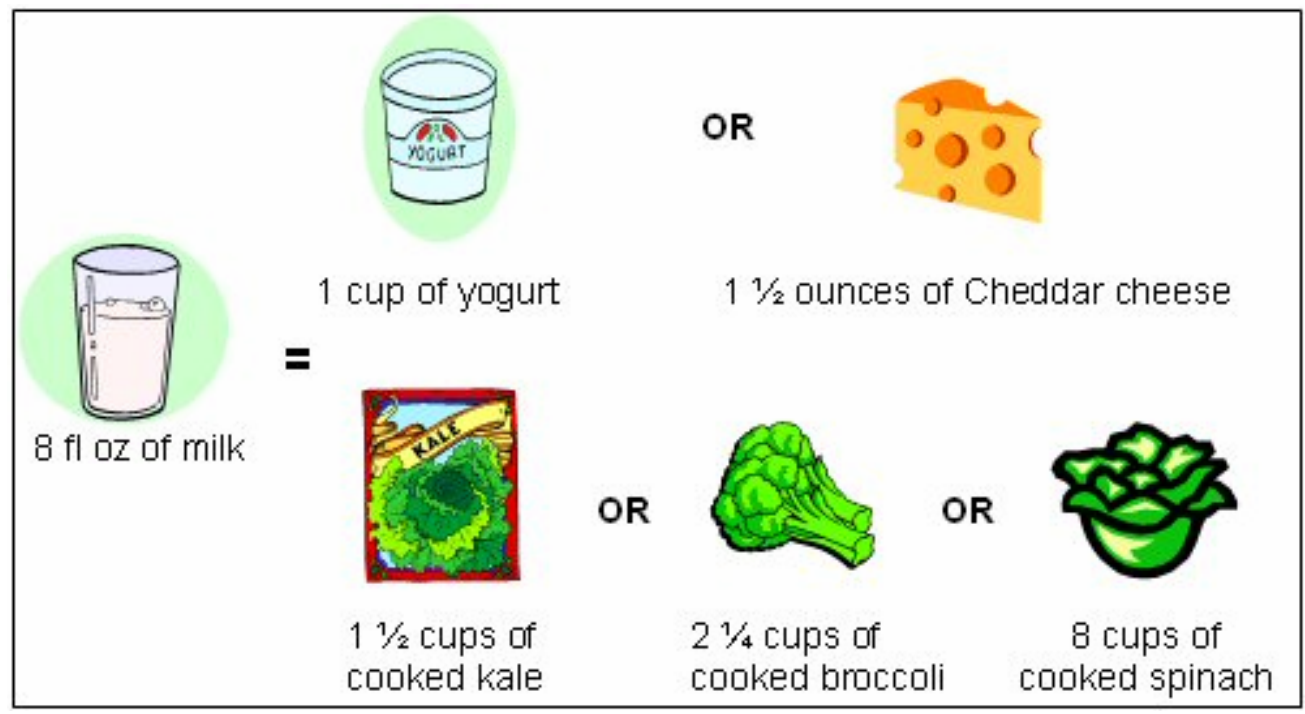

Figure 1. Dietary sources of calcium ${ }^{86}$

It is recommended that obtaining calcium from the diet is more beneficial than from supplements, because of its advantage of providing other nutrients that are important for absorbing and using calcium in the body, such as lactose in milk. The 
2005 Dietary Guidelines for Americans states, "Different foods contain different nutrients and other healthful substances. No single food can supply all the nutrients in the amounts you need". ${ }^{87}$ Building a healthful diet is thus necessary to ensure sufficient intake.

\section{Absorption and excretion}

The absorption of calcium from the GI tract can be affected by various factors:

\section{- Vitamin D}

Vitamin D is a steroid hormone involved in mineral metabolism and bone growth. It has been widely researched and proved to stimulate intestinal absorption of calcium. In the absence of vitamin $\mathrm{D}$, dietary calcium is not absorbed efficiently. ${ }^{88,89,90,91}$ Vitamin D facilitates the expression of a number of proteins involved in transporting calcium from the lumen of the intestine, across the epithelial cells and into blood. ${ }^{92,93}$ Vitamin D can be synthesized by the body when exposed to sunlight and/or obtained from food or supplements. ${ }^{94}$

\section{- Pregnancy}

It is proved that women in late pregnancy have an increased ability to absorb calcium from the intestine. ${ }^{95,96,97}$ Animal experiments showed the connection between this increase and the fetal skeleton formation and mineralization. ${ }^{98}$

\section{- Food interaction}

Vegetables such as spinach, collard greens, sweet potatoes, rhubarb, and beans contain oxalic acid. Whole grain bread, beans, seeds, nuts, grains, and soy isolates 
contain phytic acid. Both can bind to calcium and prevent it from being absorbed. ${ }^{99}$

- Age

For infants and young children when bones are growing, calcium absorption can reach $60 \%$ to satisfy the need of bone growth. The calcium absorption of a healthy adult is around $15-20 \%$. When people get even older, the calcium absorption decreases even more. ${ }^{100}$

There are also a few factors affecting calcium excretion:

- Sodium and protein

It is reported that increased intake of dietary sodium and protein can increase calcium excretion. $^{101,102}$

- Potassium

Intake of potassium can help decrease calcium excretion, especially for post menopausal women. ${ }^{103,104}$

In conclusion, a number of factors can have effects on the absorption and/or excretion of calcium. The deficiency of calcium is not uncommon among people.

\section{Dietary Supplements}

\section{Definition of nutraceuticals, dietary supplements}

In 1989, Stephen DeFelice, MD, founder of the Foundation for Innovation in Medicine (FIM) first combined the word "nutrition" and "pharmaceutical" and invented the term "nutraceutical". ${ }^{105}$ After that, this word has been commonly used in 
our daily life without a strict regulatory definition. ${ }^{106}$ In DeFelice's words, nutraceutical is "a food (or part of a food) that provides medical or health benefits, including the prevention and /or treatment of a disease". Such definition is so broad that it obviously includes nutrition strengthened food and many of our daily foods.

Dr. Ekta K. Kalra suggested in 2003 that food which "is being cooked or prepared using 'scientific intelligence' with or without knowledge of how or why it is being used" should be categorized into "functional food", so that these can be separated from more drug-like nutritional products. Kalra proposed that "nutraceutical":

- must not only supplement the diet but should also aid in the prevention and/or treatment of disease and/or disorder.

- are represented for use as a conventional food or as the sole item of a meal or diet. $^{107}$

If Kalra's proposal is accepted, the term "nutraceutical" will have a much narrower meaning than it currently has. Nowadays, nutraceutical is widely used like a synonym of "dietary supplement".

But till now, the term "nutraceutical" has still not been accepted officially. The Dietary Supplement Health and Education Act (DSHEA) and United States Pharmacopoeia (USP) use "dietary supplement" (DS) to regulate related products. According to the definition by the DSHEA in 1994, a dietary supplement:

- is a product that is intended to supplement the diet and that bears or contains one or more of the following dietary ingredients: a vitamin, a mineral, an herb or 
other botanical, an amino acid, a dietary substance for use by man to supplement the diet by increasing the total daily intake, or a concentrate, metabolite, constituent, extract, or combinations of these ingredients.

- is intended for ingestion in pill, capsule, tablet, or liquid form.

- is not represented for use as a conventional food or as the sole item of a meal or diet.

- is labeled as a "dietary supplement."

- includes products such as an approved new drug, certified antibiotic, or licensed biologic that was marketed as a dietary supplement or food before approval, certification, or license (unless the Secretary of Health and Human Services waives this provision). ${ }^{108}$

Here, the "dietary ingredient" may include vitamins, minerals, herbs or other botanicals, amino acids and substances like enzymes, organ tissues, glandulars, and metabolites. DS can be extracts or concentrates, in forms like tablets, capsules, softgels, gelcaps, liquids or powders.

Therefore, the calcium supplements studied in this research fall into this "dietary supplement" category and must comply with all requirements of the regulation.

\section{The use of dietary supplements}

By their dietary function or origin, DS are grouped into three major categories: 1) substances with proved nutritional function (vitamins, minerals, amino acids and fatty acids); 2) botanical products and their concentrates or extracts (garlic, ginseng and St. 
John's Wort); and 3) other substances with physiologic roles (pyruvate, steroid hormone precursors and chondroitin sulfate). ${ }^{109}$

Many people in the western countries view DS as an important component of a healthy lifestyle. They take DS for a variety of reasons. Most important motivations include ensuring nutritional adequacy, maintaining tissue structures and functions, reducing the risk of diseases, improving physical performance and withstanding aging. ${ }^{110,111}$ The rapid growth in the DS market reflects consumers' eager need and desire for health benefits. The scientific evidence to support the DS's efficacy, however, varies greatly from one product to another. Some active ingredients like vitamins and calcium are extensively researched, while the effects of some others, especially natural products, are in continuous debate due to the lack of their experimental proof of safety, effect, and efficacy. ${ }^{110}$

\section{The regulation of dietary supplements}

The two major government agencies that regulate DS products are the Food and Drug Administration (FDA) ${ }^{113}$ and the United States Pharmacopoeia (USP). The FDA regulates DS through its subsidiary organization, the Center for Food Safety and Applied Nutrition. Before October in 1994, DS were treated by the same regulatory system as other traditional foods, under the Food Drug and Cosmetic Act (FDCC Act - FDCA). ${ }^{114}$ After President Clinton signed DSHEA as an amendment to FDCA, this new law became the framework to regulate DS. ${ }^{115}$

Basically, DS are still regulated as foods under DSHEA. Manufacturers only 
need to ensure the safety of their product. There is no need to present evidence to substantiate the effectiveness of the DS, unlike drugs and food additives. ${ }^{116}$ Under this law, "DS manufacturers do not have to register with the FDA, or obtain FDA approval before producing or selling their products. Prior to marketing a product, manufacturers are responsible for ensuring that a dietary supplement (or a new ingredient) is safe before it is marketed. FDA has the authority to take action against unsafe dietary supplement products. Manufacturers must ensure that their product label information is truthful and not misleading."115

As for the safety inspection, the manufacturers are not legally required to report related "adverse effect" reports to the FDA. And the FDA is not capable of analyzing the composition of every DS product, due to limited resources. The FDA never reviews or analyzes DS before the supplement goes on the market. The monitor of DS safety is through voluntary adverse event reporting, labeling claims, literature, and routinely random laboratory testing, etc. The manufacturers are also responsible for ensuring that the "Supplement Fact" label and ingredient list and content are accurate. $^{116}$

Since DS are regulated as foods, it is illegal to promote them on their labels as a treatment, prevention or cure for a specific disease or condition. ${ }^{116,117}$ By law, only three types of claims can be used for DS: health claims that describe the link between a substance and disease or a health condition; structure/function claims which refer to the intended benefits; nutrient content claims that specify the amount of the dietary substance in the product. ${ }^{118,119}$ When a structure/function claim is presented, a 
"disclaimer" must also be marked on the labeling that says: "This statement has not been evaluated by the FDA. This product is not intended to diagnose, treat, cure, or prevent any disease." ${ }^{\prime 19}$ Any violation will lead to the loss of the product's status as a DS and be thus considered an unapproved or misbranded drug.

Over the years, with the increasing popularity of DS, but also based on the need to ensure the effectiveness of DS, the USP-NF has added a series of supplemental chapters and related monographs to test vitamin and mineral and some botanical products. In General Chapters, a chart for evaluating dietary supplement products has also been developed as a standard guidance.

It is voluntary for manufacturers to follow the standards prescribed in USP. In the Dietary Supplement Verification Program (DSVP), the manufacturers can apply for the tests by USP and obtain an authorization of the DSVP mark which assures consumers, health care professionals, and supplement retailers that a product:

- Contains the ingredients stated on the label in the declared amount and strength

- Meets specified standards for product purity by meeting requirements for known contaminants

- Has been manufactured properly by complying with USP and proposed FDA standards for good manufacturing practices (GMPs) $)^{120}$

At present, USP focuses on developing testing method to decide the products' acceptability, stability and performance in approved applications, while the FDA places more emphasis on marketing, labeling and safety issues. ${ }^{121}$ In addition to USP, 
the Center for Food Safety and Nutrition of the FDA also regulates vitamins, minerals and other DS. ${ }^{122}$ The advertising of DS is in the charge of the Federal Trade Commission (FTC). ${ }^{117,118}$

\section{* Concise history of dietary supplement regulation}

Although the USP and the FDA share a common mission of actively promoting the public health, and USP's DSVP complements FDA's regulation of DS products, the two agencies, however, are separate programs and focus on different aspects of DS regulation.

A brief history of developments of DS's regulation is shown in the following table.

\begin{tabular}{|l|l|}
\hline 1938 & $\begin{array}{l}\text { The Federal Food, Drug and Cosmetic Act acknowledges vitamin, } \\
\text { mineral and other dietary properties of foods. The FDA uses the drug } \\
\text { provisions of the law to stake its claim to reclassify dietary supplements } \\
\text { as drugs based on their label claims. }\end{array}$ \\
\hline 1941 & $\begin{array}{l}\text { The first recommended daily allowances (RDAs) are published } \\
\text { establishing the basis for the FDA's regulation of vitamins and minerals, } \\
\text { despite opposing opinions claiming the RDA was not reflective of } \\
\text { current scientific advances on the benefits of nutrients in maintaining } \\
\text { health }\end{array}$ \\
\hline $1966-73$ & $\begin{array}{l}\text { The FDA publishes proposed new guidelines for labeling and content of } \\
\text { dietary supplements; however, public opposition forces further hearings. } \\
\text { Finally in 1973, the FDA publishes final regulations classifying any } \\
\text { supplements stronger than 150 percent of the RDA as drugs. }\end{array}$ \\
\hline 1976 & $\begin{array}{l}\text { Proxmire Bill was passed in congress, prohibiting the FDA from } \\
\text { regulating vitamins and minerals as prescription drugs. }\end{array}$ \\
\hline
\end{tabular}




\begin{tabular}{|l|l|}
\hline 1990 & $\begin{array}{l}\text { Nutrition Labeling and Education Act (NLEA) was signed by President } \\
\text { Bush. The FDA was authorized to implement this law. }\end{array}$ \\
\hline 1991 & $\begin{array}{l}\text { USP holds an open conference on vitamins, minerals, and nutritional } \\
\text { supplements. The first proposals are discussed and reviewed. }\end{array}$ \\
\hline 1992 & $\begin{array}{l}\text { The Health Freedom Act was passed to protect the Americans to choose } \\
\text { safe and effective dietary supplements. } \\
\text { Supplement } 8 \text { to USP XXII: The first standards are established, including } \\
\text { requirements for initial disintegration testing and for dissolution testing } \\
\text { proposal for establishing dissolution requirements for nutritional } \\
\text { supplements }\end{array}$ \\
\hline 1993 & $\begin{array}{l}\text { US Congress passes DSHEA. Dietary supplements are regulated by the } \\
\text { FDA in this new framework. }\end{array}$ \\
\hline 1994 & $\begin{array}{l}\text { Supplement 1 to USP 23: Dissolution testing is established as a } \\
\text { requirement for nutritional supplements, including folic acid, index } \\
\text { vitamins, and index elements. } \\
\text { methods, and assays. } \\
\text { Supsequent }\end{array}$ \\
\hline 1999 & \begin{tabular}{l} 
The final regulation of GMP for dietary supplements was issued \\
\hline 1998
\end{tabular} \\
\hline
\end{tabular}

Table 3. A summary of the development of dietary supplements' regulations. ${ }^{123,124}$

\section{The bioavailability of dietary supplements}

All the aforementioned regulations aim to ensure the safety and efficacy of DS. However, since DS are still by far regulated as foods, the regulatory framework for them is not as rigorous as it is for drugs. Therefore, information about bioavailability, 
an essential factor that influences both the safety and efficacy of the product, has not yet been a mandatory specification. The lack of knowledge in bioavailability has limited physicians or other health professionals from giving rigorous recommendations and advice to the public. Thus, a careful choice must be based on cost and effectiveness. For instance, the cost of a 30-day supply of a calcium supplements varies from $\$ 2$ for calcium carbonate and $\$ 5$ for calcium lactate to over $\$ 10$ for calcium gluconate. And calcium carbonate is generally considered to be the most bioavailable source.

The increasing use of the DS products has raised many concerns on the need to use bioavailability as an indicator for the products' effectiveness. Developing a way to solve this issue is necessary and urgent, but challenging as well.

First, scientists have not reached a consensus on how to define bioavailability for DS. A most simple definition is the proportion of a nutrient or bioactive ingredient (relative to its total amount in the DS) that is absorbed from the gastrointestinal tract, which is a straightforward derivation from the concept of drug bioavailability. ${ }^{125}$

A challenging aspect to this is that many DS are used in different therapeutic or nutritional support purposes. While most individuals may consume calcium supplements to satisfy their required daily standard intake (RDA), the same calcium product may also be used to reduce acid or strengthen bones. Other DS, like vitamins or natural products, are also used for effects other than adequate nutrition. Effects like lipid lowering, memory enhancement and sleep improvement are frequently advertised. Such intake purposes are for more pharmacological rather than nutritional 
effects.

Second, many bioactive ingredients in supplements are also endogenous substances (vitamins, minerals, amino acids), which are subject to physiological controls of the active in the DS. Therefore, these ingredients' plasma concentration fails to characterize the product's bioavailability. For example, our bodies need to maintain a rather steady calcium level in the blood. Even when the amount of calcium in the body has raised after the intake of calcium supplements, the plasma concentration remains little changed. Thus, the traditional methods in drug availability evaluation will face unique difficulties when dealing with these products.

Third, the bioavailability performance of many DS is not extensively researched. Sources quote that the bioavailability of folate from food is only half that of folic acid from supplements, but no sufficient data are available to support and compare this claim. These data are necessary to set dietary standards like Dietary Reference Values (DRVs) and Recommended Daily Amounts (RDAs). And the customization of product use by special groups such as the elderly or pregnant women, can only be achieved by collecting sufficient related data.

Facing so many challenges, the USP has developed disintegration and dissolution standards for vitamins and minerals as an in vitro indicator for bioavailability. Although the solubility of a substance alone cannot determine bioavailability, the dissolution test is a "good step forward" as stated by Dr. V. Scrini Srinivasan. ${ }^{125}$ The test is based on evaluating the dissolution of the DS's index vitamin and/or mineral, which in part are selected based on their limited solubility. 


\section{The dissolution tests for dietary supplements}

Over recent years, the USP has established specifications for a number of DS. The tests for vitamins, minerals, and some natural products - botanicals have been standardized.

The following table lists the dissolution requirements and references for the six USP classes of vitamins, minerals and vitamins with minerals.

\begin{tabular}{|l|l|l|}
\hline Class & Dissolution & Reference \\
\hline I. Oil-soluble vitamins & Not required & \\
\hline II. Water-soluble vitamins & $\begin{array}{l}\text { One index vitamin; } \\
\text { Folic acid if present }\end{array}$ & Tablet and capsule assays $^{126}$ \\
\hline III. Water-soluble & One index vitamin and one index & Tablet assays $^{126}$ \\
vitamins with minerals & $\begin{array}{l}\text { element; } \\
\text { Folic acid if present }\end{array}$ & Capsule assays \\
\hline IV. Oil- and water- & $\begin{array}{l}\text { One index water-soluble vitamin; } \\
\text { soluble vitamins }\end{array}$ & Tablet and capsule assays ${ }^{126}$ \\
\hline V. Oil- and water-soluble & One index water-soluble vitamin and & Tablet assays ${ }^{128}$ \\
vitamins with minerals & on index element; folic acid if present & Capsule assays \\
\hline VI. Minerals & One index element & Tablet and capsule assays ${ }^{126}$ \\
\hline
\end{tabular}

Table 4. Dissolution requirement for dietary supplements.

However, it should be noted that the dissolution test which is significantly affected by solubility of the active substance, may not always be an appropriate measure of bioavailability. There are other factors like absorption and formulation also affecting the bioavailability in a great deal. 


\section{Calcium supplements}

\section{Types of calcium products and expected performance for product efficacy}

There are many types of calcium supplements on the market, both single entity and in combination with other vitamins and minerals. The majority are in traditional solid dosage forms, while some chewable tablets also become popular for their convenience.

Calcium in traditional tablets often is taken to be absorbed for systemic effects. Both disintegration and dissolution tests are required to guarantee its efficacy. As for chewable tablets, some are intended to have local effects, as an antacid in stomach. In that case, no dissolution test is necessary. For tablets labeled for any indication other than, or in addition to, antacid use, they must satisfy the specification in their monographs. $^{129}$

The most popular calcium salt forms are carbonate (Tums, OsCal, etc) and citrate (NatureMade, Citracal). Calcium carbonate is most widely used because it is inexpensive and provides the most calcium per tablet. One disadvantage is that carbonate can cause bothersome stomach gas. Since its solubility is rather low, extra stomach acid can help its dissolution and absorption. It is therefore advised to be taken with a meal.

The absorption of calcium citrate is higher than calcium carbonate; therefore it does not require to be taken with meals. For those with decreased stomach acid, the absorption of calcium citrate is far better than of carbonate. A number of studies have shown the absorption of calcium citrate is only moderately higher than 
carbonate. $^{129-134}$

Some new salt forms of calcium supplements have also been compared with carbonate and citrate. In a recent study, calcium formate showed a significantly better absorption. There are also other salt forms available on the market: tricalcium phosphate (Posture), calcium citrate malate (Calcimate), calcium lactate and calcium gluconate. Some calcium supplements also contain vitamin $\mathrm{D}$, which facilitates the calcium absorption.

For these products, the amount of elemental calcium is the indicator of their effective calcium content, which is defined as "the amount of calcium in a calcium supplement". ${ }^{129}$ During digestion, the elemental calcium is released from the compound (carbonate, citrate, etc.) and becomes available for absorption. For example, calcium carbonate is 40 percent calcium (1250 mg calcium carbonate yields $500 \mathrm{mg}$ elemental calcium); calcium citrate is 21 percent calcium (600 mg calcium citrate provides $122 \mathrm{mg}$ elemental calcium). Most products use the total number instead of the percentage as part of their brand name, indicating the amount of elemental calcium in each tablet, i.e., Caltrate 600, OsCal 500, etc. The following table and figure compare the elemental calcium in different products.

\begin{tabular}{llll}
\hline Salt & Molecule & Molecular Weight & Elemental Calcium percentage \\
\hline Carbonate & $\mathrm{CaCO}_{3}$ & 100.09 & $40 \%$ \\
Phosphate & $\mathrm{Ca}_{3}\left(\mathrm{PO}_{4}\right)_{2}+\mathrm{CaNaPO}_{4}$ & 310.18 & $38 \%$ \\
Citrate & $\mathrm{C}_{12} \mathrm{H}_{10} \mathrm{Ca}_{3} \mathrm{O}_{14} \cdot 4 \mathrm{H}_{2} \mathrm{O}$ & 570.49 & $21 \%$ \\
Lactate & $\mathrm{C}_{6} \mathrm{H}_{10} \mathrm{CaO}_{6}$ & 218.22 & $13 \%$ \\
Gluconate & $\mathrm{C}_{12} \mathrm{H}_{22} \mathrm{CaO}_{14}$ & 430.37 & $3 \%$ \\
\hline
\end{tabular}

Table 5. The comparison of elemental calcium of different calcium salts. ${ }^{169}$

Some products have very low calcium content; it is therefore necessary to take 
more tablets to satisfy daily need.

There are also some naturally occurring calcium carbonate products available, including dolomite, oyster shell, bone meal, and coral calcium. However, to this point in time, there is no regulatory agency testing these supplements. It is up to the manufacturer to assure that the lead content meets the FDA requirements.

The amount of elemental calcium in a tablet determines the amount absorbed from different calcium products. Exceeding 2,500mg of elemental calcium per day can result in toxicity.

\section{Current USP requirements for calcium supplements}

The performance test of dietary supplement products includes: $<1216>$ Tablet Friability, <2040> Disintegration and Dissolution of Dietary Supplements, $<2091>$ Weight Variation of Dietary Supplements and $<2750>$ Manufacturing Practices for Dietary Supplements. ${ }^{135}$ Since there are no specified friability, disintegration and manufacturing practice tests in the monograph of any calcium product, these tests follow the same guideline as with other solid dosage DS formulations. The disintegration test is therefore performed in distilled water, unlike the following dissolution test.

Since calcium products usually have limited solubility, which significantly affect their absorption and bioavailability, dissolution is an important factor. Different calcium salts may exhibit different dissolution profiles. USP therefore requires different specification for each product. 


\section{Existing requirements:}

- Calcium acetate tablet ${ }^{136}$

Medium: water; $900 \mathrm{~mL}$

Apparatus 2: $50 \mathrm{rpm}$

Time: 30 minutes

Procedure: atomic absorption spectrophotometry

Tolerances: not less than $80 \%(\mathrm{Q})$ of the labeled amount of $\mathrm{C}_{4} \mathrm{H}_{6} \mathrm{CaO}_{4}$ is dissolved in 30 minutes.

- Calcium carbonate tablet ${ }^{137}$

For Tablets labeled for any indication other than, or in addition to, antacid use.

Medium: $0.1 \mathrm{~N}$ hydrochloric acid; $900 \mathrm{~mL}$

Apparatus 2: 75 rpm

Time: 30 minutes

Procedure: atomic absorption spectrophotometry

Tolerance: not less than $75 \%(\mathrm{Q})$ of the labeled amount of $\mathrm{CaCO}_{3}$ is dissolved in 30 minutes.

- Calcium gluconate tablet ${ }^{138}$

Medium: water; $900 \mathrm{~mL}$

Apparatus 2: $50 \mathrm{rpm}$

Time: 45 minutes

Procedure: atomic absorption spectrophotometry

Tolerance: not less than $75 \%$ (Q) of the labeled amount of $\mathrm{C}_{12} \mathrm{H}_{22} \mathrm{CaO}_{14}$ is 
dissolved in 45 minutes.

- Calcium lactate tablet ${ }^{139}$

Medium: water; $500 \mathrm{~mL}$

Apparatus 1: $10 \mathrm{rpm}$

Time: 45 minutes

Procedure: pooled sample assay $<711>$

Tolerance: not less than $75 \%(\mathrm{Q})$ of the labeled amount of $\left(\mathrm{C}_{6} \mathrm{H}_{10} \mathrm{CaO}_{6} \cdot 5 \mathrm{H}_{2} \mathrm{O}\right)$ is dissolved in 45 minutes.

- Calcium pantothenate tablet ${ }^{140}$

Medium: water; $900 \mathrm{~mL}$

Apparatus 2: $50 \mathrm{rpm}$

Time: 45 minutes

Procedure: infrared absorption

Tolerance: not less than $75 \%$ (Q) of the labeled amount of $\mathrm{C}_{18} \mathrm{H}_{32} \mathrm{CaN}_{2} \mathrm{O}_{10}$ is dissolved in 45 minutes.

- Dibasic calcium phosphate tablet ${ }^{141}$

Medium: $0.1 \mathrm{~N}$ hydrochloric acid; $900 \mathrm{~mL}$

Apparatus 2: $75 \mathrm{rpm}$

Time: 45 minutes

Procedure: atomic absorption spectrophotometry

Tolerance: not less than $75 \%(\mathrm{Q})$ of the labeled amount of $\mathrm{CaHPO}_{4} \cdot 2 \mathrm{H}_{2} \mathrm{O}$ is dissolved in 45 minutes. 
All selected above are calcium supplements in solid dosage formulation with systemic absorption. For products used as an antacid, including some calcium carbonate tablets $^{136}$, calcium carbonate and magnesia tablets ${ }^{142}$, calcium carbonate, magnesia and simethicone tablets ${ }^{143}$, and calcium and magnesium carbonate tablets ${ }^{144}$, there are no dissolution requirements for these products. They are subject to an acid-neutralizing capacity test $<301>$ to confirm their claimed efficacy.

\section{Specifications that do not exist:}

Note that not all calcium supplements have their specifications in USP. Examples are calcium citrate tablets, supplement with vitamin D and other new salt forms.

\section{Results of previous studies on calcium supplements}

The suggestion to take calcium supplements for health benefit or disease treatment has been brought up since the $1980 \mathrm{~s} .{ }^{145,146}$ Because a series of clinical and demographic research confirmed the hypothesized benefit ${ }^{147-150}$, the importance of calcium supplementation was promoted and now has become a common health concern around the world. With its increasing popularity, the research focus has changed from demographic studies, which intend to promote awareness, to investigations more related to the product quality and efficacy, which helps consumers and physicians make the better choices in purchasing or advising.

Concerning the active ingredients, it was reported that the combination of Vitamin D and calcium can lead to much better calcium absorption. ${ }^{151}$ Early studies also agreed that extra estrogen intake can also facilitate calcium supplementation ${ }^{152-154}$, 
and this combined treatment was very common among menopausal women consumers. However, as more reports confirmed the potential adverse effect of estrogen leading to heart attacks ${ }^{155}$, breast cancer $^{156}$ and strokes ${ }^{157,158}$, the FDA ordered warnings on all estrogen labels ${ }^{159}$, and the estrogen replacement therapy is no longer suggested with calcium supplementation.

In the 1990s, coral calcium became popular with its promotion of "natural source" and "better absorption". Such claims were supported by some published research. ${ }^{160}$ The marketing of this product raised questions. ${ }^{161-163}$ Research which followed proved there was no significant advantage. ${ }^{164-167}$ In 2003, the FTC and FDA officially charged marketers of coral calcium supreme dietary supplement with making false and unsubstantiated claims. ${ }^{168}$

Since the FDA has limited resources in evaluating the calcium supplement quality, studies on quality assessment were mostly performed by academic laboratories and other third-party organizations. Early in 1989, cases of calcium tablets with impaired disintegration and dissolution were reported. ${ }^{170}$ Dr. Ralph Shangraw pointed out that many supplements failed to meet USP standards and suggested a comprehensive look at the salt type, the condition of the patient and the time of administration for the best health benefit. ${ }^{171,172}$ A more recent investigation of fifteen popular calcium products showed that two of them failed the disintegration requirement and exceeded lead amount limits. ${ }^{173}$ With the emergence of new calcium salt and new formulations, related studies have also been performed. ${ }^{174,175}$ Therefore, it is necessary to test, characterize, and control the quality of marketed products. 


\section{References for Chapter I}

1. H. A. Harper, V. W. Rodwell, P. A. Mayes, Review of Physiological Chemistry, 16th ed., Lange Medical Publications, Los Altos, California 1977

2. Gillespie WJ, Allardyce RA. Mechanisms of bone degradation in infection: a review of current hypotheses. Orthopedics. 1990 Apr;13(4):407-10.

3. Schneider P, Berger P, Kruse K, Borner W. Effect of calcitonin deficiency on bone density and bone turnover in totally thyroidectomized patients. J Endocrinol Invest. 1991 Dec;14(11):935-42.

4. Blair HC, Schlesinger PH, Ross FP, Teitelbaum SL. Recent advances toward understanding osteoclast physiology. Clin Orthop Relat Res. 1993 Sep;(294):7-22.

5. Jiang H, Stephens NL. Calcium and smooth muscle contraction. Mol Cell Biochem. 1994 Jun 15;135(1):1-9.

6. Ohtsuki I. Calcium ion regulation of muscle contraction: the regulatory role of troponin T. Mol Cell Biochem. 1999 Jan;190(1-2):33-8.

7. Moreland RS, Cilea J, Moreland S. Calcium dependent regulation of vascular smooth muscle contraction. Adv Exp Med Biol. 1991;308:81-94.

8. Schulz I, Stolze HH. The exocrine pancreas: the role of secretagogues, cyclic nucleotides, and calcium in enzyme secretion. Annu Rev Physiol. 1980;42:127-56.

9. Brown BL, Walker SW, Tomlinson S. Calcium calmodulin and hormone secretion. Clin Endocrinol (Oxf). 1985 Aug;23(2):201-18

10. Gershengorn MC. Thyrotropin-releasing hormone action: mechanism of 
calcium-mediated stimulation of prolactin secretion. Recent Prog Horm Res. $1985 ; 41: 607-53$.

11. Caroppo R, Gerbino A, Fistetto G, Colella M, Debellis L, Hofer AM, Curci S. Extracellular calcium acts as a "third messenger" to regulate enzyme and alkaline secretion. J Cell Biol. 2004 Jul 5;166(1):111-9.

12. Cooke RD, Pestell TC, Holbrook JJ. Calcium and thiol reactivity of human plasma clotting factor XIII. Biochem J. 1974 Sep;141(3):675-82.

13. Hall DD, Cromwell GL, Stahly TS. Effects of dietary calcium, phosphorus, calcium: phosphorus ratio and vitamin $\mathrm{K}$ on performance, bone strength and blood clotting status of pigs. J Anim Sci. 1991 Feb;69(2):646-55.

14. Ataullakhanov FI, Pohilko AV, Sinauridze EI, Volkova RI. Calcium threshold in human plasma clotting kinetics. Thromb Res. 1994 Aug 15;75(4):383-94.

15. Meunier PJ. Calcium, vitamin D and vitamin $\mathrm{K}$ in the prevention of fractures due to osteoporosis. Osteoporos Int. 1999;9 Suppl 2:S48-52. Review.

16. Sahota O. Osteoporosis and the role of vitamin D and calcium-vitamin D deficiency, vitamin D insufficiency and vitamin D sufficiency. Age Ageing. 2000 Jul;29(4):301-4. Review.

17. Flynn A. The role of dietary calcium in bone health. Proc Nutr Soc. 2003 Nov;62(4):851-8.

18. French SA, Fulkerson JA, Story M. Increasing weight-bearing physical activity and calcium intake for bone mass growth in children and adolescents: a review of intervention trials. Prev Med. 2000 Dec;31(6):722-31. 
19. Sunyecz JA, Weisman SM. The role of calcium in osteoporosis drug therapy. J Womens Health (Larchmt). 2005 Mar;14(2):180-92.

20. El-Hajj Fuleihan G, Baddoura R, Awada H, Okais J, Rizk P, McClung M; Middle East Densitometry Workshop. Practice guidelines on the use of bone mineral density measurements: Who to test? What measures to use? When to treat? A consensus report from the Middle East Densitometry Workshop. J Med Liban. 2002 May-Jun;50(3):89-104.

21. National Osteoporosis Foundation. Bone mineral density testing: What the numbers mean. NOF, Bone Health Updates. 2001. Available at: http://www.nof.org/osteoporosis/bmdtest.htm.

22. Kazantzis G. Cadmium, osteoporosis and calcium metabolism. Biometals. 2004 Oct;17(5):493-8.

23. Norman AW. Intestinal calcium absorption: a vitamin D-hormone-mediated adaptive response. Am J Clin Nutr. 1990 Feb;51(2):290-300.

24. Bouillon R, Van Cromphaut S, Carmeliet G. Intestinal calcium absorption: Molecular vitamin D mediated mechanisms. J Cell Biochem. 2003 Feb $1 ; 88(2): 332-9$.

25. Wasserman RH. Vitamin D and the dual processes of intestinal calcium absorption. J Nutr. 2004 Nov;134(11):3137-9.

26. Favus MJ. Factors that influence absorption and secretion of calcium in the small intestine and colon. Am J Physiol. 1985 Feb;248(2 Pt 1):G147-57.

27. Turecki T, Ewan RC, Stahr HM. Effect of phytic acid and calcium on the intestinal 
absorption of cadmium in vitro. Bull Environ Contam Toxicol. 1994

Sep;53(3):464-70.

28. Zittermann A, Sabatschus O, Jantzen S, Platen P, Danz A, Dimitriou T, Scheld K, Klein K, Stehle P. Exercise-trained young men have higher calcium absorption rates and plasma calcitriol levels compared with age-matched sedentary controls. Calcif Tissue Int. 2000 Sep;67(3):215-9.

29. Lukert BP, et al. Influence of nutritional factors on calcium-regulating hormones and bone loss. Calcif Tissue Int. 1987 Mar;40(3):119-25.

30. Joplin GF, Melvin KE, Hepner GW, Neale G, Bordier P. Calcium metabolism and bone histology in adult celiac disease. Calcif Tissue Res. 1968;:Suppl:62.

31. Molina E, Erdozain JC, Herrera A, Olveira A, Martiinez-Olmos MA, Fernandez de Paz J. Calcium metabolism and celiac disease. Am J Gastroenterol. 1996 Jun;91(6):1278-9.

32. Lau EM, et al. Nutrition and osteoporosis. Curr Opin Rheumatol. 1998 Jul;10(4):368-72.

33. McCarron DA, Rankin LI, Bennett WM, Krutzik S, McClung MR, Luft FC. Urinary calcium excretion at extremes of sodium intake in normal man. Am $\mathrm{J}$ Nephrol. 1981;1(2):84-90.

34. Ho SC, Chen YM, Woo JL, Leung SS, Lam TH, Janus ED. Sodium is the leading dietary factor associated with urinary calcium excretion in Hong Kong Chinese adults. Osteoporos Int. 2001;12(9):723-31

35. Use of female standard leads to underdiagnosis of osteoporosis in men. J Gend 
Specif Med. 2000 Nov-Dec;3(8):8.

36. Christiansen C. Postmenopausal bone loss and the risk of osteoporosis. Osteoporos Int. 1994;4 Suppl 1:47-51.

37. Watts NB. Postmenopausal osteoporosis. Obstet Gynecol Surv. 1999 Aug;54(8):532-8.

38. Blake GM, Fogelman I. Bone densitometry and the diagnosis of osteoporosis. Semin Nucl Med. 2001 Jan;31(1):69-81.

39. Mackelvie KJ, McKay HA, Khan KM, Crocker PR. Lifestyle risk factors for osteoporosis in Asian and Caucasian girls. Med Sci Sports Exerc. 2001 Nov;33(11):1818-24.

40. Liew YL, Mann D, Piterman L. Osteoporosis risks. A comparative study of Asian Australian and Caucasian Australian women. Aust Fam Physician. 2002 Mar;31(3):291-3, 297.

41. Soroko SB, Barrett-Connor E, Edelstein SL, Kritz-Silverstein D. Family history of osteoporosis and bone mineral density at the axial skeleton: the Rancho Bernardo Study. J Bone Miner Res. 1994 Jun;9(6):761-9.

42. Keen RW, Hart DJ, Arden NK, Doyle DV, Spector TD. Family history of appendicular fracture and risk of osteoporosis: a population-based study. Osteoporos Int. 1999;10(2):161-6.

43. Edwards BJ, Perry HM 3rd. Age-related osteoporosis. Clin Geriatr Med. 1994 Nov;10(4):575-88.

44. Boonen S, Aerssens J, Broos P, Pelemans W, Dequeker J. Age-related bone loss 
and senile osteoporosis: evidence for both secondary hyperparathyroidism and skeletal growth factor deficiency in the elderly. Aging (Milano). 1995 Dec;7(6):414-22.

45. Kimberg DV. Effects of vitamin D and steroid hormones on the active transport of calcium by the intestine. N Engl J Med. 1969 Jun 19;280(25):1396-405.

46. Lekkerkerker JF, Doorenbos H. The influence of thyroid hormone on calcium absorption from the gut in relation to urinary calcium excretion. Acta Endocrinol (Copenh). 1973 Aug;73(4):672-80.

47. Reinhold JG, Faradji B, Abadi P, Ismail-Beigi F. The Journal of Nutrition, Volume 106, 1976: Decreased absorption of calcium, magnesium, zinc and phosphorus by humans due to increased fiber and phosphorus consumption as wheat bread. Nutr Rev. 1991 Jul;49(7):204-6.

48. el-Hajj Fuleihan G. Osteoporosis: an update. J Med Liban. 1998 Jan-Feb;46(1):23-8.

49. Broulik PD, et al. The effect of chronic nicotine administration on bone mineral content in mice. Horm Metab Res. 1993 Apr;25(4):219-21.

50. Ernst E. Smoking, a cause of back trouble? Br J Rheumatol. 1993 Mar;32(3):239-42.

51. Rylander R, Megevand Y, Lasserre B, Amstutz W, Granbom S. Moderate alcohol consumption and urinary excretion of magnesium and calcium. Scand J Clin Lab Invest. $2001 ; 61(5): 401-5$.

52. NIH. Osteoporosis prevention, diagnosis, and therapy. NIH Consensus Statement 
Online 2000 March 27-29, 2000:1-36.

53. Food and Drug Administration. Health Claims: calcium and osteoporosis. 1993. available at: http://www.cfsan.fda.gov/ 1rd/cf101-72.html.

54. Thomas WC Jr. Kidney stone disease today--an overview and some current developments. Trans Am Clin Climatol Assoc. 1992;104:1-6.

55. Massey LK, Roman-Smith H, Sutton RA. Effect of dietary oxalate and calcium on urinary oxalate and risk of formation of calcium oxalate kidney stones. J Am Diet Assoc. 1993 Aug;93(8):901-6.

56. Pena JC, Monforte MF, Briceno A. The role of oxalate and calcium oxalate activity and formation product ratio in patients with renal stones before and during treatment. J Urol. 1987 Nov;138(5):1137-40.

57. Curhan G, Willett WC, Rimm E, Stampher MJ. A prospective study of dietary calcium and other nutrients and the risk of symptomatic kidney stones. N Engl J Med 1993;328:833-8.

58. Hall WD, Pettinger M, Oberman A, et al. Risk factors for kidney stones in older women in the Southern United States. Am J Med Sci 2001;322:12-18.

59. Martini LA. Stop dietary calcium restriction in kidney stone-forming patients. Nutr Rev. 2002 Jul;60(7 Pt 1):212-4.

60. Drueke TB. Renal osteodystrophy: management of hyperphosphataemia. Nephrol Dial Transplant. 2000;15 Suppl 5:32-3.

61. Pflanz S, Henderson IS, McElduff N, Jones MC. Calcium acetate versus calcium carbonate as phosphate-binding agents in chronic haemodialysis. Nephrol Dial 
Transplant. 1994;9(8):1121-4.

62. Diskin CJ, Thomas CE, Zellner CP. Time of administration of calcium acetate and phosphate binding. N Engl J Med. 1989 Sep 28;321(13):904-5.

63. Pope CE 2nd. Acid-reflux disorders. N Engl J Med. 1994 Sep 8;331(10):656-60.

64. Watson AR, Bowling TE. Acid reflux and gastro-oesophageal reflux disease. Br J Community Nurs. 2004 Aug;9(8):326-30.

65. Morrissey JF, Barreras RF. Drug therapy. Antacid therapy. N Engl J Med. 1974 $\operatorname{Mar} 7 ; 290(10): 550-4$.

66. Chines A, Pacifici R. Antacid and sucralfate-induced hypophosphatemic osteomalacia: a case report and review of the literature. Calcif Tissue Int. 1990 Nov;47(5):291-5.

67. Berkow SE, Barnard ND. Blood pressure regulation and vegetarian diets. Nutr Rev. 2005 Jan;63(1):1-8.

68. Civantos B, Aleixandre A. Effect of dietary calcium supplements and amlodipine on growth, arterial blood pressure, and cardiac hypertrophy of spontaneously hypertensive rats. Clin Exp Hypertens. 2003 Nov;25(8):495-508.

69. Hajjar IM, Grim CE, Kotchen TA. Dietary calcium lowers the age-related rise in blood pressure in the United States: the NHANES III survey. J Clin Hypertens (Greenwich). 2003 Mar-Apr;5(2):122-6.

70. Vogt TM, Appel LJ, Obarzanek E, Moore TJ, Vollmer WM, Svetkey LP, Sacks FM, Bray GA, Cutler JA, Windhauser MM, Lin PH, Karanja NM. Dietary Approaches to Stop Hypertension: rationale, design, and methods. DASH 
Collaborative Research Group. J Am Diet Assoc. 1999 Aug;99(8 Suppl):S12-8.

71. Tomson C. Calcium supplementation for prevention of colorectal cancer. Lancet. 2004 Dec 11;364(9451):2095.

72. Kripke C. Calcium and prevention of colorectal cancer. Am Fam Physician. 2004 Dec 1;70(11):2109.

73. Flood A, Peters U, Chatterjee N, Lacey JV Jr, Schairer C, Schatzkin A. Calcium from diet and supplements is associated with reduced risk of colorectal cancer in a prospective cohort of women. Cancer Epidemiol Biomarkers Prev. 2005 Jan;14(1):126-32.

74. Lin J, Zhang SM, Cook NR, Manson JE, Lee IM, Buring JE. Intakes of calcium and vitamin D and risk of colorectal cancer in women. Am J Epidemiol. $2005 \mathrm{Apr}$ 15;161(8):755-64.

75. Gross MD. Vitamin D and calcium in the prevention of prostate and colon cancer: new approaches for the identification of needs. J Nutr. 2005 Feb;135(2):326-31.

76. Rodriguez C, McCullough ML, Mondul AM, Jacobs EJ, Fakhrabadi-Shokoohi D, Giovannucci EL, Thun MJ, Calle EE. Calcium, dairy products, and risk of prostate cancer in a prospective cohort of United States men. Cancer Epidemiol Biomarkers Prev. 2003 Jul;12(7):597-603.

77. Cascinu S, Del Ferro E, Cioccolini P. Effects of calcium and vitamin supplementation on colon cancer cell proliferation in colorectal cancer. Cancer Invest 2000;18:411-416.

78. Zemel MB, Shi H, Greer B, DiRienzo DD, Zemel P. Regulation of adiposity by 
dietary calcium. FASEB J 2000;14:1132-38.

79. Shi H, DiRienzo DD, Zemel MB. Effects of dietary calcium on adipocyte lipid metabolism and body weight regulation in energy-restricted aP2-agouti transgenic mice. FASEB J 2001;15:291-93.

80. Heaney RP. Calcium and weight: clinical studies. J Am Coll Nutr 2002;21:152S-155S.

81. Wellspan Health Library - calcium. Available at:

http://www.wellspan.org/library/healthguide/en-us/cam/topic.asp?hwid=hn-28180 04

82. Standing Committee on the Scientific Evaluation of Dietary Reference Intakes, Food and Nutrition Board, Institute of Medicine. Dietary Reference Intakes for Calcium, Phosphorus, Magnesium, Vitamin D and Fluoride. Washington DC: The National Academies Press, 1997.

83. U.S. Department of Agriculture. Results from the United States Department of Agriculture's 1994-96 Continuing Survey of Food Intakes by Individuals/Diet and Health Knowledge Survey. 1994-96. Available at:

http://www.barc.usda.gov/bhnrc/foodsurvey/Products9496.

html\#foodandnutrientintakes

84. Subar AF, Krebs-Smith SM, Cook A, Kahle LL. Dietary sources of nutrients among US adults. J Am Diet Assoc 1998;98:537-47.

85. Harriet Kohn. Food Guide Pyramid: Milk, Yogurt and Cheese Group. Available at: http://ianrpubs.unl.edu/foods/nf183.htm 
86. Weaver CM, Proulx WR, Heaney RP. Choices for achieving adequate dietary calcium with a vegetarian diet. Am J Clin Nutr 1999;70:543S-8S.

87. USDA. Dietary Guidelines for Americans 2005. Available at: http://www.health.gov/ dietaryguidelines/dga2005/document/

88. Scotti A, Bianchini C, Abbiati G, Marzo A. Absorption of calcium administered alone or in fixed combination with vitamin D to healthy volunteers. Arzneimittelforschung. 2001;51(6):493-500.

89. Devine A, Wilson SG, Dick IM, Prince RL. Effects of vitamin D metabolites on intestinal calcium absorption and bone turnover in elderly women. Am J Clin Nutr. 2002 Feb;75(2):283-8.

90. Arden NK, Major P, Poole JR, Keen RW, Vaja S, Swaminathan R, Cooper C, Spector TD. Size at birth, adult intestinal calcium absorption and 1,25(OH)(2) vitamin D. QJM. 2002 Jan;95(1):15-21.

91. Lee WT, Jiang J, Hu P, Hu X, Roberts DC, Cheng JC. Use of stable calcium isotopes (42Ca \& 44Ca) in evaluation of calcium absorption in Beijing adolescents with low vitamin D status. Food Nutr Bull. 2002 Sep;23(3 Suppl):42-7.

92. R. H. Wasserman. Vitamin D and the Dual Processes of Intestinal Calcium Absorption. J Nutr. 2004 Nov;134(11):3137-9.

93. Bouillon R, Van Cromphaut S, Carmeliet G. Intestinal calcium absorption: Molecular vitamin D mediated mechanisms. J Cell Biochem. 2003 Feb 
$1 ; 88(2): 332-9$

94. Venning G. Recent developments in vitamin D deficiency and muscle weakness among elderly people. BMJ. 2005 Mar 5;330(7490):524-6.

95. Shenolikar IS. Absorption of dietary calcium in pregnancy. Am J Clin Nutr. 1970 Jan;23(1):63-7.

96. Kent GN, Price RI, Gutteridge DH, Rosman KJ, Smith M, Allen JR, Hickling CJ, Blakeman SL. The efficiency of intestinal calcium absorption is increased in late pregnancy but not in established lactation. Calcif Tissue Int. 1991 Apr;48(4):293-5.

97. O'Brien KO, Nathanson MS, Mancini J, Witter FR. Calcium absorption is significantly higher in adolescents during pregnancy than in the early postpartum period. Am J Clin Nutr. 2003 Dec;78(6):1188-93.

98. Quan-Sheng D, Miller SC. Calciotrophic hormone levels and calcium absorption during pregnancy in rats. Am J Physiol. 1989 Jul;257(1 Pt 1):E118-23.

99. U.S. Department of Agriculture ARS. USDA Nutrient Database for Standard Reference Release 16. Nutrient Data Laboratory Home Page. 2003. Available at: http://www.nal.usda.gov/fnic/foodcomp.

100. NIH. National Institutes of Health consensus statement: Optimal calcium intake. 1994;12:1-31.

101. Weaver CM, Proulx WR, Heaney RP. Choices for achieving adequate dietary calcium with a vegetarian diet. Am J Clin Nutr 1999;70:543S-8S.

102. Heaney RP. Bone mass, nutrition, and other lifestyle factors. Nutr Rev 
1996;54:S3-S10.

103. Sellmeyer DE, Schloetter M, Sebastian A. Potassium citrate prevents increased urine calcium excretion and bone resorption induced by a high sodium chloride diet. J Clin Endocrinol Metab 2002;87:2008-12.

104. Standing Committee on the Scientific Evaluation of Dietary Reference Intakes, Food and Nutrition Board, Institute of Medicine. Dietary Reference Intakes for Water, Potassium, Sodium, Chloride, and Sulfate. Washington DC: The National Academies Press, 2004.

105. Brower V. Nutraceuticals: poised for a healthy slice of the healthcare market? Nat Biotechnol. 1998; 16:728-31

106. Zeisel SH. Regulation of "Nutraceuticals." Science. 1999; 285:185-186

107. Kalra EK. Nutraceutical - Definition and Introduction. AAPS PharmSci 2003; 5(3) Article 25

108. Dietary Supplement Health and Education Act of 1994. FDA/CFSAN resources page. Food and Drug Administration web site. Available at: http://vm.cfsan.fda.gov/ dms/dietsupp.html

109. Federal Trade Commission. Enforcement Policy Statement on Food Advertising. 1994; May. Available at: http://www.ftc.gov/bcp/policystmt/ad-food.htm

110. Radimer K, Bindewald B, Hughes J, Ervin B, Swanson C, Picciano MF. Dietary supplement use by US adults: data from the National Health and Nutrition Examination Survey, 1999-2000. Am J Epidemiol. 2004 Aug 15;160(4):339-49 
111. Nutrition Business Journal (1998) Volume 3, no. 4, pp. 1-2.

112. Hathcock JN, Rulis AM. The role and activities of the Food and Drug Administration in food safety. Encyclopedia of Food Science, Food Technology and Nutrition 1993;7:4656-4661 Academic Press London, UK.

113. Federal Food Drug and Cosmetic Act (FDCA). Available at: http://www.fda.gov/opacom/laws/fdcact/fdctoc.htm

114. Dietary Supplement Health and Education Act of 1994. Public Law 103-417 103rd Congress. Available at: http://www.fda.gov/opacom/laws/dshea.html

115. Pinco RG, Rubin PD. Ambiguities of the Dietary Supplement Health and Education Act of 1994. Food Drug Law J 1996;51:383-405

116. Federal Trade Commission (1994) Enforcement Policy Statement on Food Advertising, May 1994. Federal Trade Commission, Washington, DC.

117. Federal Trade Commission Dietary Supplements: An Advertising Guide for Industry 1998 Federal Trade Commission Washington, DC.

118. Peeler CL, Cohn S. The Federal Trade Commission's regulation of advertising claims for dietary supplements. Food Drug Law J 1995;50:349-355

119. Claims That Can Be Made for Conventional Foods and Dietary Supplements. September 2003. CFSAN/Office of Nutritional Products, Labeling, and Dietary Supplements. Available at: http://www.cfsan.fda.gov/ dms/hclaims.html 120. USP's Dietary Supplement Verification Program Overview. Available at: http://www.uspverified.org/pinfo/overview.html

121. McNamara SH, Siegner AW Jr. FDA has substantial and sufficient authority 
to regulate dietary supplements. Food Drug Law J. 2002;57(1):15-24.

122. Levitt JA. Regulation of dietary supplements: FDA's strategic plan. Food Drug Law J. 2002;57(1):1-13.

123. Taborsky CJ, Hanson R. Dissolution Testing of Nutritional Supplements. May 1999, 6(2)

124. National Nutritional Foods Association, History of Dietary Supplement Legislation Timeline. Available at: http://www.nnfa.org/news/media_kit/timeline.htm

125. US Office of Dietary Supplements (ODS) of the National Institutes of Health (NIH) in collaboration with the Life Sciences Research Office (LSRO) of the American Society for Nutritional Sciences (ASNS). Bioavailability of dietary supplements. NIH Conference January 5-6, 2000

126. USP 28/NF 23 Supplement 5

127. USP 28/NF 23 Supplement 7

128. USP 28/NF 23 Supplement 9

129. Nicar MJ, Pak CY. Calcium bioavailability from calcium carbonate and calcium citrate. J Clin Endocrinol Metab. 1985 Aug;61(2):391-3.

130. Harvey JA, Zobitz MM, Pak CY. Dose dependency of calcium absorption: a comparison of calcium carbonate and calcium citrate. J Bone Miner Res. 1988 Jun;3(3):253-8.

131. Heaney RP, Dowell MS, Barger-Lux MJ. Absorption of calcium as the carbonate and citrate salts, with some observations on method. Osteoporos Int. 
1999;9(1):19-23.

132. Sakhaee K, Bhuket T, Adams-Huet B, Rao DS. Meta-analysis of calcium bioavailability: a comparison of calcium citrate with calcium carbonate. Am J Ther. 1999 Nov;6(6):313-21.

133. Kenny AM, Prestwood KM, Biskup B, Robbins B, Zayas E, Kleppinger A, Burleson JA, Raisz LG. Comparison of the effects of calcium loading with calcium citrate or calcium carbonate on bone turnover in postmenopausal women. Osteoporos Int. 2004 Apr;15(4):290-4. Epub 2004 Jan 13.

134. Hanzlik RP, Fowler SC, Fisher DH. Relative Bioavailability of Calcium from Calcium Formate, Calcium Citrate and Calcium Carbonate. J Pharmacol Exp Ther. 2005 Feb 25

135. USP 28/NF 23 General Chapters. Chart 12. Dietary Supplement Products. 2196

136. USP 28/NF 23 Official Monographs. Calcium Acetate Tablets. 318

137. USP 28/NF 23 Official Monographs. Calcium Carbonate Tablets. 320-1

138. USP 28/NF 23 Official Monographs. Calcium Gluconate Tablets. 328

139. USP 28/NF 23 Official Monographs. Calcium Lactate Tablets. 329-30

140. USP 28/NF 23 Official Monographs. Calcium Pantothenate Tablets. 331-2

141. USP 28/NF 23 Official Monographs. Dibasic Calcium Phosphate Tablets. 333

142. USP 28/NF 23 Official Monographs. Calcium Carbonate and Magnesia Tablets. 321 
143. USP 28/NF 23 Official Monographs. Calcium Carbonate, Magnesia, and Simethicone Tablets. 321-2

144. USP 28/NF 23 Official Monographs. Calcium and Magnesium Carbonate Tablets. 323-4

145. Dubovsky J. Osteoporosis and calcium: to supplement or not to supplement. Ala J Med Sci. 1987 Oct;24(4):431-5.

146. Zawada ET Jr, Brautbar N. Calcium supplement therapy of hypertension--has the time come? Nephron. 1985;41(2):129-31.

147. Bell RA, Quandt SA, Spangler JG, Case LD. Dietary calcium intake and supplement use among older African American, white, and Native American women in a rural southeastern community. J Am Diet Assoc. 2002 Jun;102(6):844-7.

148. Chang $\mathrm{CH}$, Chiang TL. Vitamin/calcium supplement use in Taiwan: findings from the 1994 National Health Interview Survey. Kaohsiung J Med Sci. 2002 Apr;18(4):171-81.

149. Pro-Risquez A, Harris SS, Song L, Rudicel S, Barnewolt B, Dawson-Hughes B. Calcium supplement and osteoporosis medication use in women and men with recent fractures. Osteoporos Int. 2004 Sep;15(9):689-94. Epub 2004 Jun 17.

150. Dawson-Hughes B, Harris SS, Dallal GE, Lancaster DR, Zhou Q. Calcium supplement and bone medication use in a US Medicare health maintenance organization. Osteoporos Int. 2002 Aug;13(8):657-62.

151. Deroisy R, Collette J, Albert A, Jupsin I, Reginster JY. Administration of a 
supplement containing both calcium and vitamin $\mathrm{D}$ is more effective than calcium alone to reduce secondary hyperparathyroidism in postmenopausal women with low 25(OH)vitamin D circulating levels. Aging Clin Exp Res. 2002 Feb;14(1):13-7.

152. Nieves JW, Komar L, Cosman F, Lindsay R. Calcium potentiates the effect of estrogen and calcitonin on bone mass: review and analysis. Am J Clin Nutr. 1998 Jan;67(1):18-24.

153. Davis JW, Ross PD, Johnson NE, Wasnich RD. Estrogen and calcium supplement use among Japanese-American women: effects upon bone loss when used singly and in combination. Bone. 1995 Oct;17(4):369-73.

154. Davis JW, Ross PD, Wasnich RD. A longitudinal study of estrogen and calcium supplement use among Japanese women living in Hawaii. Prev Med. 1995 Mar;24(2):159-65.

155. Khan MA, Liu MW, Singh D, Pal A, Chio FL, Lawson D, Dean LS. Long-term (three years) effect of estrogen replacement therapy on major adverse cardiac events in postmenopausal women after intracoronary stenting. Am J Cardiol. 2000 Aug 1;86(3):330-3.

156. LeBlanc ES, Viscoli CM, Henrich JB. Postmenopausal estrogen replacement therapy is associated with adverse breast cancer prognostic indices. J Womens Health Gend Based Med. 1999 Jul-Aug;8(6):815-23.

157. Paganini-Hill A. Estrogen replacement therapy and stroke. Prog Cardiovasc Dis. 1995 Nov-Dec;38(3):223-42. 
158. Simon JA, Hsia J, Cauley JA, Richards C, Harris F, Fong J, Barrett-Connor E, Hulley SB. Postmenopausal hormone therapy and risk of stroke: The Heart and Estrogen-progestin Replacement Study (HERS). Circulation. 2001 Feb 6;103(5):638-42.

159. FDA Approves New Labels for Estrogen and Estrogen with Progestin Therapies for Postmenopausal Women Following Review of Women's Health Initiative Data. Available at:

http://www.fda.gov/bbs/topics/NEWS/2003/NEW00863.html

160. Ishitani K, Itakura E, Goto S, Esashi T. Calcium absorption from the ingestion of coral-derived calcium by humans. J Nutr Sci Vitaminol (Tokyo). 1999 Oct;45(5):509-17.

161. Robb-Nicholson C. By the way, doctor. I recently saw a TV ad for a product called "coral calcium," which is supposed to prevent osteoporosis and other diseases. What do you know about it? Harv Womens Health Watch. 2003 Aug;10(12):8.

162. Marcason W. What is the lowdown on Coral Calcium? J Am Diet Assoc. 2003 Oct;103(10):1319.

163. "I've heard that coral calcium is one of the best-absorbed calcium sources because it's natural. I'm thinking about switching from my usual calcium citrate supplement.” Mayo Clin Health Lett. 2003 Sep;21(9):8.

164. Alpaslan G, Alpaslan C, Bilgihan A, Yamalik K. Serum alkaline phosphatase, calcium, and phosphate levels following clinical use of natural coral. Case reports. 
Aust Dent J. 1995 Oct;40(5):327-9.

165. Blumberg S. Is coral calcium a safe and effective supplement? J Am Diet Assoc. 2004 Sep;104(9):1335-6.

166. Tsang G. Alert! Coral Calcium Supplements Scam. Available at:

http://www.healthcastle.com/coralcalcium-scam.shtml

167. Barrett S. Be Wary of Coral Calcium and Robert Barefoot. Quackwatch. Janurary 2004. Available at:

http://www.quackwatch.org/01QuackeryRelatedTopics/DSH/coral.html

168. FTC and FDA Take New Actions in Fight Against Deceptive Marketing. Available at: http://www.ftc.gov/opa/2003/06/trudeau.htm

169. Levenson D, Bockman R. A review of calcium preparations. Nutr Rev $1994 ; 52: 221-32$.

170. Kobrin SM, Goldstein SJ, Shangraw RF, Raja RM. Variable efficacy of calcium carbonate tablets. Am J Kidney Dis. 1989 Dec;14(6):461-5.

171. Shangraw RF. Factors to consider in the selection of a calcium supplement. Public Health Rep. 1989 Sep-Oct;104 Suppl:46-50.

172. Carr CJ, Shangraw RF. Nutritional and pharmaceutical aspects of calcium supplementation. Am Pharm. 1987 Feb;NS27(2):49-50, 54-7.

173. Product Review: Calcium. ConsumerLab.com June 2003. Available at: http://www.consumerlab.com/results/calcium.asp

174. Ekman M, Reizenstein P, Teigen SW, Ronneberg R. Comparative absorption of calcium from carbonate tablets, lactogluconate/carbonate effervescent tablet, 
and chloride solution. Bone. 1991;12(2):93-7.

175. Ohtani M, Tsugawa N, Kamao M, Okano T. Absorbability of calcium from a new calcium supplement prepared from bovine marrow-free bone in rats. J Nutr Sci Vitaminol (Tokyo). 1998 Dec;44(6):887-95. 


\section{Chapter II}

\section{Goals and Objectives}

\section{* General goal}

Given the history just presented (Chapter I), concerning pharmaceutical efficacy issues related to nutraceuticals, the primary goal of this research goal was to evaluate both the pharmaceutical quality of several commercially available calcium supplements, as well as the appropriate revisions of the USP methodologies (esp. dissolution) for testing these products. Physical tests were performed to examine their dosage uniformity and other physical properties. Disintegration and dissolution were tested to estimate these tablets' in vitro behavior as an indicator of these supplements' in vivo bioavailability and effectiveness.

In order for a drug to have its effect after oral administration, it must go into solution and then diffuse through the gut wall into the body. The first step in that process is the disintegration of the dosage form followed by dissolution of the active ingredient. Dissolution of a pure substance follows the Noyes Whitney Equation:

$$
\frac{d m}{d t}=k_{D} A\left(C_{S}-C_{B}\right)
$$

Where $\mathrm{dm} / \mathrm{dt}$ is the rate of dissolution, $\mathrm{k}_{\mathrm{D}}$ is the dissolution rate constant, $\mathrm{A}$ is the 
surface area of the dissolving solid, $\mathrm{C}_{\mathrm{S}}$ is the saturation concentration of drug in diffusion layer and $\mathrm{C}_{\mathrm{B}}$ is the concentration of drug in dissolution media (or the bulk). Dissolution rate constant $\mathrm{k}_{\mathrm{D}}$ is a function of the diffusion coefficient $\mathrm{D}$ and the thickness of the diffusion boundary layer $\delta$.

$$
k_{D}=\frac{D}{\delta}
$$

In order to increase dissolution rate of poorly soluble drugs, stirring speed can be increased to reduce the thickness of the diffusion boundary layer $\delta$. At the same time, the increased agitation also facilitates the disintegration, breaking the tablet into fine particles in a shorter period of time and thus increasing the surface area A. Another approach is to keep a low $\mathrm{C}_{\mathrm{B}}$ during the course of dissolution. The third is to increase the solubility of the drug in the medium solution. With greater $\mathrm{C}_{\mathrm{S}}$, both the dissolution rate and extent are enhanced. Based on this dissolution theory, a series of experiments were performed in an attempt in the second phase of this work to achieve the best dissolution profile by changing each variable. The testing parameters under which the dissolution test reaches the best sensitivity are called the "optimized testing criterion". This revised testing method ("optimized methodology") was then used in the test of several other calcium products to confirm its feasibility and sensitivity.

\section{* Specific Objectives}

- Evaluate the pharmaceutical properties of several calcium supplements, including weight variation, thickness, hardness, friability and disintegration. 
- Examine the dissolution of the products by USP standard dissolution method.

- Improve the dissolution test method by increasing stirring speed and the volume of dissolution medium.

- Improve the dissolution test method by using phosphate binding medium

- Improve the dissolution test method by adding surfactant to the dissolution medium

- Determine optimized dissolution testing conditions

- Demonstrate utility and sensitivity of "optimized" methodology by comparing products' dissolution under “optimized" vs. USP conditions. 


\section{Chapter III}

\section{Materials and methods}

To achieve the goal of the research, studies have been carried out in two parts: the first (Phase I) is to evaluate the pharmaceutical quality of commercially available calcium supplements; the second (Phase II) is aimed to optimize the sensitivity and reproducibility of the test guidance (i.e.: performance testing standards); the third (Phase III) is to evaluate both oral and chewable calcium supplements with the optimized testing method.

\section{Phase I:}

In order to assess the pharmaceutical quality of the calcium products, the following tests were performed:

I. Disintegration

II. Hardness

III. Dissolution

\section{Phase II:}

To revise the standard test, so as to develop and propose an improved testing method of dissolution, the studies went as follows, where variables were changed which in theory, should affect dissolution kinetics and thus improve the test sensitivity: 
I. Increase the speed of dissolution medium

II. Increase the volume of dissolution medium

III. Use other buffer system as the dissolution medium

IV. Addition of surfactant

\section{Phase III:}

To evaluate chewable calcium products (chewable, slow and fast dissolve, and oral, three salt forms) with the optimized dissolution testing method. Compare the revised test with the USP standard test results

\section{Materials and equipments}

A list of chemicals, calcium supplement products, equipments and reagents prepared to carry out the aforementioned tests is shown below.

\section{A. Chemicals:}

\begin{tabular}{ll}
\hline Chemical & Provider \\
\hline Hydrochloric Acid $(\mathrm{HCl})$ & Fisher Chemical \\
Sodium Chloride $(\mathrm{NaCl})$ & Fisher Chemical \\
Sodium Hydroxide $(\mathrm{NaOH})$ & Fisher Chemical \\
Potassium Phosphate Monobasic $\left(\mathrm{KH}_{2} \mathrm{PO}_{4}\right)$ & Fisher Chemical \\
Sodium Lauryl Sulfate $(\mathrm{SLS})$ & Fisher Chemical \\
Tween 80 & Fisher Chemical \\
Calcium Ionic Strength Adjustor $(\mathrm{ISA})$ & Orion \\
Calcium Standard $\left(0.1 \mathrm{M} \mathrm{Ca}{ }^{2+}\right)$ & Orion \\
\hline
\end{tabular}

Table 6. Chemicals used in research 


\section{B. Commercial calcium products}

\begin{tabular}{llll}
\hline Brand name & Salt form & Lot/Exp date & Elemental calcium \\
\hline CVS & Calcium Carbonate & OMB0304;06/05 & $600 \mathrm{mg}$ \\
Caltrate & Calcium Carbonate & $483-005 ; 08 / 02$ & $600 \mathrm{mg}$ \\
RiteAid HiCal & Calcium Carbonate & OCO1486;02/05 & $200 \mathrm{mg} *$ carbonate \\
Major & Calcium Carbonate & $2351 ; 06 / 05$ & $240 \mathrm{mg} *$ carbonate \\
Walgreens & Calcium Carbonate & OFO1786;06/05 & $600 \mathrm{mg}$ \\
Leader & Calcium Carbonate & $1 \mathrm{HN} 0579 ; 04 / 04$ & $600 \mathrm{mg}$ \\
OsCal & Calcium Carbonate & $1 \mathrm{G} 0925 ; 05 / 04$ & $500 \mathrm{mg}$ \\
PhosLo & Calcium Acetate & POL336; 12/03 & $667 \mathrm{mg} *$ acetate \\
NatureMade & Calcium Carbonate & MK11563; 10/05 & $500 \mathrm{mg}$ \\
NatureMade & Calcium Citrate Vit D & NB10929;02/06 & $250 \mathrm{mg}$ \\
Tums ** & Calcium Carbonate & $4 \mathrm{D} 19,4 \mathrm{H} 08$ & $750 \mathrm{mg}$ carbonate \\
\hline
\end{tabular}

Table 7. Commercial calcium products tested in the research.

* For PhosLo, $667 \mathrm{mg}$ is the amount of calcium acetate salt in one tablet; for HiCal, Major and Tums, labeled content is the amount of calcium carbonate salt in one tablet.

** Tums is the chewable supplement in quick-dissolve formulations in the research. All others are in traditional tablet formulation.

\section{Equipments}

- $\quad$ Disintegration apparatus

Vankel $^{\circledR}$ Model 35-1200, Serial 20-A72-010

Basket-rack assembly and $1000 \mathrm{ml}$ low-form beakers are also provided by Vankel $^{\circledR}$. (USP apparatus A and B)

- Ultrapure water system

Barnstead $^{\circledR}$ NANOpure UV, Model NO. D7334 Serial NO. 852970479018

- Balance 
Mettler Toledo ${ }^{\circledR}$ AB54 NO. 228064 SNR 1115352741

- $\mathrm{pH}$ meter

Fisher Scientific Accumet ${ }^{\circledR}$ Basic AB15 pH Meter

- $\quad$ Hardness tester

Vector/Schleuniqer 6D Ver 3.0

- $\underline{\mathrm{mV} \text { meter }}$

ThermoOrion ${ }^{\circledR}$ Model 290

- Calcium electrode

ThermoOrion $^{\circledR}$ Ionplus ${ }^{\circledR}$

- $\quad \underline{\text { Dissolution apparatus }}$

Vankel $^{\circledR}$ VK 7000

D. Reagents

- Water:

Directly obtained from Nanopure UV Ultrapure water system.

$\mathrm{pH}$ value ranges from 5-7.

- Simulated gastric fluid (SGF) for disintegration test:

Simulated gastric fluid was prepared according to USP standards. $6 \mathrm{~g}$ of $\mathrm{NaCl}$ was placed in a $3 \mathrm{~L}$ round bottom volumetric flask, $2500 \mathrm{ml}$ of distilled water and $21 \mathrm{~mL}$ of $1 \mathrm{~N} \mathrm{HCl}$ were added and mixed well. The volume was adjusted and the solution $\mathrm{pH}$ was adjusted to 1.5 with either $1 \mathrm{~N} \mathrm{HCl}$ or $0.2 \mathrm{~N} \mathrm{NaOH}$. 
- Simulated intestinal fluid (SIF) for disintegration test:

Simulated intestinal fluid was prepared according to USP standards. $20.4 \mathrm{~g}$ of potassium monobasic phosphate $\left(\mathrm{KH}_{2} \mathrm{PO}_{4}\right)$ was placed in a $3 \mathrm{~L}$ round bottom volumetric flask, and $570 \mathrm{ml}$ of $0.2 \mathrm{~N} \mathrm{NaOH}$ was added. The volume was adjusted with distilled water. The solution $\mathrm{pH}$ was adjusted to 7.5 with either 1 $\mathrm{N} \mathrm{HCl}$ or $0.2 \mathrm{~N} \mathrm{NaOH}$.

- Simulated gastric fluid for dissolution test

1. Dissolve $50 \mathrm{~mL} \mathrm{HCl}$ in $6 \mathrm{~L}$ distilled water

2. Stir well and adjust $\mathrm{pH}$ to 1.0 with either $1 \mathrm{~N} \mathrm{HCl}$ or water.

- Phosphate buffer system

1. Measure out $76.7 \mathrm{~g} \mathrm{KH}_{2} \mathrm{PO}_{4}$ and $192.3 \mathrm{~g} \quad \mathrm{~K}_{2} \mathrm{HPO}_{4}$.

2. Dissolve the powders in $3 \mathrm{~L}$ distilled water.

3. Check the $\mathrm{pH}$ and adjust to $\mathrm{pH}=7.5$. Add $\mathrm{HCl}$ or $\mathrm{NaOH}$ if necessary.

\section{Methods}

\section{Phase I - Testing of performance of commercially available calcium products}

As dietary supplements, the performance tests of calcium products include tablet friability, disintegration and dissolution, and weight variation. ${ }^{1}$

\section{In vitro disintegration:}

According to USP General Chapters <701> DISINTEGRATION, complete 
disintegration is defined as "that state in which any residue of the unit, except fragments of insoluble coating or capsule shell, remaining on the screen of the test apparatus is a soft mass having no palpably firm core." Disintegration "does not imply complete solution of the unit or even of its active constituent.",3

Standard apparatus includes Apparatus A and Apparatus B. For tablets smaller than $18 \mathrm{~mm}$ in length, Apparatus A should be used, while others should be tested in Apparatus B. ${ }^{2}$ In our research, five products, namely Caltrate, Walgreens, HiCal, Leader and OsCal, are longer than $18 \mathrm{~mm}$, and therefore must be tested in Apparatus B.

The apparatus A consists of a basket-rack holding six open-end glass tubes. Each is $7.75 \pm 0.25 \mathrm{~cm}$ long and has an inside diameter of about $21.5 \mathrm{~mm}$ and wall thickness of approximately $2 \mathrm{~mm}$. Attached by screws to the underside of the lower plate holding the tubes are a 10 mesh stainless steel wire cloth. The basket rack is suspended through an arm immersed in a $1000 \mathrm{~mL}$ beaker containing disintegration medium at $37 \pm 2{ }^{\circ} \mathrm{C}$. The basket rack is never less than $2.5 \mathrm{~cm}$ below the surface of the fluid or above the bottom of the beaker. ${ }^{3}$ The apparatus B has a similar basket-rack with three open-end glass tubes, which has an inside diameter of $30 \mathrm{~mm}^{2}$

For uncoated tablets, the disintegration medium should be $900 \mathrm{ml}$ of distilled water, and disintegration be run for thirty minutes. In order to meet USP specifications, six tablets should first be tested. If 1 or 2 tablets fail to disintegrate completely within 30 minutes, the test should be repeated on an additional twelve tablets. Not less than 16 out of 18 tablets tested should disintegrate completely. For 
those tablets longer than $18 \mathrm{~mm}$, tests are required to be performed in Apparatus B.

Since the goal of the study was to both assess product meeting the USP specifications as well as characterize product performance, our disintegration test was performed in three media: simulated gastric fluid (SGF) with a $\mathrm{pH} \mathrm{1.5,} \mathrm{simulated}$ intestinal fluid (SIF) with a $\mathrm{pH} 7.5$ and distilled water (DW) from NANOpure water system with a $\mathrm{pH}$ 5-7. The disintegration times for 18 randomly selected tablets from each product were measured at the same time, if a preliminary study of disintegration time gave disintegration time greater than 5 minutes; otherwise six tablets were measured at a time, with individual disintegration time readings taken, and the study repeated two more times.

In order to obtain the disintegration time of each tablet, our tests were stopped every 15 seconds to observe the sample. This visual was needed since the disintegration medium soon became milky in appearance, as more calcium disintegrated and dissolved. Also, the test was not discontinued at 30 minutes, but went on until every tablet had disintegrated completely or up to 8 hours, whichever occurred first. Time was noted for the disintegration time of each tablet, and their time $(n=18)$ averaged to determine the "average time for disintegration and variability" for the specific product. These data were then used to determine:

1. Whether the product passed the USP monograph standard for disintegration.

2. Exhibited a significantly short or long disintegration time.

3. Exhibited sensitivity in disintegration to $\mathrm{pH}$ conditions.

4. Showed broad variability in disintegration to $\mathrm{pH}$ conditions. 


\section{Tablet hardness and thickness}

The hardness tester uses two steel moving bars to squeeze the tablet tested. In the squeezing process, the increasing strength resistance is measured. At the moment the tablet breaks, the force recorded is then the tablet hardness.

Ten (10) tablets of each product were randomly selected from one batch (the same bottle). Their hardness was tested by a hardness tester and their thickness was measured by the callipers attached. The average and variation were calculated.

To study the connection between tablet hardness and disintegration time, three products (CVS, OsCal and Caltrate) were picked out as representatives for quick, average and slow disintegrating formulations. Their hardness and disintegration were compared.

\section{Tablet friability}

In the friability test, a specially designed drum is used to tumble the tablets. The drum has an internal diameter between 283 and $291 \mathrm{~mm}$ and a depth between 36 and $40 \mathrm{~mm}$. It is made of synthetic polymer with polished internal surfaces. No static charge should build up during the test. In the test, the drum keeps rolling and tumbling the tablets inside with each revolution. The collision of tablet onto the drum wall or between each other may lead to their breakage, cracking or weight loss. If any tablet breaks in the process, the whole set fails the test. A maximum weight loss of not more than $1 \%$ of the weight of the tablets being tested is considered acceptable. Chewable tablets are not subject to this test. ${ }^{4}$ 
For each calcium product, ten (10) tablets were randomly selected. Having been dedusted and accurately weighed out, these were placed in the drum. After the drum completed 100 rotations, the tablets were removed, dedusted again and weighed out accurately. Then, the weight loss percentage was calculated.

\section{Weight variation}

Weight variation is a method to estimate dosage uniformity. ${ }^{6}$ In the test, twenty (20) randomly selected tablets were accurately weighed out individually. The average and standard deviation were calculated. The USP requirement is met if the weights of not more than 2 of the tablets differ from the average weight by more than the percentage listed in the table below, and no tablet differs in weight by more than double that percentage.

\begin{tabular}{ll}
\hline Average weight of tablet, $\mathrm{mg}$ & Percentage difference \\
\hline$<130$ & 10 \\
$130 \sim 324$ & 7.5 \\
$>324$ & 5 \\
\hline
\end{tabular}

Table 8. Passing criteria of weight variation test ${ }^{5,6}$

The percentage difference used in our research is $5 \%$, since all our calcium products exceed $324 \mathrm{mg}$.

\section{Dissolution by USP method}

In the USP General Chapters, dissolution condition for index minerals is:

Medium: 0.1 N hydrochloric acid; $900 \mathrm{~mL}$.

Apparatus 1: $100 \mathrm{rpm}$, for capsules.

Apparatus 2: $75 \mathrm{rpm}$, for tablets. 
Time: 1 hour. $^{2}$

Since some calcium supplements have their own specified monograph which has different testing parameters, we followed the conditions for calcium carbonate tablets:

Medium: $0.1 \mathrm{~N}$ hydrochloric acid; $900 \mathrm{~mL}$.

Apparatus 2: $75 \mathrm{rpm}$

Time: 30 min. $^{7}$

If necessary, the testing time will be as long as two (2) hours for dissolution to complete or reach saturation. Dissolution was measured using USP General Chapter $<711>$ apparatus II, paddle stirring element. ${ }^{6}$ (Apparatus I is the basket stirring element.)

USP apparatus II consists of a motor, a paddle shaft as the stirring element, and a covered glass vessel, cylindrical on the bottom that contains the dissolution medium. The shaft is positioned so that its axis is not more than $2 \mathrm{~mm}$ at any point from the vertical axis of the vessel and rotates smoothly without significant wobble. The dissolution medium is heated by a water bath to keep the inside temperature at $37 \pm$ $0.5^{\circ} \mathrm{C}$ during the test. The dosage unit should be positioned at the bottom of the vessel before the start of the test.

To meet the USP specifications, calcium carbonate, 75\% (Q) of its label claim, needs to be released in $0.1 \mathrm{~N}$ hydrochloric acid in 30 minutes, at a stirring speed of 75 rpm. For calcium acetate tablets, at a stirring speed of $50 \mathrm{rpm}$, no less than $80 \%$ of the labeled amount should be dissolved in water in 30 minutes. The tablets of other calcium forms have no specific requirement in USP, and thus were treated the same 
way as calcium acetate and carbonate tablets. Calcium concentration was measured by a calcium ion selective electrode and an $\mathrm{mV}$ meter. Standard calibration curves were developed for the electrode. From these, the concentration of the drug dissolved was determined, with percent of drug release calculated to generate product dissolution profiles.

In our research, six (6) tablets were tested at a time. When the dissolution medium was preheated $37 \pm 0.5^{\circ} \mathrm{C}$, tablets were dropped to the bottom of each beaker and the test was started at the same time. At specific time intervals (usually 10 or 15 min), $2 \mathrm{~mL}$ sample solutions was drawn out, and filtered into a test tube. The same amount of dissolution medium was added in to make up for loss of samples taken. The test usually took 30 minutes. After the last sample was drawn, the dissolution test kept running for another hour. Then another sample was taken to confirm the dissolution was complete and/or unchanged at the last sample time. After that, the whole rack of solutions was cooled down to room temperature for further analysis.

\section{The use of calcium ion selective electrode}

- Confirmation of electrode operation (slope)

Calcium standard solutions of $0.001 \mathrm{M}$ and $0.01 \mathrm{M}$ were prepared by diluting the $0.1 \mathrm{M}$ stock solution according to the following table.

\begin{tabular}{|c|c|c|c|}
\hline Checking solution & 0.1 M calcium stock solution $(\mathrm{mL})$ & Distilled water $(\mathrm{mL})$ & ISA* $(\mathrm{mL})$ \\
\hline I & 1.0 & 100 & 2 \\
\hline II & 10.0 & 100 & 2 \\
\hline
\end{tabular}

Table 9. The preparation of standard solutions for the assessment of electrode operation.

*The ISA stands for ion strength adjuster, which is a $\mathrm{NaCl}$ solution.

After immersing the sensor part of the calcium ion selective electrode into those 
standard solutions, the potentials shown in the $\mathrm{mV}$ meter were then recorded. The difference between the first and second potential reading was defined as the slope of the electrode. The difference should be in the range of 25 to $30 \mathrm{mV} / \mathrm{decade}$ when the solution temperature is $25 \pm 5^{\circ} \mathrm{C}$.

This examination was required to be performed every time before measuring so as to guarantee the reading's sensitivity. Since the temperature of the solution measured can affect the reading, the test was not started until the solution was cooled down.

- Calibrate the electrode

For calibration, the standard solutions at a series of concentrations at $0.01 \mathrm{M}$, $0.001 \mathrm{M}$ and $0.0001 \mathrm{M}$ were prepared by diluting $0.1 \mathrm{M}$ stock solution with distilled water.

\begin{tabular}{|r|c|c|c|c|}
\hline \multicolumn{5}{|c|}{ Standard solution } \\
\hline Calcium concentration $(\mathrm{mol} / \mathrm{L})$ & 0.0001 & 0.001 & 0.01 & 0.1 \\
\hline $0.1 \mathrm{M}$ calcium Stock solution $(\mathrm{mL})$ & 0.01 & 0.1 & 1 & 10 \\
\hline Distilled water $(\mathrm{mL})$ & 9.99 & 9.9 & 9 & 0 \\
\hline Ion strength adjuster $(\mathrm{mL})$ & 0.2 & 0.2 & 0.2 & 0.2 \\
\hline
\end{tabular}

Table 10. The preparation of standard solutions for the calibration curve.

Then the potential at each concentration was measured by the calcium ion selective electrode. The recorded readings were plotted on the linear axis against their concentrations on the $\log$ axis. The linear region should cover from 0.0001 to $0.1 \mathrm{M}$. Typical calibration data and a representative profile is shown below: 


\begin{tabular}{|r|r|r|r|r|}
\hline \multicolumn{5}{|c|}{ Calcium Electrode Calibration Curve } \\
\hline Calcium Concentration (M) & 0.0001 & 0.001 & 0.01 & 0.1 \\
\hline Measurement (mV) & -67.3 & -41.0 & -5.3 & 25.5 \\
\hline
\end{tabular}

Table 11. An example of typical readings in calibration.

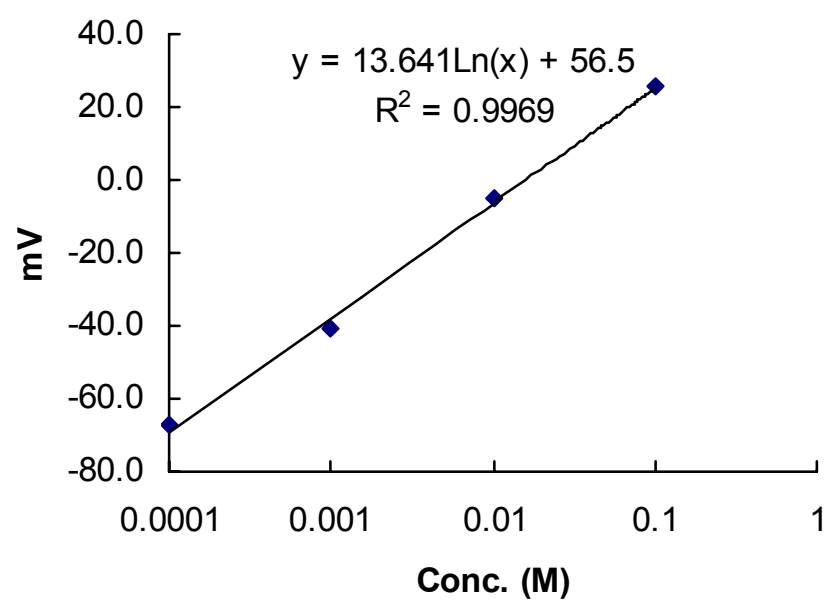

Figure 2. A typical calibration curve with its regression equation.

The calibration curve may be affected by a variety of factors, such as room temperature, the filling solution inside the electrode. Therefore, it was necessary to calibrate the electrode every time before measurement of a set of samples. A calibration equation was obtained to convert all potential readings $(\mathrm{mV})$ into drug concentration, and then release percentage.

- Dissolution sample analysis

The dissolution samples were taken at specific intervals during the course of the test. The sample solutions were first filtered into test tubes. After that, ion strength adjuster (ISA) was added in each at a ratio of 1:50. When samples were mixed well and cooled to room temperature, the electrode was then used to read the potential. By using the calibration equation, all $\mathrm{mV}$ values were then turned into calcium 
concentrations, which were in the end converted into percentage of release by product claimed content.

- Conversion from potential $(\mathrm{mV})$ to release percentage

A typical calibration equation has a form of $y=a \ln (x)+b$ (example shown in Figure 3, above), where $\mathrm{y}$ is the potential reading from the $\mathrm{mV}$ meter and $\mathrm{x}$ is the concentration of calcium in solution. For a product, the calculation of relative drug release percentage is:

$$
\text { Percentage_of_release }=\frac{E X P[(\text { potential }-b) / a] \times \text { medium_volume } \times 40}{\text { labeled_amount_of_elemental_calcium }}
$$

(Equation 3)

The dissolution profile is a curve showing the calcium release percentage over time.

\section{Phase II - Dissolution test method development}

Using the dissolution testing methodology described in "Methods - Phase I", the following studies were performed to improve the test's sensitivity.

Our rationale is based on the dissolution theory of a pure substance which follows the Noyes Whitney Equation:

$$
\frac{d m}{d t}=k_{D} A\left(C_{S}-C_{B}\right)
$$

Where $\mathrm{dm} / \mathrm{dt}$ is the rate of dissolution, $\mathrm{k}_{\mathrm{D}}$ is the dissolution rate constant, $\mathrm{A}$ is the surface area of the dissolving solid, $\mathrm{C}_{\mathrm{S}}$ is the saturation concentration of drug in 
diffusion layer and $C_{B}$ is the concentration of drug in dissolution media (or the bulk). Dissolution rate constant $\mathrm{k}_{\mathrm{D}}$ is a function of the diffusion coefficient $\mathrm{D}$ and the thickness of the diffusion boundary layer $\delta$.

$$
k_{D}=\frac{D}{\delta}
$$

Therefore, changing one or more variables in the dissolution conditions should, in theory, affect the calcium release profile and the sensitivity of the test.

\section{Increase the stirring speed}

Increased agitation can reduce the thickness of the diffusion boundary layer $\delta$. Another effect is to facilitate tablets' disintegration into fine particles which have a larger surface area, A. In both ways, stirring speed can increase the dissolution rate.

In the test, a high speed stirrer (greater than $75 \mathrm{rpm}$ ) was used and the dissolution was performed in a separate beaker. After the $\mathrm{pH}=1.0$ simulated gastric medium was heated to $37 \pm 0.5^{\circ} \mathrm{C}$, the dissolution was performed one tablet at a time. Samples were taken at specific intervals. Calcium released was measured by the calibrated calcium ion selective electrode. Using the calibration equation, all potential readings in $\mathrm{mV}$ were converted to release percentage. A dissolution profile was then generated and compared with that from the USP standard test.

\section{Larger volume dissolution test}

Since the calcium dissolution appeared to saturation easily in the USP test, the amount of calcium ions in solution, which could be measured by the electrode, was 
low and dissolution profiles of different products appeared too similar to discriminate. Therefore, the volume of the dissolution medium was increased in attempt to achieve a more complete dissolution.

In a larger sized beaker, the dissolution test was performed with different medium volumes at $1 \times \operatorname{USP}(0.9 \mathrm{~L})$ to $2 \times \mathrm{USP}(1.8 \mathrm{~L})$ and $4 \times \mathrm{USP}(3.6 \mathrm{~L})$, with $\mathrm{pH}=1.0$. Unknown as the speed of the stirrer (far greater than $75 \mathrm{rpm}$ ), its velocity remained the same in all the revised dissolution tests. Calcium tablets were picked randomly for this revised test.

Test in $8 \times$ USP was actually performed in $4 \times$ USP, i.e. $3.6 \mathrm{~L}$ simulated gastric fluid, with the sample tablets cut in half.

Products in different salt forms were investigated, NatureMade (calcium citrate), PhosLo (calcium acetate), OsCal and Major (calcium carbonate). Since in $8 \times$ USP test half-sized tablets were used, no products with coatings were tested.

After the medium was heated, one tablet was dropped and the test was started. Sample solutions were drawn at specific time intervals. The calcium released was measured by the calibrated calcium ion selective electrode. After this test was repeated for six randomly selected tablets, dissolution profiles were generated and compared with those obtained by the USP standard method.

\section{III.Phosphate medium dissolution test}

A phosphate dissolution medium was used on the premise that phosphate ion would bind some calcium ions, and in this way, increase $\mathrm{C}_{\mathrm{S}}$ and promote the release 
of calcium. The phosphate buffer medium was prepared by dissolving $\mathrm{KH}_{2} \mathrm{PO}_{4}$ and $\mathrm{K}_{2} \mathrm{HPO}_{4}$ at a ratio of $76.7: 192.3$ in distilled water, and was adjusted to $\mathrm{pH}=7.5$ with $1 \mathrm{~N} \mathrm{HCl}$ or $\mathrm{NaOH}$ if necessary.

Tablets in different salt forms were tested, namely NatureMade (calcium citrate), OsCal (calcium carbonate), and PhosLo (calcium acetate). For each product, six randomly picked tablets were tested together, with three in phosphate buffer medium and the other three in USP standard gastric fluid $(\mathrm{pH}=1,0.1 \mathrm{M} \mathrm{HCl})$.

The test was performed by the USP standard II paddle method with the medium volume of $0.9 \mathrm{~L}$, stirring speed at $75 \mathrm{rpm}$. Sample solutions were drawn at specific time intervals and measured by the calcium ion selective electrode. Recorded potential data were then converted into release percentage. The dissolution profiles in different media were compared.

\section{Surfactant medium dissolution test}

The addition of surfactant is another approach to increase the relative solubility of the calcium salt. In theory, increased $\mathrm{C}_{\mathrm{S}}$ will improve dissolution in both rate and extent. When surfactant is added into $0.1 \mathrm{~N}$ hydrochloric acid dissolution medium, the pH may change accordingly, shown in Table 12.

\begin{tabular}{|l|l|l|l|l|l|l|}
\hline Tween 80 Concentration & 0 & $0.5 \%$ & $1.0 \%$ & $2.0 \%$ & $5.0 \%$ & $10.0 \%$ \\
\hline Final $\mathrm{pH}$ & 1.0 & 1.4 & 2.1 & 2.7 & 4.2 & 6.5 \\
\hline
\end{tabular}

Table 12. the change of $\mathrm{pH}$ at different surfactant concentrations 
- Optimization of surfactant level $(0.1 \% \sim 2 \%)$

The $\mathrm{pH}=1.0$ simulated gastric fluid $(0.1 \mathrm{M} \mathrm{HCl})$ was prepared and preheated to $37^{\circ} \mathrm{C}$ in the dissolution apparatus. With continuous stirring, different amount of Tween 80 were added into each beaker. The surfactant-containing media were prepared at concentrations of $0 \%, 0.1 \%, 0.2 \%, 0.5 \%, 1 \%$ and $2 \%$.

The dissolution test of six (6) NatureMade (calcium citrate) tablets was performed at the stirring speed of $50 \mathrm{rpm}$. Samples were drawn out and measured by the electrode. The dissolution profiles under every condition were compared.

The same test was also performed at the stirring speed of $75 \mathrm{rpm}$. The drug release profiles were compared with those obtained at $50 \mathrm{rpm}$.

- Optimization of surfactant level (10\% 15\%)

The $\mathrm{pH}=1.0$ simulated gastric fluid $(0.1 \mathrm{M} \mathrm{HCl})$ was placed in the dissolution apparatus and preheated to $37^{\circ} \mathrm{C}$. With continuous agitation, the dissolution media were prepared with Tween 80 concentrations of $0 \%, 1 \%, 10 \%, 12.5 \%$, and $15 \%$.

Six (6) NatureMade (calcium citrate) tablets were tested at the stirring speed of $100 \mathrm{rpm}$, for as long as 240 minutes. Sample solutions were drawn out for measurement of calcium release at specific time intervals.

For a more accurate measurement, standard calcium solutions with surfactant were prepared for the electrode calibration. The composite of standard solutions is shown below: 
a)

\begin{tabular}{|r|c|c|c|c|}
\hline \multicolumn{5}{|c|}{ Standard solution with no Tween 80} \\
\hline Calcium concentration (mol/L) & 0.0001 & 0.001 & 0.01 & 0.1 \\
\hline $0.1 \mathrm{M}$ calcium stock solution $(\mathrm{mL})$ & 0.01 & 0.1 & 1 & 10 \\
\hline Distilled water $(\mathrm{mL})$ & 9.99 & 9.9 & 9 & 0 \\
\hline Ion strength adjuster $(\mathrm{mL})$ & 0.2 & 0.2 & 0.2 & 0.2 \\
\hline
\end{tabular}

b)

\begin{tabular}{|r|c|c|c|c|}
\hline \multicolumn{7}{|c|}{$1 \%$ Tween 80 standard solution } \\
\hline Calcium concentration $(\mathrm{mol} / \mathrm{L})$ & 0.0001 & 0.001 & 0.01 & 0.1 \\
\hline $0.1 \mathrm{M}$ calcium stock solution $(\mathrm{mL})$ & 0.01 & 0.1 & 1 & 10 \\
\hline Distilled water $(\mathrm{mL})$ & 9.99 & 9.9 & 9 & 0 \\
\hline Ion strength adjuster $(\mathrm{mL})$ & 0.2 & 0.2 & 0.2 & 0.2 \\
\hline Tween $80(\mathrm{~g})$ & 0.102 & 0.102 & 0.102 & 0.102 \\
\hline
\end{tabular}

c)

\begin{tabular}{|r|c|c|c|c|}
\hline \multicolumn{7}{|c|}{$10 \%$ Tween 80 standard solution } \\
\hline $10 \%$ Tween 80 standard solution & 0.0001 & 0.001 & 0.01 & 0.1 \\
\hline $0.1 \mathrm{M}$ calcium stock solution $(\mathrm{mL})$ & 0.01 & 0.1 & 1 & 10 \\
\hline Distilled water $(\mathrm{mL})$ & 9.99 & 9.9 & 9 & 0 \\
\hline Ion strength adjuster $(\mathrm{mL})$ & 0.2 & 0.2 & 0.2 & 0.2 \\
\hline Tween $80(\mathrm{~g})$ & 1.02 & 1.02 & 1.02 & 1.02 \\
\hline
\end{tabular}

d)

\begin{tabular}{|r|c|c|c|c|}
\hline \multicolumn{7}{|c|}{$12.5 \%$ Tween 80 standard solution } \\
\hline Calcium concentration $(\mathrm{mol} / \mathrm{L})$ & 0.0001 & 0.001 & 0.01 & 0.1 \\
\hline $0.1 \mathrm{M}$ calcium stock solution $(\mathrm{mL})$ & 0.01 & 0.1 & 1 & 10 \\
\hline Distilled water $(\mathrm{mL})$ & 9.99 & 9.9 & 9 & 0 \\
\hline Ion strength adjuster $(\mathrm{mL})$ & 0.2 & 0.2 & 0.2 & 0.2 \\
\hline Tween $80(\mathrm{~g})$ & 1.275 & 1.275 & 1.275 & 1.275 \\
\hline
\end{tabular}


e)

\begin{tabular}{|r|c|c|c|c|}
\hline \multicolumn{7}{|c|}{$15 \%$ Tween 80 standard solution } \\
\hline Calcium concentration $(\mathrm{mol} / \mathrm{L})$ & 0.0001 & 0.001 & 0.01 & 0.1 \\
\hline $0.1 \mathrm{M}$ calcium stock solution $(\mathrm{mL})$ & 0.01 & 0.1 & 1 & 10 \\
\hline Distilled water $(\mathrm{mL})$ & 9.99 & 9.9 & 9 & 0 \\
\hline Ion strength adjuster $(\mathrm{mL})$ & 0.2 & 0.2 & 0.2 & 0.2 \\
\hline Tween $80(\mathrm{~g})$ & 1.53 & 1.53 & 1.53 & 1.53 \\
\hline
\end{tabular}

Table 13. The composite of surfactant-containing standard solutions for electrode calibration.

The calcium electrode was calibrated with corresponding standard solutions every time before taking any measurement. The release profiles were generated and compared. The condition under which the most release percentage was achieved was selected as the best surfactant level.

- Optimization of stirring speed

Since the dissolution rate decreased in a medium with high concentration of surfactant, stirring speed was increased in an attempt to complete the dissolution in an hour.

Six (6) tablets from products of three different calcium forms were tested by USP standard II paddle method. Tween 80 concentration was at $0 \%, 10 \%$ and $15 \%$. Stirring speed was set at $100 \mathrm{rpm}$ and $150 \mathrm{rpm}$. Samples were taken at specific time intervals, and the test lasted 240 min to confirm complete dissolution. The calcium electrode was calibrated in standard solutions with corresponding surfactant level. Dissolution profiles for each experiment were generated and compared to pick the optimum testing criterion. 
The optimized test conditions should be those under which the calcium salt can reach complete dissolution, i.e. $100 \%$ release, or otherwise, reach saturation at a higher release percentage and thus give a better sensitivity.

Phase III - Testing of performance of commercially available calcium products:

\section{Optimized vs. USP dissolution method.}

\section{Physical tests}

Tums quick-dissolve tablets were tested for their physical properties. Four different Tums flavored tablets were in one bottle, sharing the same lot number, but obviously made in different formulation. Therefore, each flavored type was tested respectively and compared. Physical tests included weight variation, hardness, thickness and friability. All are described in detail in Phase I method part. Note that for chewable tablets, friability testing is not necessary but only for the purpose of comparison with regular tablets. Since there are not enough tablets (less than 6) for the yellow ones, there is no result for that flavor. The traditional chewable tablets were also tested.

\section{Disintegration tests}

Again, this is not necessary for chewable tablet but only for the purpose of comparison. The length of Tums tablets is greater than $18 \mathrm{~mm}$ and therefore was tested by Apparatus B, with the three chamber basket. Tests were performed only in distilled water. The traditional chewable tablets and "quick dissolve" tablets were 
compared.

\section{Dissolution tests under the conditions of both the USP method and the revised method}

In the USP condition, the dissolution medium was $\mathrm{pH}=1.0$ hydrochloric acid solution; stirring speed was at $75 \mathrm{rpm}$; three tablets of the same flavor (four flavors altogether) were tested. In the revised method, dissolution medium was $10 \%$ Tween 80 in $1 \mathrm{~N}$ hydrochloric acid solution. With all other conditions the same, the dissolution profiles by these two methods were compared. Traditional Tums chewable tablets were also tested in the same way for comparison. 


\section{References for Chapter III}

1. USP 28/NF 23 General Chapters. Chart 12. Dietary Supplement Products. 2196

2. USP 28/NF 23 General Chapters. $<1216>$ DISINTEGRATION AND DISSOLUTION OF DIETARY SUPPLEMENTS. 2778-80

3. USP 28/NF 23 General Chapters. <701> DISINTEGRATION. 2411-2

4. USP 28/NF 23 General Chapters. <2040> TABLET FRIABILITY. 2745

5. USP 28/NF 23 General Chapters. <2091> WEIGHT VARIATION OF DIETARY SUPPLEMENTS. 2780-1

6. USP 28/NF 23 General Chapters. <905> UNIFORMITY OF DOSAGE UNITS. 2503

7. USP 28/NF 23 General Chapters. <711> DISSOLUTION. 2412-4

8. USP 28/NF 23 Official Monographs. Calcium Carbonate Tablets. 320-1

* USP 28/NF 23 is for the year of 2005. 


\section{Chapter IV}

\section{Results and Discussion}

\section{Phase I - Testing of performance of commercially available calcium products}

\section{Physical tests}

Physical properties of tablets can reflect the quality of the products. Especially, the tablets' hardness and friability are factors that can affect the disintegration rate and their dissolution behavior.

\begin{tabular}{|c|c|c|c|c|c|c|c|c|}
\hline \multicolumn{9}{|c|}{ Physical properties } \\
\hline \multicolumn{2}{|l|}{ Brand } & NatureMade & Leader & OsCal & CVS & PhosLo & Walgreens & HiCal \\
\hline \multicolumn{2}{|l|}{ Salt form } & Carbonate & Carbonate & Carbonate & Carbonate & Acetate & Carbonate & Carbonate \\
\hline \multicolumn{2}{|c|}{ Elemental calcium content } & $500 \mathrm{mg}$ & $600 \mathrm{mg}$ & $500 \mathrm{mg}$ & $600 \mathrm{mg}$ & $169 \mathrm{mg}^{* *}$ & $600 \mathrm{mg}$ & $200 \mathrm{mg} * *$ \\
\hline \multicolumn{2}{|l|}{ Lot } & NB10929 & 1HN0579 & $1 \mathrm{G} 0925$ & OMB0304 & POL336 & 0F01786 & OCO1486 \\
\hline \multirow{2}{*}{$\begin{array}{l}\text { Weight } \\
\text { Variation (g) }\end{array}$} & Mean & 1.354 & 1.723 & $-*$ & 1.753 & 0.715 & 1.716 & 1.508 \\
\hline & Std Dev & 0.023 & 0.025 & $-*$ & 0.009 & 0.007 & 0.027 & 0.007 \\
\hline \multirow{2}{*}{ Thickness (inch) } & Mean & 0.3541 & 0.2917 & 0.2713 & 0.3054 & 0.2155 & 0.2770 & 0.2689 \\
\hline & Std Dev & 0.0040 & 0.0034 & 0.0023 & 0.0013 & 0.0011 & 0.0017 & 0.0020 \\
\hline \multirow{2}{*}{ Hardness (kP) } & Mean & 19.3 & 23.3 & 31.3 & 8.4 & 7.6 & 31.9 & 26.3 \\
\hline & Std Dev & 2.1 & 2.2 & 2.2 & 1.2 & 0.8 & 2.2 & 1.6 \\
\hline \multicolumn{2}{|l|}{ Friability } & $0.1 \%$ & fail & $0.0 \%$ & Fail & $0.8 \%$ & fail & $0.0 \%$ \\
\hline
\end{tabular}

Table 14. Physical properties for each calcium supplement product.

* There were not enough tablets for weight variation test of OsCal and thickness and hardness test of Tums Yellow.

** The elemental calcium of PhosLo and HiCal was calculated from its labeled amount of calcium salt.

*** Chewable tablets (Tums) are covered in Phase III results. 
From this table, the standard deviation of weight variation, thickness, and hardness of all products were low, indicating that a good conformity within batch has been achieved.

According to our results, Leader, CVS and Walgreens failed the friability tests, since there was at least one tablet broken during the test. For Tums products, since they are chewable tablets, which are designed to easily break apart, their tablet hardness is low and it is not expected that they would pass the friability test. They are typically so friable that shaking the bottle by hand can lead to some breakage. Tums were the only chewable calcium products tested.

For all regular tablets, different products had different hardness, ranging from 7.6 to $31.9 \mathrm{kP}$. It is anticipated that extremes in hardness may affect disintegration performance primarily and dissolution, secondarily.

\section{In vitro disintegration}

\section{A. Comparison of Apparatus for large tablets}

First, the disintegration behavior in standard Apparatus A and Apparatus B was investigated to compare the two apparatus and to see whether a significant change in disintegration occurs for tablets longer than $18 \mathrm{~mm}$. Tests were performed in simulated gastric fluid (SGF), simulated intestinal fluid (SIF) and distilled water (DW). The disintegration in both standard apparatus was compared and related to the length of the 
tablet. The results are shown below in Table 15 and Figure 3.

\begin{tabular}{|c|c|c|c|c|c|c|c|c|c|c|c|c|c|}
\hline \multirow{3}{*}{ Brand } & \multirow{3}{*}{$\begin{array}{l}\text { Length } \\
(\mathrm{mm})\end{array}$} & \multicolumn{4}{|c|}{ SGF } & \multicolumn{4}{|c|}{ SIF } & \multicolumn{4}{|c|}{ DW } \\
\hline & & \multicolumn{2}{|c|}{ Apparatus A } & \multicolumn{2}{|c|}{ Apparatus B } & \multicolumn{2}{|c|}{ Apparatus A } & \multicolumn{2}{|c|}{ Apparatus B } & \multicolumn{2}{|c|}{ Apparatus A } & \multicolumn{2}{|c|}{ Apparatus B } \\
\hline & & AVG & $\mathrm{SD}$ & AVG & SD & AVG & $\mathrm{SD}$ & AVG & $\mathrm{SD}$ & AVG & SD & AVG & $\mathrm{SD}$ \\
\hline Caltrate & 20.4 & 22.15 & 2.00 & 9.42 & 0.99 & $>60$ & - & 20.93 & 1.66 & 31.63 & 1.83 & 20.04 & 1.83 \\
\hline Walgreens & 20.5 & 21.94 & 2.76 & 9.14 & 0.75 & 27.11 & 2.23 & 18.88 & 2.23 & 26.74 & 1.95 & 17.04 & 1.17 \\
\hline HiCal & 19.6 & 1.24 & 0.18 & 1.75 & 0.19 & 1.56 & 0.11 & 2.25 & 0.41 & 1.31 & 0.11 & 1.77 & 0.07 \\
\hline Leader & 19.3 & 9.78 & 0.82 & 1.63 & 0.15 & 15.03 & 1.14 & 2.58 & 0.15 & 10.50 & 0.94 & 2.61 & 0.20 \\
\hline OsCal & 19.2 & 12.19 & 0.42 & 11.63 & 1.34 & 12.93 & 0.21 & 12.83 & 0.99 & 12.88 & 0.25 & 12.54 & 0.85 \\
\hline
\end{tabular}

Table 15. Length of the tablets and their disintegration profile in Apparatus A and B.

* AVG: average time (min); SD: standard deviation (min).

For Caltrate, its disintegration in SIF by Apparatus A was not complete in 30 minutes, so its test was extended to 60 minutes. After 60 minutes when complete disintegration still was not achieved, the test was stopped. Therefore, no standard deviation was shown in the table above.

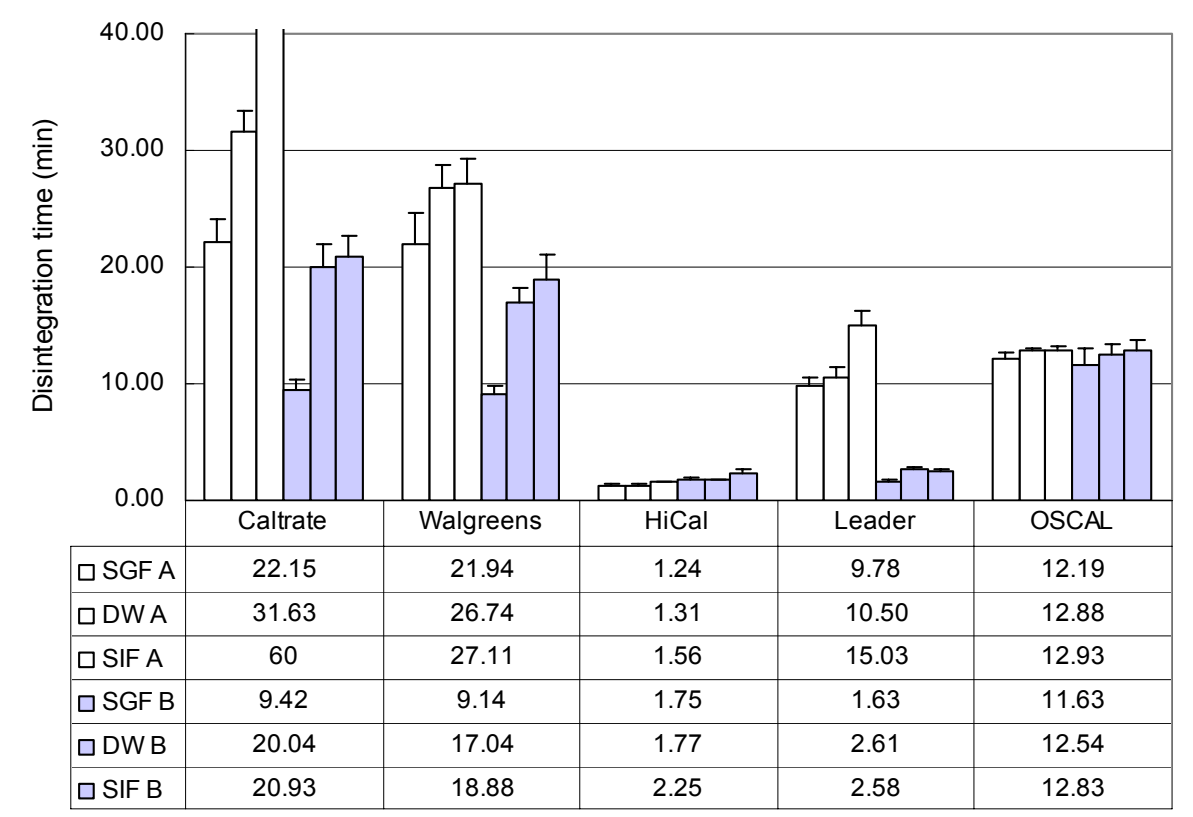

Figure 3. Comparison of disintegration in SGF, DW and SIF by Apparatus A and B

From these results, it is seen that for larger tablet supplements, there is a difference of disintegration time between Apparatus A and B, with Apparatus B causing a faster 
disintegration. This difference is not significant for a fast disintegrating product, like RiteAid HiCal. Though not the primary focus of this study, of note also in this data set is the sensitivity of all five products' disintegration time to $\mathrm{pH}$ (regardless of the apparatus) with disintegration time increasing with increasing $\mathrm{pH}$.

This difference between the results from the two apparatus is likely partly caused by the different movement of the disintegration medium of the medium across the surface of the tablets. In Apparatus B, the tablet can lie flat on the bottom mesh plate. The sufficient space between the tablet and basket allows smooth flow across the tablet, which will facilitate the wearing off of coating material (if there is any), ultimately eroding the surface into a coarse state and helping tablet disintegration. Experiencing the same hydrodynamics, tablets show less deviation in disintegration time.

For Apparatus A, however, longer tablets may stand at an angle against the wall. Some may not be able to move up and down freely with the current of the medium, but stick at a position in the basket and move with it. Some others may still be able to be carried along with the current, but collisions with the wall can happen and the orientation of the tablet is random. The irregular current (i.e. Hydrodynamic effects) around tablets and the limited movement would hamper the wearing off of coating material, and/or retard the disintegration processes in some other manner. This also appears to lead to a greater deviation in tablet disintegration time.

As a result, as with pharmaceutical products, it appears also that nutraceutical tablets need to be measured by length first to decide the appropriate device for 
disintegration testing.

\section{B. Disintegration as a function of $\mathbf{p H}$}

The following research shows the disintegration performance of all eight products in traditional tablet formulation. The disintegration of the Tums chewable product is not included in this data set.

\begin{tabular}{ccccccc}
\hline \multirow{2}{*}{ Brand } & \multicolumn{2}{c}{ Simulated Gastric Fluid } & \multicolumn{2}{c}{ Simulated Intestinal Fluid } & \multicolumn{2}{c}{ Distilled Water } \\
\cline { 2 - 6 } & AVG & SD & AVG & SD & AVG & SD \\
\hline Caltrate & 9.42 & 0.99 & 20.93 & 1.66 & 20.04 & 1.83 \\
Walgreens & 9.14 & 0.75 & 18.88 & 2.23 & 17.04 & 1.17 \\
HiCal & 1.75 & 0.19 & 2.25 & 0.41 & 1.75 & 0.07 \\
Major & 1.36 & 0.20 & 3.08 & 0.38 & 3.78 & 0.21 \\
CVS & 7.72 & 3.95 & 10.89 & 8.32 & 7.28 & 6.79 \\
PhosLo & 3.32 & 0.38 & 4.86 & 0.20 & 3.06 & 0.36 \\
Leader & 1.63 & 0.15 & 2.58 & 0.15 & 2.61 & 0.20 \\
OsCal & 11.63 & 1.34 & 12.83 & 0.99 & 12.54 & 0.85 \\
\hline
\end{tabular}

Table 16. Disintegration data of each calcium supplement.

AVG: average disintegration time (min); SD: standard deviation (min)

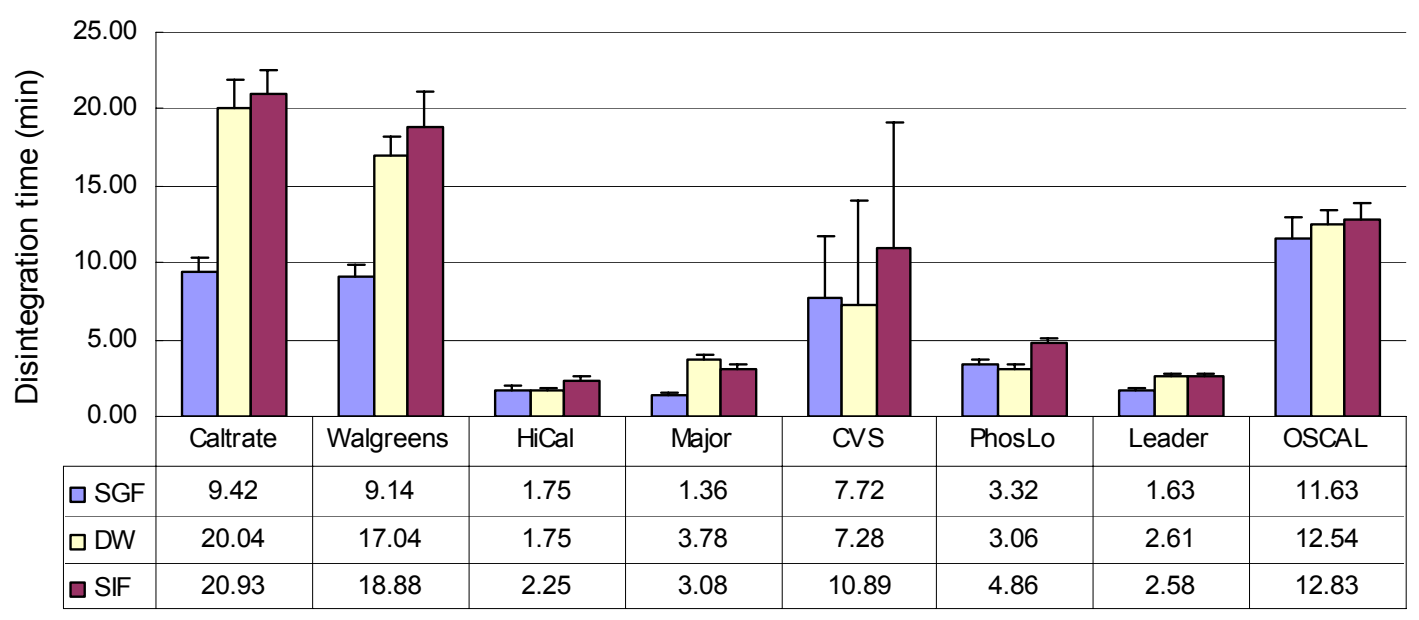

Figure 4. Disintegration profile of each calcium supplement 
The USP required medium for calcium supplements is distilled water. From the result, all eight products are compliant with this requirement. Although they differ significantly in their disintegration rate, all of them can successfully pass through the mesh within thirty (30) minutes in all the three different $\mathrm{pH}$ media.

Some of the samples disintegrate extremely fast (in two to three minutes). Brands in this category are HiCal, Major and Leader. For them, no significant change has been observed in the different media, perhaps due to their short disintegration time. For relatively slow disintegrating products, such as Caltrate and Walgreens, their disintegration can last as long as $20 \mathrm{~min}$. Higher $\mathrm{pH}$ media, namely distilled water and simulated intestinal medium, significantly prolonged their disintegration. In general, all products disintegrated in simulated gastric fluid faster than under other conditions. This would be the preferred performance, since calcium supplements should disintegrate and begin dissolving in the stomach, when taken orally.

In relation to the products' physical properties (shown in Table 13), friability does not appear to correlate with disintegration time. For hardness, some connection is observed. Soft tablets like CVS and PhosLo exhibit a faster disintegration, while harder ones such as Walgreens and OsCal take a longer time to disintegrate. The significant variability seen on CVS disintegration could be in part, due to the products' poor friability and low hardness. 


\section{In vitro dissolution - USP conditions}

Some commercially available calcium products (as shown in table 7) were tested using the USP II standard paddle test. Six (6) tablets were tested in the medium of $\mathrm{pH}=1.0$ hydrochloric acid. The percentage of active elemental calcium (based on salt and product labeling) dissolved to the labeled amount is calculated and graphed out as dissolution profiles, which are shown below.

RiteAid HiCal

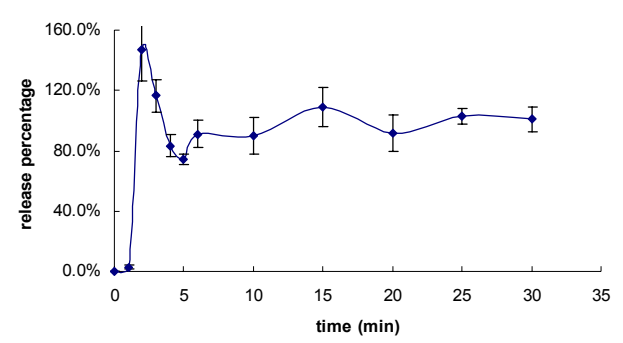

OSCAL

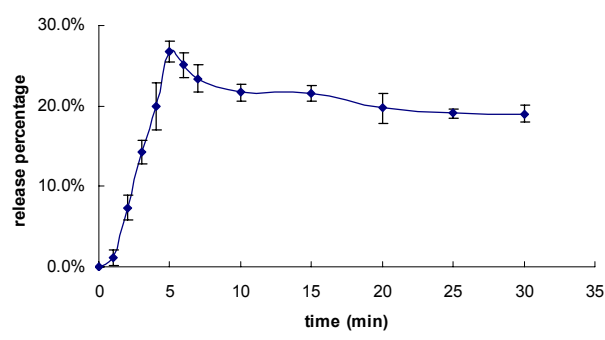

cvs

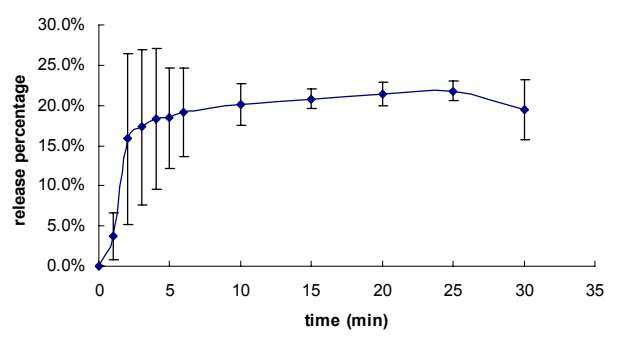

Major

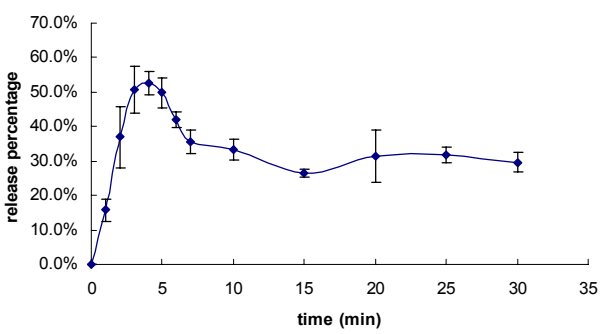

Walgreens

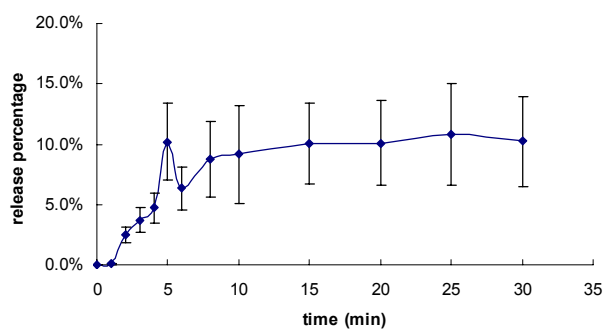

PhosLo

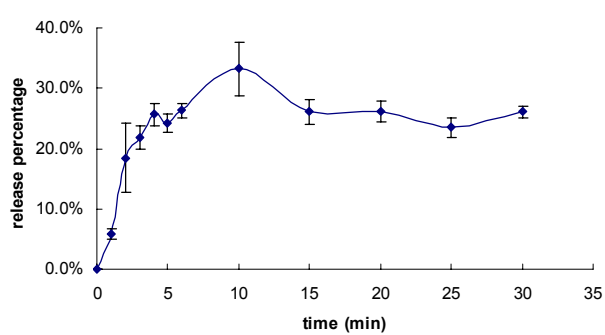

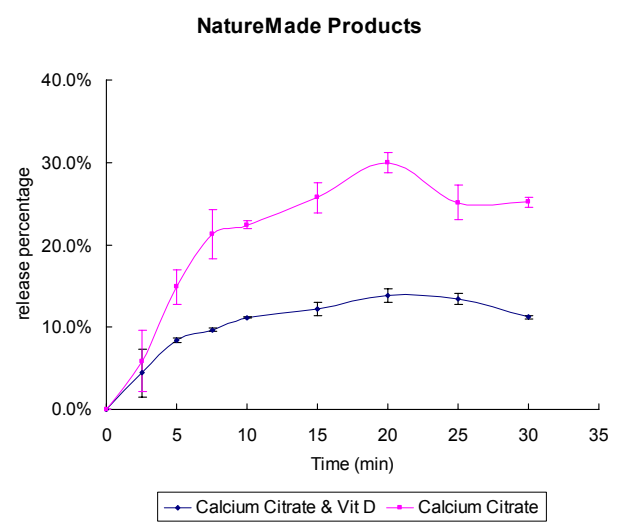

Figure 5. Calcium supplement dissolution profiles by USP standard paddle method. 
From the graphs shown in Figure 6, except for RiteAid HiCal, none of the other products reached a final drug release of over $50 \%$. Some products, Major and OsCal namely, experienced a sharp increase (quick dissolution, or quick drug release) in the first few minutes, producing a notable initial peak. After this, the calcium concentration in solution dropped to a lower level and kept relatively unchanged till the end of the study. This may indicate an oversaturated initial state upon dissolution or a method-related aberration, due to stirring speed.

For some other products like CVS, PhosLo, Walgreens and NatureMade, their initial release does peak. It takes from 5 to 10 minutes for them to reach a relatively stable value, where a plateau is then reached, indicating the maximum release amount.

This irregular dissolution behavior may be a result of the low solubility of calcium salts, even in acidic media. The structure and solubility of the three calcium salts are shown below:

\begin{tabular}{|c|c|c|c|c|}
\hline Salt form & Formula & Structure & $\begin{array}{l}\text { Molecular } \\
\text { weight }\end{array}$ & $\begin{array}{l}\text { Solubility in } \\
\text { water } 25\end{array}$ \\
\hline Calcium acetate & $\mathrm{C}_{4} \mathrm{H}_{6} \mathrm{CaO}_{4}$ & & 158.169 & $37.4 \%$ \\
\hline Calcium carbonate & $\mathrm{CaCO}_{3}$ & & 100.0892 & $0.0015 \%$ \\
\hline Calcium citrate & $\mathrm{C}_{12} \mathrm{H}_{10} \mathrm{Ca}_{3} \mathrm{O}_{14}$ & & 498.4426 & $0.22 \%$ \\
\hline Calcium Chloride & $\mathrm{CaCl}_{2}$ & & 110.99 & $74.5 \%$ \\
\hline
\end{tabular}

Table 17. The chemical properties of the three calcium salt forms. ${ }^{1}$ 
On the other hand, the dissolution of calcium tablets can neutralize the some acid and make the environment less acidic. The calcium amount in the dissolution medium is thus limited. This may get reflected for a quick releasing product in an over saturation of the solvent (i.e. dissolution peak) that leads to calcium precipitation and subsequent dissolution to a less saturated state. It can also be inferred from the curve that the solubility of carbonate is lower than other salt forms since, except for one case, it reaches a lower release percentage, which conforms to the reference data. It can also be observed that most calcium carbonate products release faster than other salt forms.

This result (shown in Figure 6) indicates that the current USP dissolution testing methodology is inadequate in case of those less soluble drugs. To obtain a sensitive and reproducible analysis result, efforts should be made to improve the dissolution, allowing for greater calcium release in the dissolution medium. The following revised tests were then performed, in order to modify this test method.

\section{Phase II - Development of an optimized dissolution testing methodology for calcium-based supplements}

\section{Increased speed, larger volume dissolution}

Different calcium salts have been tested by the increased volume method. Six (6) tablets of each product were tested in the medium of $\mathrm{pH}=1.0$ hydrochloric acid. The volume of dissolution media increased from $1 \times \operatorname{USP}(0.9 \mathrm{~L})$, to $2 \times \mathrm{USP}(1.8 \mathrm{~L}), 4 \times$ 
USP (3.6 L) and $8 \times$ USP (half tablet in $3.6 \mathrm{~L}$ ). The stirring speed was increased to nearly $500 \mathrm{rpm}$. The dissolution profiles were compared with each other. Profiles are shown below.

Dissolution Profiles of OSCAL

Calcium Carbonate

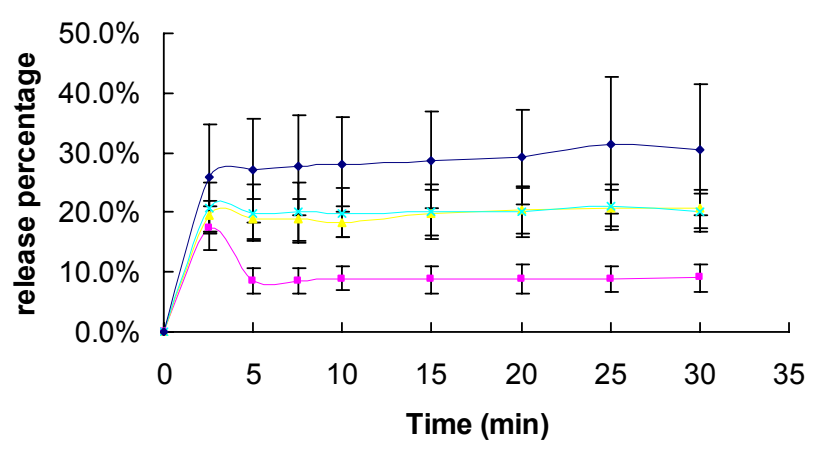

- USP USP X $2 *$ USP X $4 \rightarrow$ USP $\times 8$

Dissolution Profiles of NatureMade Calcium Carbonate

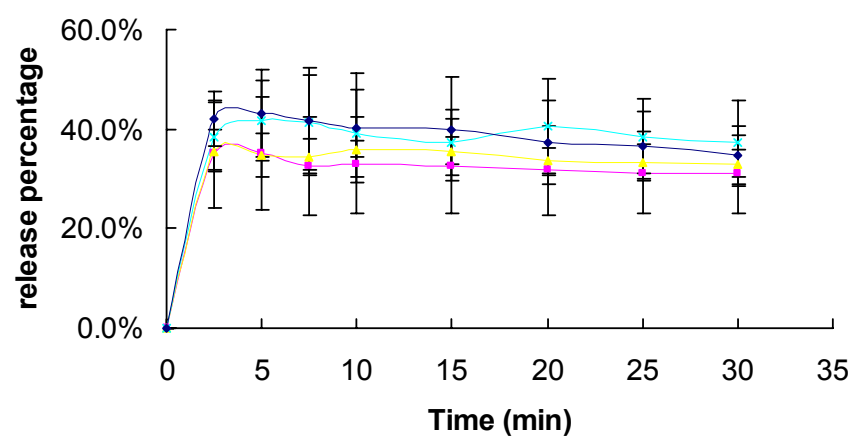

- USP USP $\times 2 \div$ USP $\times 4 \rightarrow$ USP $\times 8$
Dissolution Profile of PhosLo Calcium Acetate

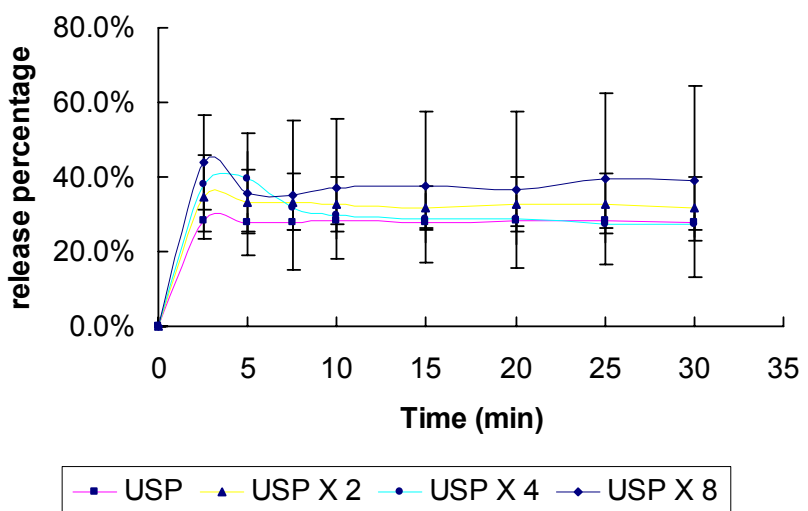

Figure 6. Calcium supplements' dissolution profiles in increased speed and larger volume tests.

Since the dissolution test in bigger sized beakers cannot be performed simultaneously for one product, it is believed that the change in medium and other factors contribute to the relatively large deviation. In order to better observe the change 
due to volume change, the deviation bars are removed in the following figure to compare the shifting trend.

\section{Dissolution Profiles of OSCAL Calcium Carbonate}

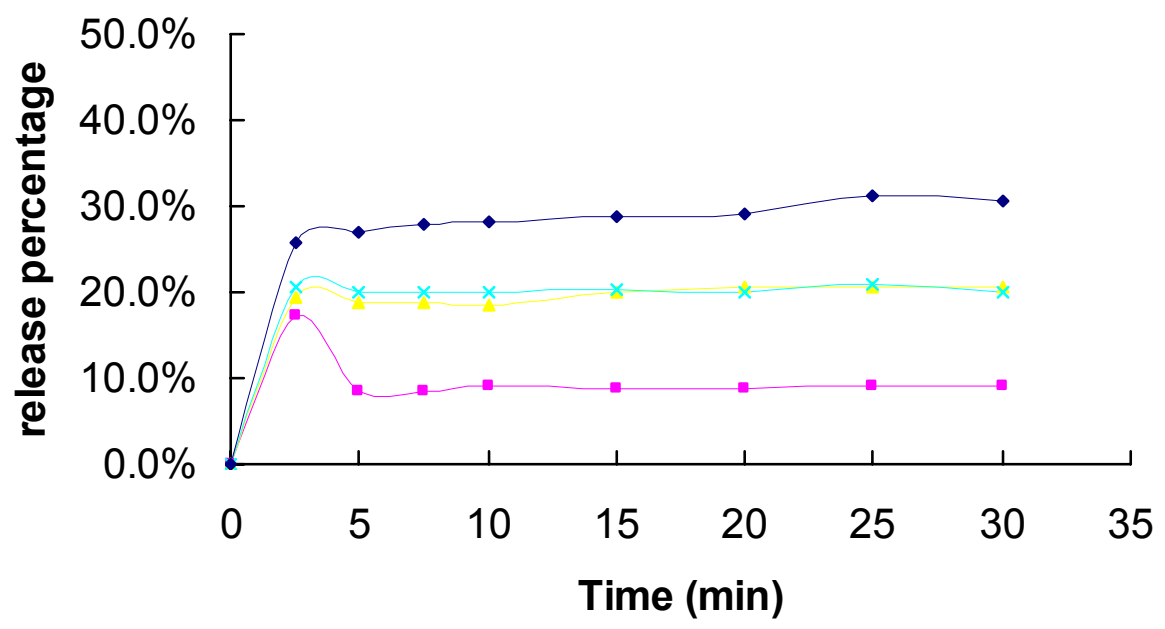

- USP $\rightarrow$ USP X $2 *$ USP X $4-$ USP X 8

\section{Dissolution Profiles of Major \\ Calcium Carbonate}

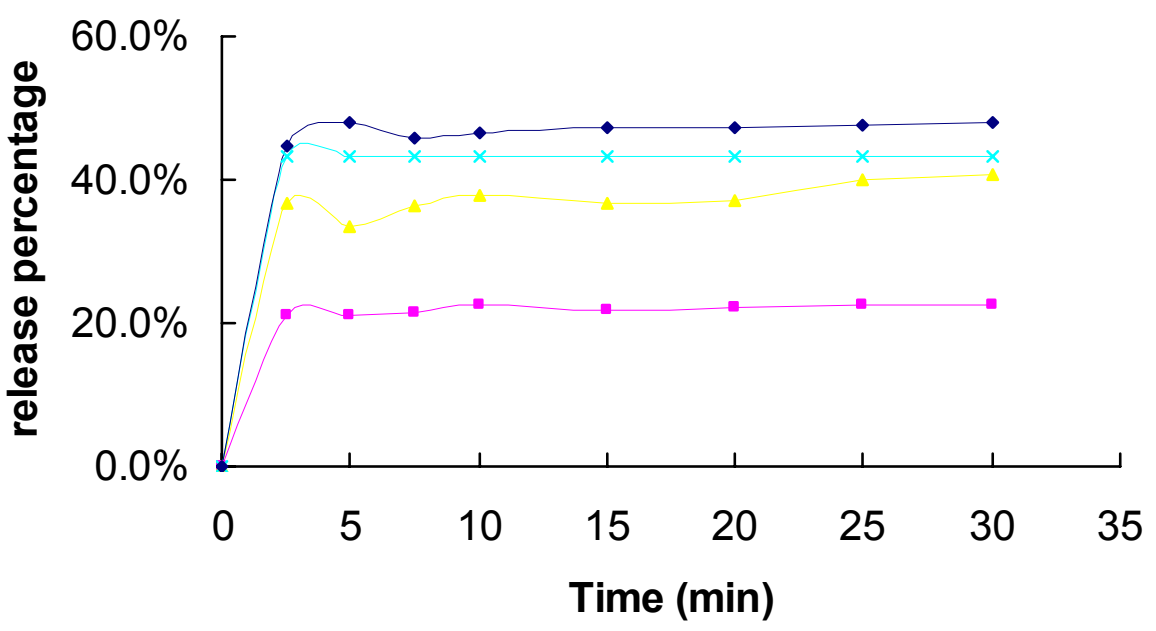

- USP - USP X $2 *$ USP X $4-$ USP X 8 


\section{Dissolution Profiles of NatureMade Calcium Carbonate}

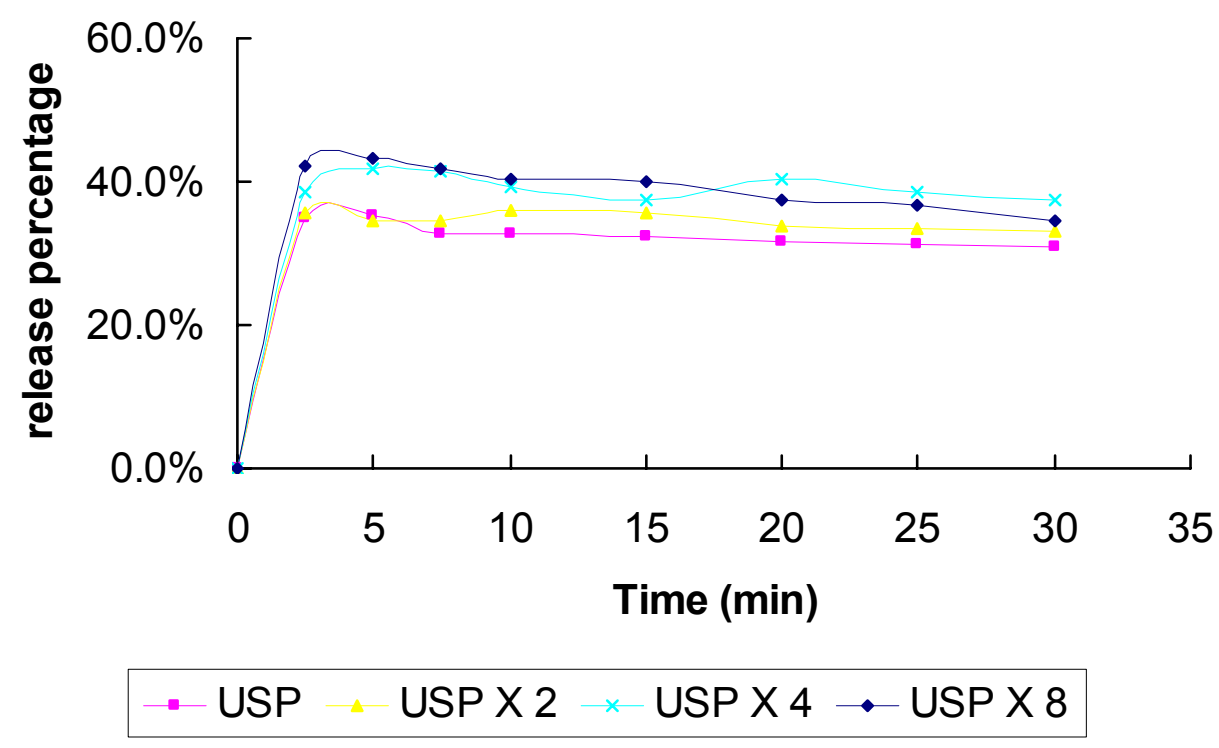

\section{Dissolution Profile of PhosLo Calcium Acetate}

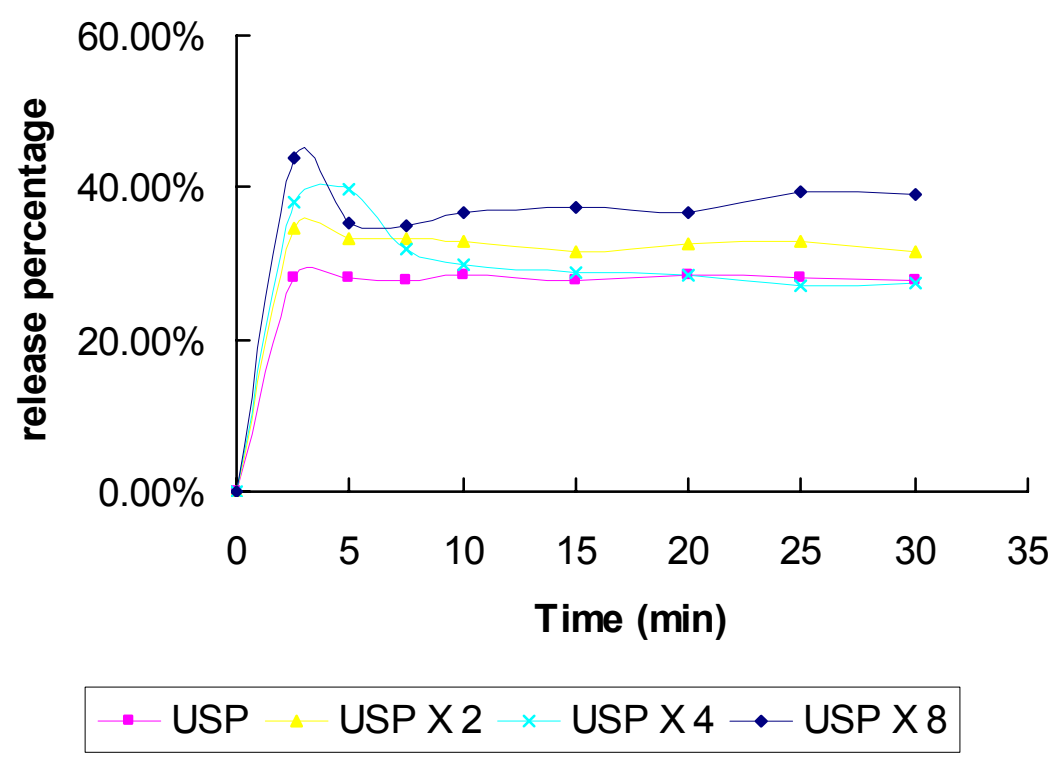

Figure 7. Calcium supplements' dissolution profiles in increased speed and larger volume tests.

For this revised paddle testing method, increased stirring speed and volume of dissolution medium did improve the dissolution. Although the trend of increased drug 
release was observed, yet such improvement was not as good as anticipated; the result is still not discriminating. Although the deviation at each sample point can be reduced by proper experiment design, it is yet not practical to increase the medium to an even larger volume to reach a better drug release. Under these new conditions, the initial peak/burst seen with the carbonate products with the USP method was eliminated.

\section{Phosphate binding medium}

A phosphate dissolution medium was used here on the premise that phosphate ion will bind some calcium ions, and in this way, promote calcium release.

The different calcium salts were tested in $\mathrm{pH}=7.5$ phosphate medium by the USP paddle method with the stirring speed at $50 \mathrm{rpm}$. The profiles are compared with those in acidic media.

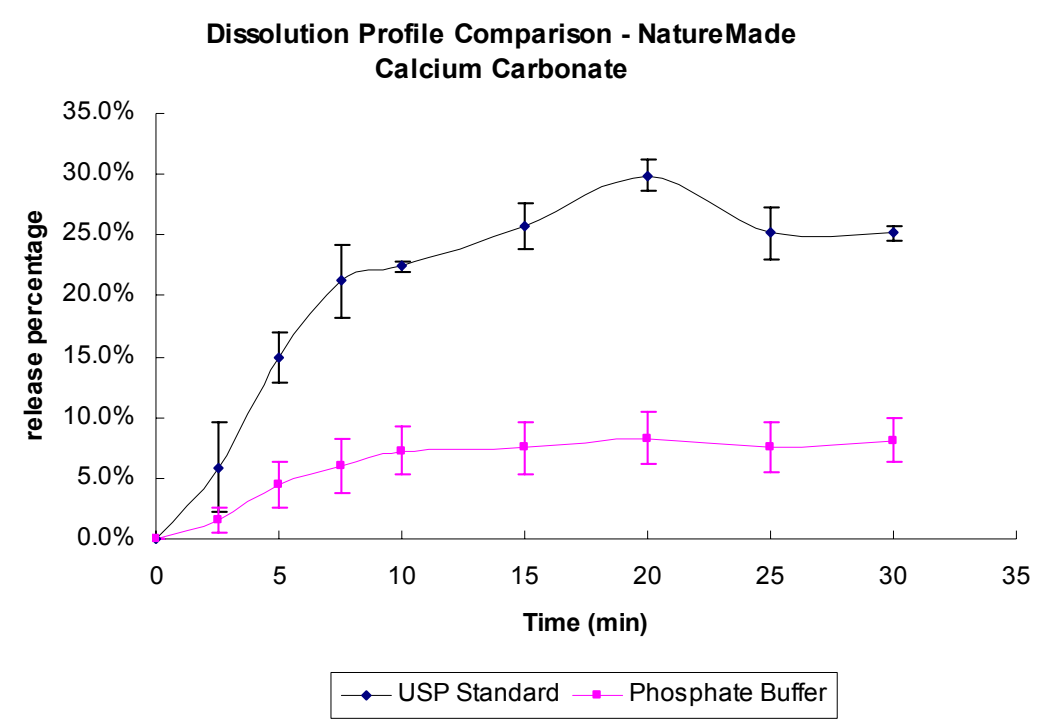




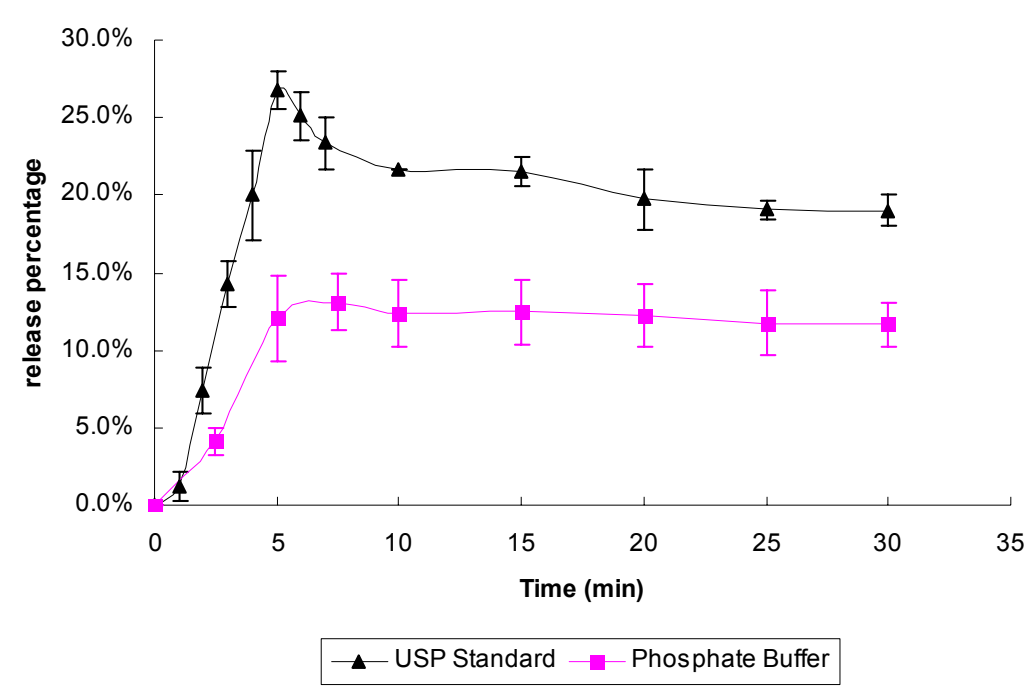

Dissolution Profile Comparison - PhosLo Calcium Acetate

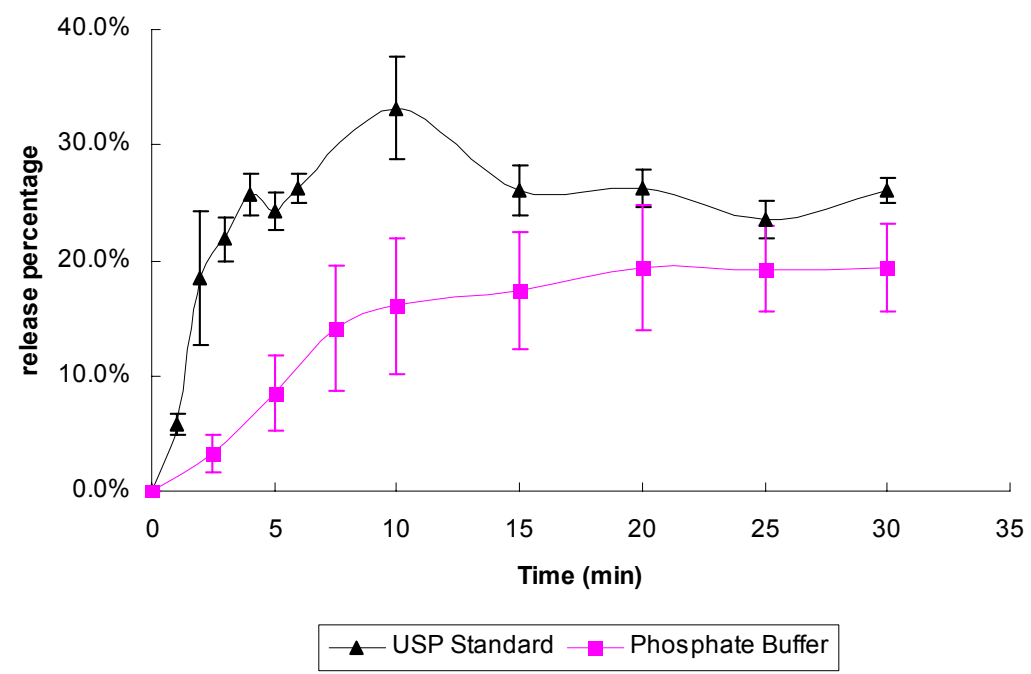

Figure 8. Calcium supplements' dissolution profiles in phosphate buffer medium

From the figures above, the phosphate buffer media significantly failed to improve the dissolution of less soluble calcium salts. Although phosphate binding may be a favorable factor to facilitate dissolution, this medium's high $\mathrm{pH}$ (7.5) may have contributed more in limiting the calcium release in the experiments. 


\section{Surfactant medium}

Surfactant molecules are by nature bipolar. They usually contain a polar head group which is hydrophilic, and a hydrophobic hydrocarbon chain tail. When placed in water, these amphiphiles then form clusters of molecules known as micelles, which help the less soluble drug particles dissolve in water.

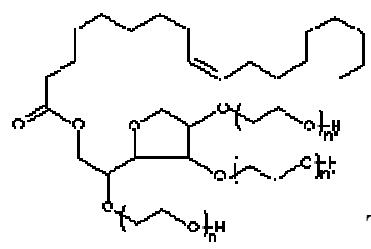

The structure of Tween 80

In our preliminary experiments, two popular surfactants, SLS and Tween 80, were used. However, since SLS had some salt effect with calcium samples and formed precipitation instantly, Tween 80 became a standard surfactant in our following tests.

\section{A. Optimization of surfactant level I}

1. NatureMade calcium carbonate release profile at $50 \mathrm{rpm}$.

\begin{tabular}{|c|c|c|c|c|c|c|}
\hline \multicolumn{7}{|c|}{ Relative \% of Calcium Dissolved in Each Sample } \\
\hline \multirow{2}{*}{ Time (min) } & \multicolumn{7}{|c|}{ Surfactant concentration } \\
\cline { 2 - 7 } & $0 \%$ & $0.1 \%$ & $0.2 \%$ & $0.5 \%$ & $1.0 \%$ & $2.0 \%$ \\
\hline 0.0 & $0.00 \%$ & $0.00 \%$ & $0.00 \%$ & $0.00 \%$ & $0.00 \%$ & $0.00 \%$ \\
\hline 2.5 & $9.71 \%$ & $4.06 \%$ & $2.90 \%$ & $7.93 \%$ & - & $1.40 \%$ \\
\hline 5.0 & $12.75 \%$ & $8.57 \%$ & $9.26 \%$ & $16.48 \%$ & $4.18 \%$ & $5.31 \%$ \\
\hline 7.5 & $14.78 \%$ & $13.05 \%$ & $13.78 \%$ & $26.50 \%$ & $12.65 \%$ & $11.23 \%$ \\
\hline 10.0 & $17.27 \%$ & $16.87 \%$ & $17.54 \%$ & $31.69 \%$ & $21.23 \%$ & $19.76 \%$ \\
\hline 15.0 & $20.33 \%$ & $20.02 \%$ & $26.29 \%$ & $37.32 \%$ & $32.13 \%$ & $30.87 \%$ \\
\hline 20.0 & $21.81 \%$ & $23.58 \%$ & $30.01 \%$ & $41.29 \%$ & $37.37 \%$ & $37.37 \%$ \\
\hline 25.0 & $21.47 \%$ & $23.39 \%$ & $29.32 \%$ & $42.27 \%$ & $40.47 \%$ & $42.45 \%$ \\
\hline 30.0 & $20.49 \%$ & $23.03 \%$ & $30.48 \%$ & $44.98 \%$ & $43.14 \%$ & $42.79 \%$ \\
\hline Infinite & $18.25 \%$ & $19.76 \%$ & $24.50 \%$ & $45.97 \%$ & $49.39 \%$ & $48.61 \%$ \\
\hline
\end{tabular}

Table 18. Calcium supplements' dissolution in surfactant containing media $50 \mathrm{rpm}$ 


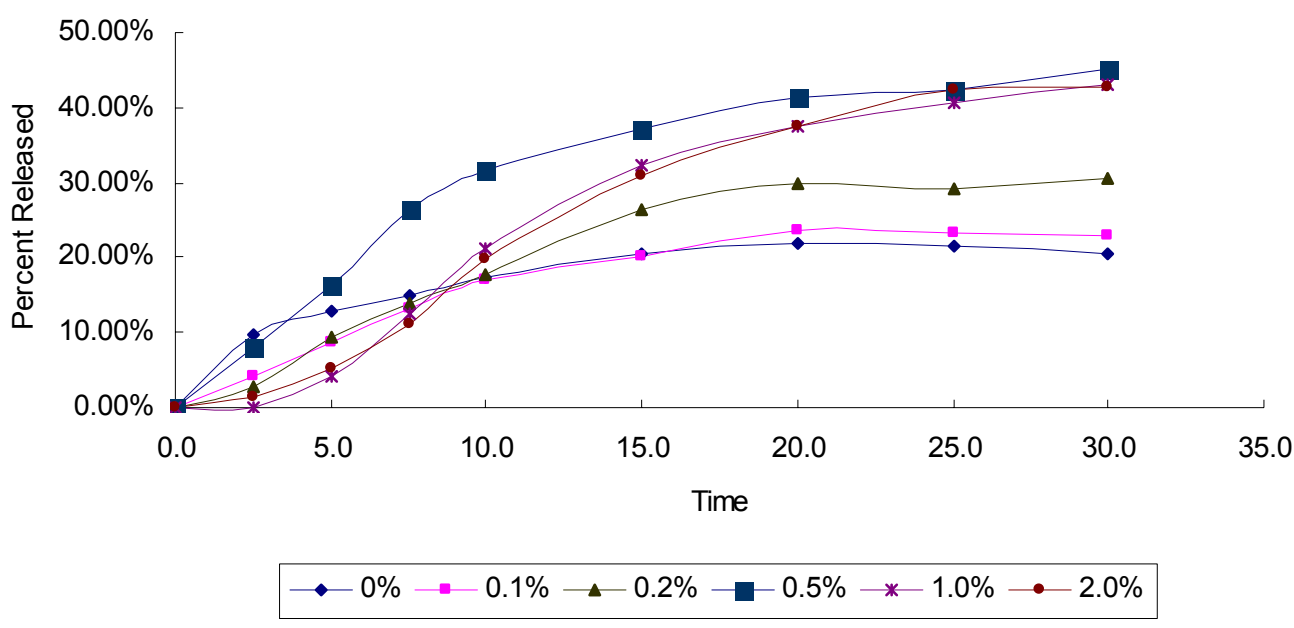

Figure 9. Calcium supplements' dissolution profiles in surfactant containing media $50 \mathrm{rpm}$

This test was intended to be a preliminary estimation of the impact of surfactant on calcium salt dissolution. Therefore, no repetitive runs were performed for accurate measurement. The results show that the dissolution is both improved and more characteristic with the increasing amount of surfactant. The initial release rate may be lowered due to the $\mathrm{pH}$ change, from 1 to about 3 , by addition of Tween 80 . The release extent, however, is significantly improved. Since our aim is to reach the maximum release amount in thirty (30) minutes, the stirring speed is also increased in the following tests and higher level of surfactant is also tested.

2. Drug release profile at $75 \mathrm{rpm}$.

Since the dissolution rate was decreased with the addition of surfactant, the stirring speed was increased to $75 \mathrm{rpm}$ to reduce this effect. At the same time, higher concentration at 5\% surfactant was included in the test to see whether the dissolution extent could be further enhanced. 


\begin{tabular}{|c|c|c|c|c|c|c|}
\hline \multicolumn{7}{|c|}{ Relative percentage of Calcium Dissolved in Each Sample } \\
\hline \multirow{2}{*}{ Time (min) } & \multicolumn{7}{|c|}{ Surfactant concentration } \\
\cline { 2 - 7 } & $0 \%$ & $0.1 \%$ & $0.2 \%$ & $1 \%$ & $2 \%$ & $5 \%$ \\
\hline 0.0 & $0.00 \%$ & $0.00 \%$ & $0.00 \%$ & $0.00 \%$ & $0.00 \%$ & $0.00 \%$ \\
\hline 2.5 & $3.61 \%$ & $3.36 \%$ & $3.07 \%$ & $2.69 \%$ & $1.59 \%$ & $2.20 \%$ \\
\hline 5.0 & $6.87 \%$ & $4.76 \%$ & $7.96 \%$ & $7.22 \%$ & $5.21 \%$ & $5.98 \%$ \\
\hline 7.5 & $8.70 \%$ & $7.83 \%$ & $16.30 \%$ & $12.46 \%$ & $11.86 \%$ & $19.82 \%$ \\
\hline 10.0 & $10.41 \%$ & $16.84 \%$ & $22.40 \%$ & $16.98 \%$ & $17.98 \%$ & $30.53 \%$ \\
\hline 15.0 & $10.25 \%$ & $16.30 \%$ & $23.33 \%$ & $23.91 \%$ & $33.12 \%$ & $40.93 \%$ \\
\hline 20.0 & $10.33 \%$ & $16.57 \%$ & $24.30 \%$ & $29.79 \%$ & $45.14 \%$ & $44.41 \%$ \\
\hline 25.0 & $11.21 \%$ & $17.40 \%$ & $25.52 \%$ & $29.31 \%$ & $44.77 \%$ & $46.26 \%$ \\
\hline 30.0 & $12.98 \%$ & $16.84 \%$ & $23.91 \%$ & $29.07 \%$ & $46.63 \%$ & $47.79 \%$ \\
\hline Infinite & $11.11 \%$ & $18.42 \%$ & $23.52 \%$ & $29.55 \%$ & $45.88 \%$ & $48.18 \%$ \\
\hline
\end{tabular}

Table 19. Calcium supplements' dissolution in surfactant containing media $75 \mathrm{rpm}$

\section{Diss olution Profile of Nature Made Calcium Carbonate in Different Level of Surfactant Mediums}

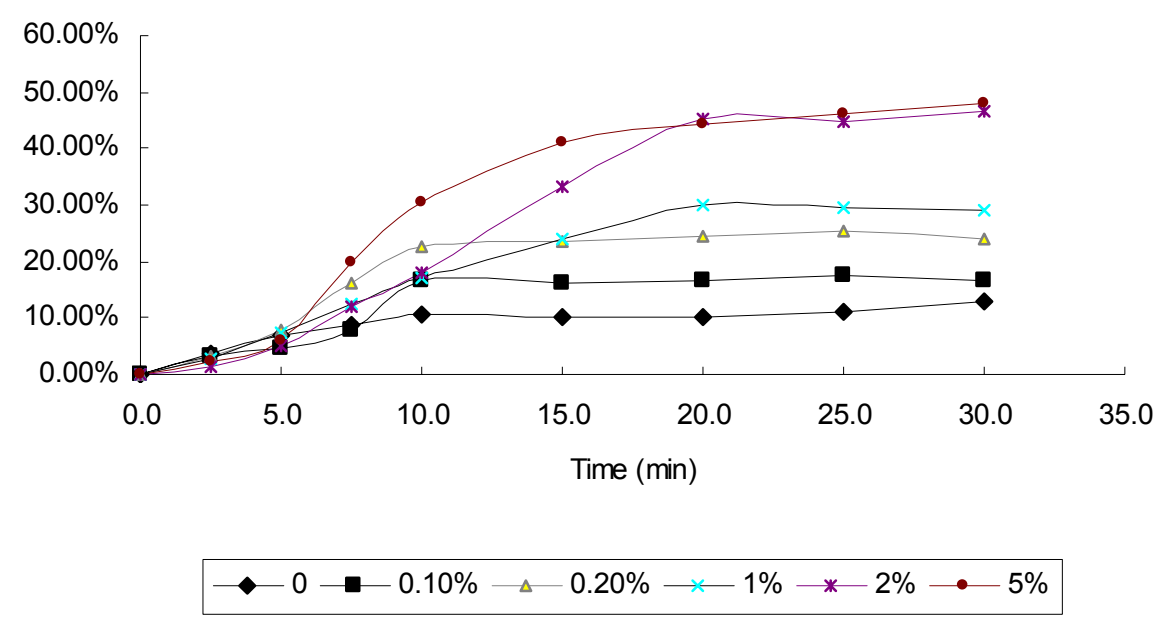

Figure 10. Calcium supplements' dissolution profiles in surfactant containing media $75 \mathrm{rpm}$

Again, the test provided an estimation of the extent to which surfactant would improve the dissolution. No repetitive runs were performed in this experiment. The results showed no obvious difference in release profiles from $50 \mathrm{rpm}$ and $75 \mathrm{rpm}$ experiments, except in the case of $2 \%$ surfactant. However, increased amount of Tween 80 improved the dissolution extent while slowing down the initial phase of release. For calcium dissolution in $2 \%$ and $5 \%$ media, it was not clear whether the dissolution was 
completed in 30 minutes. Therefore, it was necessary to run the dissolution at even higher stirring speed when surfactant concentration is high.

\section{B. Optimization of surfactant level II and optimization of stirring speed}

Based on the previous results, the following experiments were performed under conditions at higher stirring speeds (100 and $150 \mathrm{rpm})$. Higher Tween 80 concentrations were also tested to determine the upper limit of surfactant level.

1. Optimized Surfactant Level for NatureMade calcium carbonate

\begin{tabular}{|c|c|c|c|c|c|c|c|c|c|c|c|c|}
\hline \multicolumn{13}{|c|}{ Release percentage of Calcium in Each Sample } \\
\hline & \multicolumn{2}{|c|}{$\begin{array}{c}\text { Tween } 80 \text { 0\% } \\
\text { 100rpm }\end{array}$} & \multicolumn{2}{|c|}{$\begin{array}{c}\text { Tween } 80 \text { 10\% } \\
\text { 100rpm }\end{array}$} & \multicolumn{2}{|c|}{$\begin{array}{c}\text { Tween } 8012.5 \% \\
100 \mathrm{rpm}\end{array}$} & \multicolumn{2}{|c|}{$\begin{array}{c}\text { Tween } 8015 \% \\
\text { 100rpm }\end{array}$} & \multicolumn{2}{|c|}{$\begin{array}{c}\text { Tween } 80 \text { 10\% } \\
\text { 150rpm }\end{array}$} & \multicolumn{2}{|c|}{$\begin{array}{c}\text { Tween } 80 \text { 15\% } \\
\text { 150rpm }\end{array}$} \\
\hline Time (min) & AVG & $\mathrm{SD}$ & AVG & $\mathrm{SD}$ & AVG & SD & AVG & $\mathrm{SD}$ & AVG & $\mathrm{SD}$ & AVG & SD \\
\hline 0.0 & $0.00 \%$ & $0.00 \%$ & $0.00 \%$ & $0.00 \%$ & $0.00 \%$ & $.00 \%$ & $0.00 \%$ & $0.00 \%$ & $0.00 \%$ & $0.00 \%$ & $0.00 \%$ & $0.00 \%$ \\
\hline 2.5 & $1.37 \%$ & $0.22 \%$ & $3.64 \%$ & $1.01 \%$ & $1.57 \%$ & $0.58 \%$ & $1.27 \%$ & $0.36 \%$ & $1.92 \%$ & $0.92 \%$ & $1.25 \%$ & $0.36 \%$ \\
\hline 5.0 & $3.42 \%$ & $0.44 \%$ & $6.04 \%$ & $1.49 \%$ & $4.81 \%$ & $0.96 \%$ & $4.43 \%$ & $0.68 \%$ & $4.76 \%$ & $0.78 \%$ & $5.95 \%$ & $0.48 \%$ \\
\hline 7.5 & $10.69 \%$ & $1.71 \%$ & $14.93 \%$ & $2.93 \%$ & $13.63 \%$ & $1.53 \%$ & $11.49 \%$ & $0.84 \%$ & $16.88 \%$ & $2.29 \%$ & $14.08 \%$ & $0.32 \%$ \\
\hline 10.0 & $19.28 \%$ & $2.92 \%$ & $26.72 \%$ & $2.68 \%$ & $23.60 \%$ & $2.69 \%$ & $19.83 \%$ & $1.25 \%$ & $30.56 \%$ & $4.87 \%$ & $23.07 \%$ & $0.87 \%$ \\
\hline 15.0 & $18.98 \%$ & $0.86 \%$ & $38.32 \%$ & $1.76 \%$ & $38.04 \%$ & $1.00 \%$ & $31.78 \%$ & $1.16 \%$ & $44.50 \%$ & $6.42 \%$ & $33.41 \%$ & $2.32 \%$ \\
\hline 20.0 & $19.22 \%$ & $0.97 \%$ & $44.12 \%$ & $1.47 \%$ & $42.12 \%$ & $2.95 \%$ & $40.21 \%$ & $2.21 \%$ & $48.45 \%$ & $1.92 \%$ & $42.63 \%$ & $2.62 \%$ \\
\hline 25.0 & $19.33 \%$ & $0.90 \%$ & $48.63 \%$ & $2.22 \%$ & $46.94 \%$ & 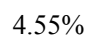 & $43.56 \%$ & $3.05 \%$ & $49.33 \%$ & $0.91 \%$ & $47.39 \%$ & $1.98 \%$ \\
\hline 30.0 & $19.20 \%$ & $0.20 \%$ & $50.82 \%$ & $1.27 \%$ & $48.69 \%$ & $4.77 \%$ & $44.63 \%$ & $3.06 \%$ & $49.63 \%$ & $1.15 \%$ & $49.04 \%$ & $2.92 \%$ \\
\hline 60.0 & $19.79 \%$ & $0.00 \%$ & $54.21 \%$ & $3.17 \%$ & $52.13 \%$ & $3.20 \%$ & $48.57 \%$ & $2.22 \%$ & $49.80 \%$ & $1.83 \%$ & $49.35 \%$ & $3.17 \%$ \\
\hline 90.0 & $19.74 \%$ & $0.91 \%$ & $55.09 \%$ & $2.33 \%$ & $51.67 \%$ & $3.62 \%$ & $49.16 \%$ & $2.10 \%$ & $49.49 \%$ & $1.38 \%$ & $49.33 \%$ & $2.73 \%$ \\
\hline 120.0 & $19.87 \%$ & $1.14 \%$ & $56.01 \%$ & $2.18 \%$ & $53.55 \%$ & $2.49 \%$ & $49.78 \%$ & $2.63 \%$ & $49.63 \%$ & $0.95 \%$ & $49.60 \%$ & $1.70 \%$ \\
\hline 150.0 & $19.93 \%$ & $1.18 \%$ & $56.48 \%$ & $2.29 \%$ & $53.05 \%$ & $2.18 \%$ & $50.09 \%$ & $2.86 \%$ & $49.95 \%$ & $1.88 \%$ & $49.47 \%$ & $2.32 \%$ \\
\hline 180.0 & $20.00 \%$ & $1.24 \%$ & $56.65 \%$ & $2.64 \%$ & $53.86 \%$ & $1.85 \%$ & $50.69 \%$ & $2.36 \%$ & $51.04 \%$ & $1.90 \%$ & $49.30 \%$ & $1.44 \%$ \\
\hline 210.0 & $20.00 \%$ & $1.41 \%$ & $56.33 \%$ & $2.35 \%$ & $53.70 \%$ & $2.12 \%$ & $50.85 \%$ & $2.43 \%$ & $49.95 \%$ & $1.62 \%$ & $50.08 \%$ & $2.49 \%$ \\
\hline 240.0 & $20.26 \%$ & $1.67 \%$ & $55.39 \%$ & $1.93 \%$ & $54.03 \%$ & $2.04 \%$ & $51.18 \%$ & $3.14 \%$ & $50.71 \%$ & $1.23 \%$ & $50.70 \%$ & $2.81 \%$ \\
\hline
\end{tabular}

Table 20. NatureMade calcium carbonate's dissolution profile in optimized test.

* AVG: average percentage; SD: standard deviation. total test runs $n=3$ 


\section{Optimized Surfactant Level for NatureMade Calcium Carbonate}

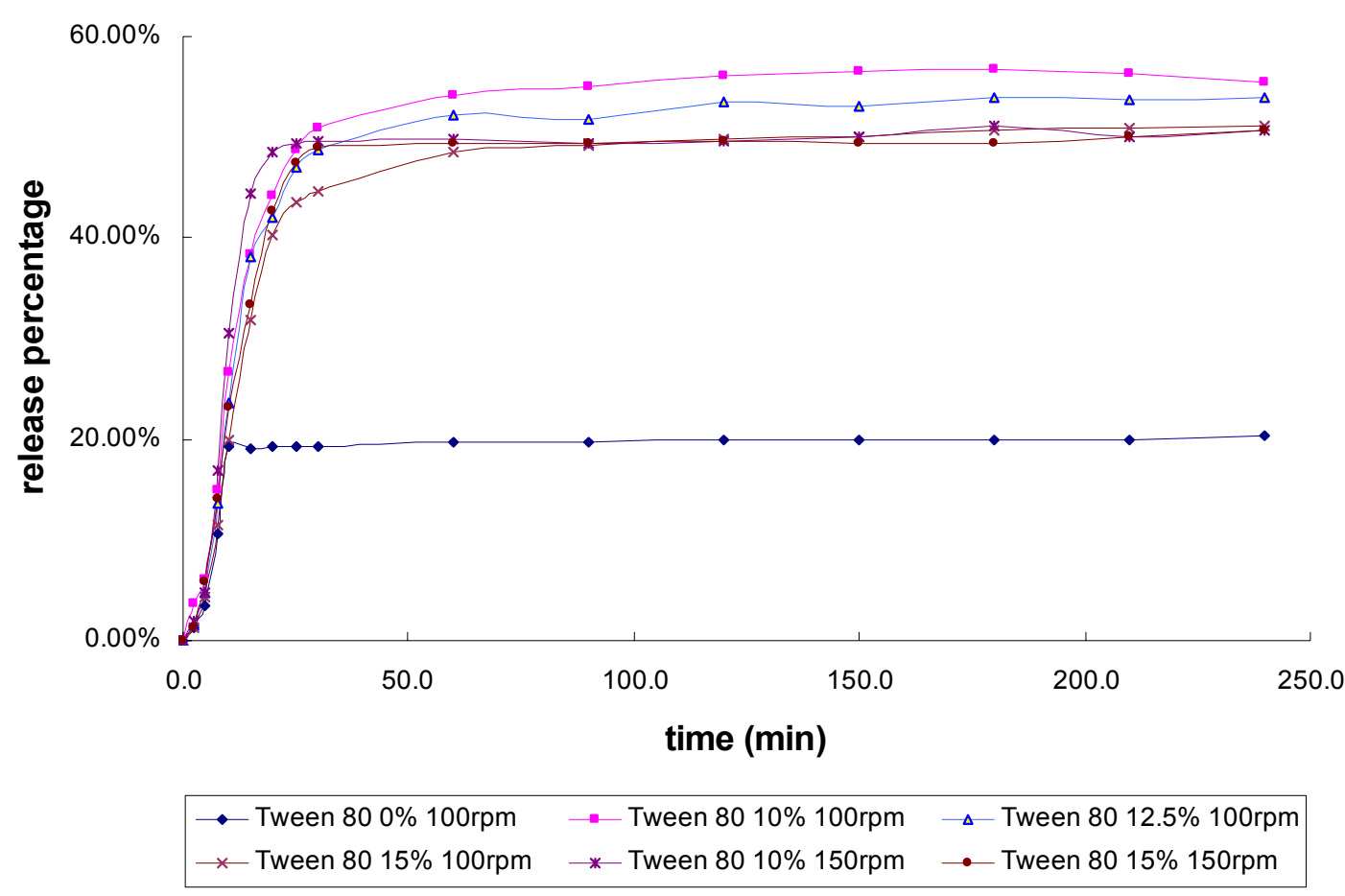

Figure 11. NatureMade Calcium Carbonate's dissolution profile in optimized test.

In the figure above, the deviation bars of the experiments are not shown for easier reading. The results show that the improvement of dissolution from increasing stirring speed is limited. For calcium carbonate, the testing with a speed of $100 \mathrm{rpm}$ is sufficiently high, and the optimum concentration of Tween 80 is $10 \%$. Further increase does not achieve better performance/greater dissolution.

2. Optimized Surfactant Level for Major Calcium Carbonate

The dissolution conditions used in the test for Major calcium carbonate and PhosLo calcium acetate were picked from the previous result of NatureMade calcium carbonate. Stirring speed was tested at 100 and $150 \mathrm{rpm}$; surfactant concentration was set at $10 \%$ and $15 \%$. The dissolution in surfactant containing medium was compared.

For Major calcium carbonate, the results are shown below: 


\begin{tabular}{|r|c|c|c|c|c|c|c|c|}
\hline \multicolumn{7}{|c|}{ Relative percentage of Calcium Dissolved in Each Sample } \\
\hline & \multicolumn{2}{|c|}{$\begin{array}{c}\text { Tween 80 0\% } \\
100 \text { rpm }\end{array}$} & \multicolumn{2}{c|}{$\begin{array}{c}\text { Tween 80 10\% } \\
100 r p m\end{array}$} & \multicolumn{2}{c|}{$\begin{array}{c}\text { Tween 80 10\% } \\
150 r p m\end{array}$} & \multicolumn{2}{c|}{$\begin{array}{c}\text { Tween 80 15\% } \\
150 r p m\end{array}$} \\
\hline & AVG & SD & AVG & SD & AVG & SD & AVG & SD \\
\hline Time (min) & $0.00 \%$ & $0.00 \%$ & $0.00 \%$ & $0.00 \%$ & $0.00 \%$ & $0.00 \%$ & $0.00 \%$ & $0.00 \%$ \\
\hline 2.0 & $11.04 \%$ & $1.72 \%$ & $4.39 \%$ & $1.23 \%$ & $5.13 \%$ & $1.15 \%$ & $4.19 \%$ & $0.33 \%$ \\
\hline 5.5 & $12.64 \%$ & $1.05 \%$ & $8.40 \%$ & $1.10 \%$ & $8.98 \%$ & $1.91 \%$ & $6.45 \%$ & $1.18 \%$ \\
\hline 7.5 & $13.31 \%$ & $0.96 \%$ & $10.76 \%$ & $0.79 \%$ & $10.83 \%$ & $1.09 \%$ & $9.40 \%$ & $0.79 \%$ \\
\hline 10.0 & $13.65 \%$ & $0.13 \%$ & $13.14 \%$ & $1.15 \%$ & $14.20 \%$ & $1.91 \%$ & $12.13 \%$ & $0.49 \%$ \\
\hline 15.0 & $13.73 \%$ & $0.26 \%$ & $15.32 \%$ & $0.66 \%$ & $15.29 \%$ & $1.72 \%$ & $13.83 \%$ & $0.59 \%$ \\
\hline 20.0 & $13.96 \%$ & $0.18 \%$ & $16.39 \%$ & $1.44 \%$ & $16.71 \%$ & $1.22 \%$ & $14.82 \%$ & $0.78 \%$ \\
\hline 25.0 & $14.00 \%$ & $0.24 \%$ & $16.71 \%$ & $1.40 \%$ & $16.98 \%$ & $1.36 \%$ & $15.40 \%$ & $1.15 \%$ \\
\hline 30.0 & $14.35 \%$ & $0.42 \%$ & $16.72 \%$ & $1.62 \%$ & $17.18 \%$ & $1.35 \%$ & $16.11 \%$ & $1.54 \%$ \\
\hline 60.0 & $14.68 \%$ & $0.67 \%$ & $17.07 \%$ & $1.34 \%$ & $17.29 \%$ & $1.35 \%$ & $16.47 \%$ & $1.60 \%$ \\
\hline 90.0 & $14.64 \%$ & $0.79 \%$ & $16.88 \%$ & $1.12 \%$ & $17.41 \%$ & $1.64 \%$ & $16.68 \%$ & $1.54 \%$ \\
\hline 120.0 & $14.51 \%$ & $0.52 \%$ & $16.75 \%$ & $1.29 \%$ & $17.41 \%$ & $1.62 \%$ & $16.61 \%$ & $1.38 \%$ \\
\hline 150.0 & $14.67 \%$ & $0.49 \%$ & $16.90 \%$ & $1.53 \%$ & $17.77 \%$ & $1.42 \%$ & $16.79 \%$ & $1.64 \%$ \\
\hline 180.0 & $14.63 \%$ & $0.48 \%$ & $17.14 \%$ & $1.64 \%$ & $17.50 \%$ & $1.33 \%$ & $16.73 \%$ & $1.59 \%$ \\
\hline 210.0 & $14.47 \%$ & $0.46 \%$ & $16.90 \%$ & $1.62 \%$ & $17.61 \%$ & $1.41 \%$ & $16.77 \%$ & $1.40 \%$ \\
\hline 240.0 & $14.67 \%$ & $0.45 \%$ & $16.98 \%$ & $1.42 \%$ & $17.49 \%$ & $1.19 \%$ & $16.95 \%$ & $1.67 \%$ \\
\hline
\end{tabular}

Table 21. Major Calcium Carbonate's dissolution profile in optimized test.

Optimized Surfactant Level for

Major Calcium Carbonate

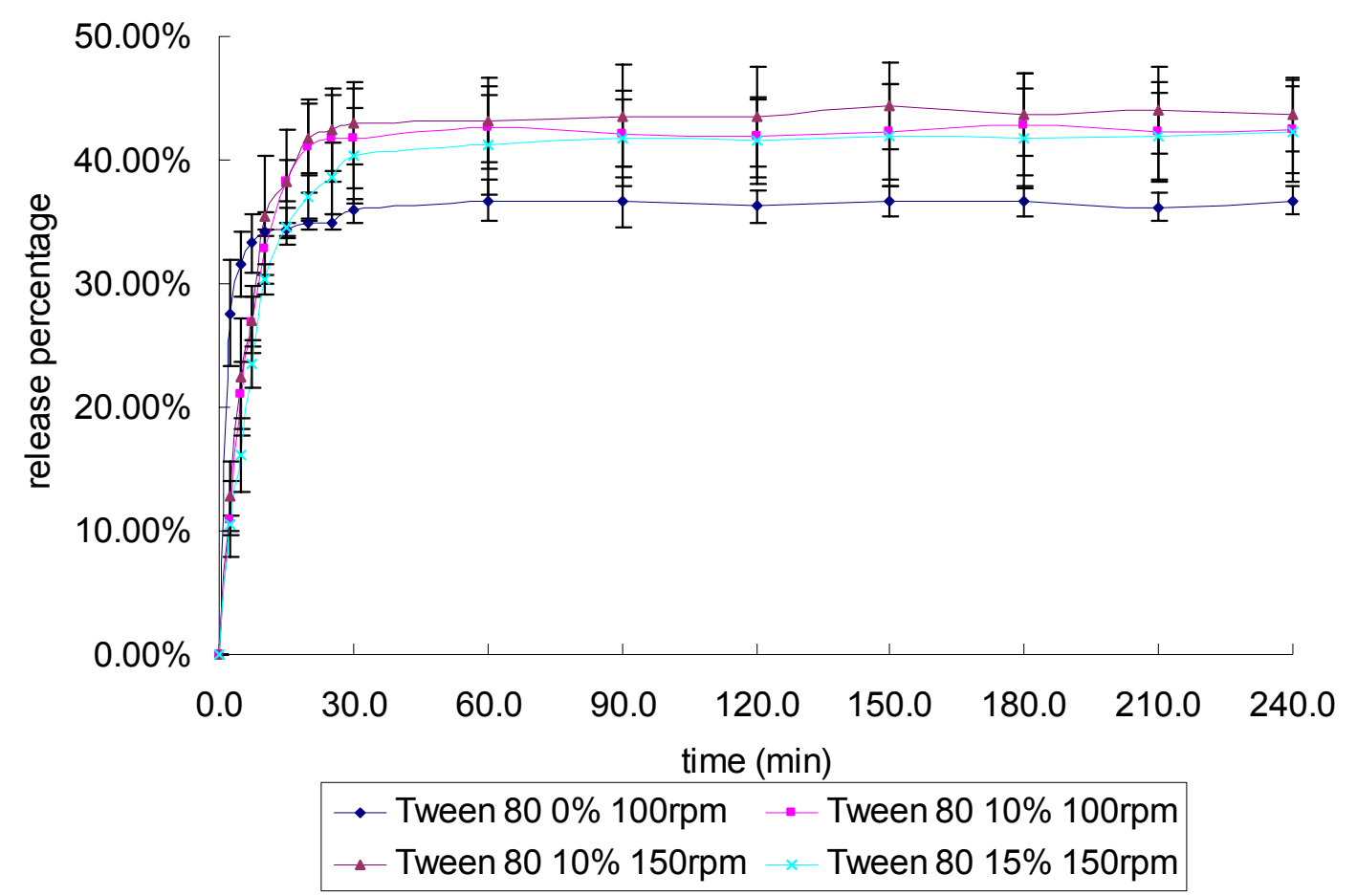

Figure 12. Major Calcium Carbonate's dissolution profile in optimized test. 
3. Optimized Surfactant Level for PhosLo Calcium Acetate

For PhosLo calcium acetate, the results are shown below:

\begin{tabular}{|c|c|c|c|c|c|c|c|c|}
\hline \multicolumn{9}{|c|}{ Relative percentage of Calcium Dissolved in Each Sample } \\
\hline & \multicolumn{2}{|c|}{$\begin{array}{c}\text { Tween } 800 \% \\
\text { 100rpm }\end{array}$} & \multicolumn{2}{|c|}{$\begin{array}{c}\text { Tween } 8010 \% \\
\text { 100rpm }\end{array}$} & \multicolumn{2}{|c|}{$\begin{array}{c}\text { Tween } 8010 \% \\
150 \mathrm{rpm}\end{array}$} & \multicolumn{2}{|c|}{$\begin{array}{c}\text { Tween } 80 \text { 15\% } \\
\text { 150rpm }\end{array}$} \\
\hline Time (min) & AVG & SD & AVG & SD & AVG & SD & AVG & SD \\
\hline 0.0 & $0.00 \%$ & $0.00 \%$ & $0.00 \%$ & $0.00 \%$ & $0.00 \%$ & $0.00 \%$ & $0.00 \%$ & $0.00 \%$ \\
\hline 2.5 & $15.59 \%$ & $3.34 \%$ & $3.57 \%$ & $0.70 \%$ & $5.29 \%$ & $1.26 \%$ & $2.84 \%$ & $0.72 \%$ \\
\hline 5.0 & $16.95 \%$ & $1.64 \%$ & $5.37 \%$ & $1.87 \%$ & $12.31 \%$ & $3.33 \%$ & $4.83 \%$ & $0.64 \%$ \\
\hline 7.5 & $17.91 \%$ & $1.85 \%$ & $7.15 \%$ & $2.74 \%$ & $18.58 \%$ & $3.35 \%$ & $10.05 \%$ & $2.35 \%$ \\
\hline 10.0 & $17.53 \%$ & $1.13 \%$ & $9.69 \%$ & $2.47 \%$ & $24.33 \%$ & $1.78 \%$ & $19.10 \%$ & $3.13 \%$ \\
\hline 15.0 & $17.18 \%$ & $0.64 \%$ & $13.32 \%$ & $2.40 \%$ & $25.88 \%$ & $2.44 \%$ & $22.29 \%$ & $1.27 \%$ \\
\hline 20.0 & $17.47 \%$ & $0.70 \%$ & $16.44 \%$ & $1.07 \%$ & $26.02 \%$ & $2.09 \%$ & $22.49 \%$ & $2.50 \%$ \\
\hline 25.0 & $18.04 \%$ & $1.43 \%$ & $19.42 \%$ & $3.72 \%$ & $26.61 \%$ & $2.76 \%$ & $22.81 \%$ & $2.99 \%$ \\
\hline 30.0 & $17.89 \%$ & $1.45 \%$ & $21.69 \%$ & $3.14 \%$ & $26.44 \%$ & $2.66 \%$ & $23.09 \%$ & $2.88 \%$ \\
\hline 60.0 & $18.44 \%$ & $1.57 \%$ & $24.01 \%$ & $2.13 \%$ & $27.15 \%$ & $2.24 \%$ & $22.98 \%$ & $3.27 \%$ \\
\hline 90.0 & $18.55 \%$ & $1.63 \%$ & $26.11 \%$ & $3.75 \%$ & $26.99 \%$ & $2.28 \%$ & $23.75 \%$ & $2.96 \%$ \\
\hline 120.0 & $18.44 \%$ & $2.24 \%$ & $26.25 \%$ & $2.80 \%$ & $26.99 \%$ & $2.40 \%$ & $24.16 \%$ & $3.41 \%$ \\
\hline 150.0 & $18.64 \%$ & $1.37 \%$ & $25.80 \%$ & $3.47 \%$ & $27.02 \%$ & $2.85 \%$ & $24.52 \%$ & $3.26 \%$ \\
\hline 180.0 & $18.17 \%$ & $1.94 \%$ & $26.24 \%$ & $3.64 \%$ & $26.61 \%$ & $2.76 \%$ & $24.39 \%$ & $3.53 \%$ \\
\hline 210.0 & $18.15 \%$ & $1.74 \%$ & $26.46 \%$ & $2.56 \%$ & $26.50 \%$ & $2.18 \%$ & $24.77 \%$ & $3.45 \%$ \\
\hline 240.0 & $18.55 \%$ & $1.71 \%$ & $27.04 \%$ & $2.30 \%$ & $27.43 \%$ & $2.76 \%$ & $24.55 \%$ & $2.64 \%$ \\
\hline
\end{tabular}

Table 22. PhosLo Calcium Acetate's dissolution profile in optimized test. 


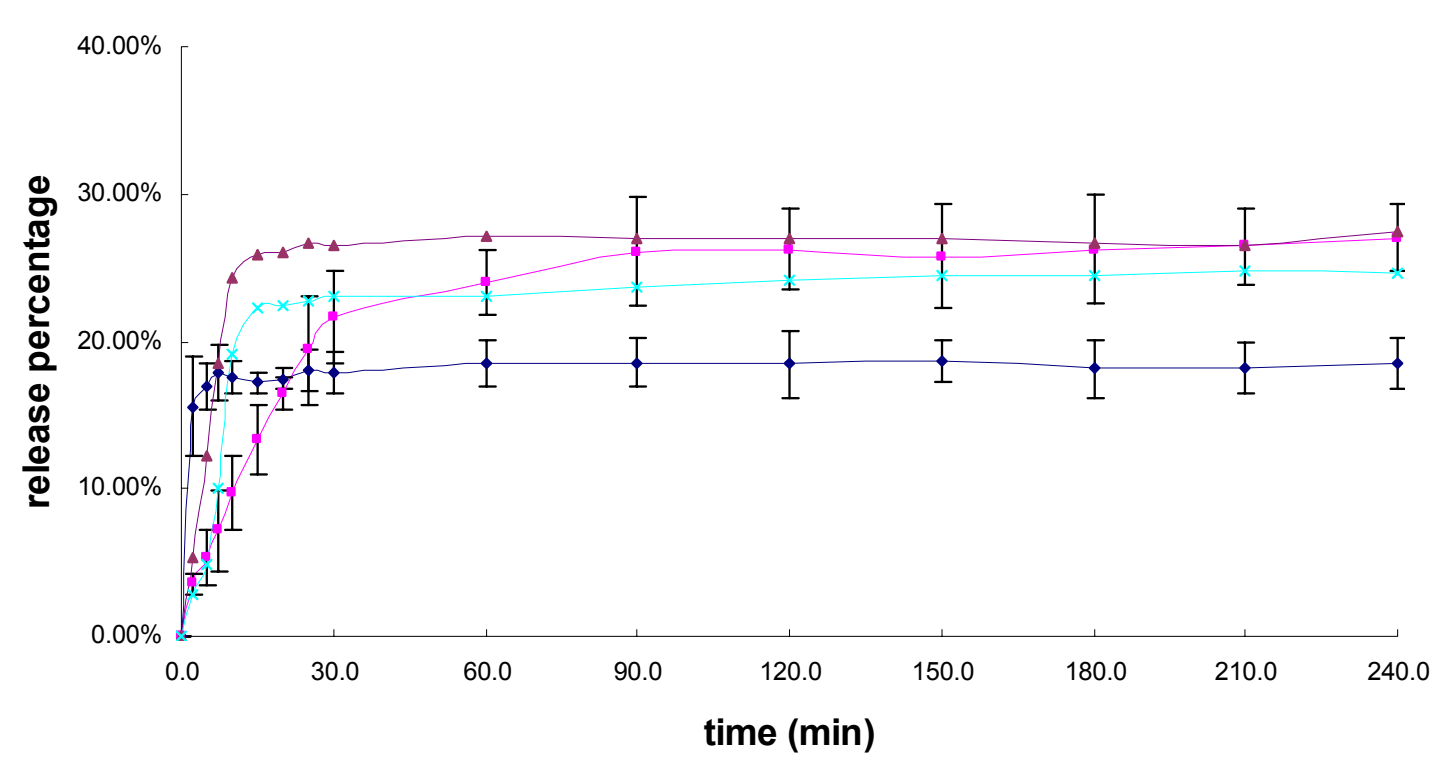

- Tween 80 0\% 100rpm - Tween 80 10\% 100rpm

^- Tween 80 10\% 150rpm * Tween 80 15\% 150rpm

Figure 13. PhosLo Calcium Acetate's dissolution profile in optimized test.

The best testing method for Naturemade calcium carbonate was used for both Major and PhosLo. The surfactant level was compared between $10 \%$ and $15 \%$, while stirring is between 100 and $150 \mathrm{rpm}$. From the data shown in Figures 13 and 14, the dissolution of calcium has increased significantly compared with that in plain medium (with no surfactant). And again, there is no meaningful improvement when the stirring speed is higher that $100 \mathrm{rpm}$ or the surfactant level higher than $10 \%$.

The general structure of a surfactant includes a hydrophilic portion (usually a polar or ionic group, water soluble) and a hydrophobic portion (usually a long fatty or hydrocarbon chain, water insoluble). This dual functionality helps wetting and spreading across the particle surface. The relative solubility is thus improved. The 
results above seem to confirm this. The addition of surfactant increases the extent of drug release significantly, making the test more sensitive. The results show that the upper limit of surfactant (Tween 80) for optimization is about $10 \%$. The salt most sensitive to this effect appears to be calcium carbonate.

When the surfactant is added into the solution, the dissolution medium becomes less acidic. In the lack of the low $\mathrm{pH}$ environment (a low $\mathrm{pH}$ facilitates tablet disintegration and increase the surface area of calcium available for dissolution), the dissolution rate is then decreased, taking longer time to reach saturation. Faster stirring can help reduce this delay. The results show increased agitation can make the dissolution completed in 30 minutes, a typical length of time for the dissolution test. The optimum stirring speed should be decided based on the release rate of each product. For calcium acetate, $150 \mathrm{rpm}$ stirring is favored, while in other two products, no significant change can be seen between 100 and $150 \mathrm{rpm}$.

In conclusion, the optimum testing methodology should be:

- Calcium carbonate tablet

Medium: 10\% Tween 80 in 1N hydrochloric acid, $900 \mathrm{~mL}$

Apparatus 2: $100 \mathrm{rpm}$

Time: 30 minutes

- Calcium acetate tablet

Medium: 10\% Tween 80 in 1N hydrochloric acid, $900 \mathrm{~mL}$

Apparatus 2: $150 \mathrm{rpm}$

Time: 30 minutes 
As for the tolerance of the test, even under this optimum condition, it is not realistic to require $75 \%(\mathrm{Q})$ dissolution in the experiment. As seen in the results aforementioned, around $50 \%$ calcium release is the best to be achieved.

\section{Phase III - Use of revised method to evaluate dissolution of calcium}

\section{supplement tablets}

1. Physical tests

\begin{tabular}{|c|c|c|c|c|c|}
\hline \multicolumn{2}{|l|}{ Brand } & $\begin{array}{l}\text { Tums } \\
\text { Pink }\end{array}$ & $\begin{array}{c}\text { Tums } \\
\text { Orange }\end{array}$ & $\begin{array}{c}\text { Tums } \\
\text { Brown }\end{array}$ & $\begin{array}{l}\text { Tums } \\
\text { Yellow }\end{array}$ \\
\hline \multicolumn{2}{|l|}{ Salt form } & Carbonate & Carbonate & Carbonate & Carbonate \\
\hline \multicolumn{2}{|c|}{ Elemental calcium content } & \multicolumn{4}{|c|}{$300 \mathrm{mg}$} \\
\hline \multicolumn{2}{|l|}{ Lot } & \multicolumn{4}{|c|}{ 4D19 } \\
\hline \multirow{2}{*}{$\begin{array}{l}\text { Weight } \\
\text { Variation (g) }\end{array}$} & Mean & 1.894 & 1.896 & 1.886 & 1.885 \\
\hline & Std Dev & 0.007 & 0.014 & 0.008 & 0.006 \\
\hline \multirow{2}{*}{ Thickness (inch) } & Mean & 0.2194 & 0.2167 & 0.2205 & - \\
\hline & Std Dev & 0.0007 & 0.0008 & 0.0083 & - \\
\hline \multirow{2}{*}{ Hardness (kP) } & Mean & 11.1 & 11.2 & 12.6 & - \\
\hline & Std Dev & 0.5 & 0.7 & 0.8 & - \\
\hline
\end{tabular}

Table 23. Physical properties of Tums calcium carbonate chewable tablets

* Not enough tablets for physical tests of Tums Yellow.

** Elemental calcium content was calculated from the products' labeled content $\mathrm{CaCO}_{3} 750 \mathrm{mg}$.

*** The tested Tums is the chewable, quick dissolve product.

Since there are four different flavor tablets in one bottle (using the same lot number), we separated them and tested these individually.

According to the results, the formulation variation of different flavored tablets does not result in significant change in their physical properties. Therefore, the amount of flavor and color additive are limited and do not appear to affect the tablets' physical properties significantly. Since the processing parameter and other excipients for each 
flavor may be the same, which guarantees the conformity within the batch, it is reasonable for the manufacturer to use the same lot number for all four flavor tablets.

\section{Disintegration tests}

Chewable tablets are not formulated to disintegrate. (They have no inherent disintegration behavior, as they are chewed.) These studies were still performed, however, for purpose of comparison. The disintegration medium used was distilled water, $\mathrm{pH}=5-7$. The disintegration of the tested tablet cannot significantly change the $\mathrm{pH}$ of the medium.

\begin{tabular}{|l|c|c|c|c|}
\hline Brand & Tums Pink & Tums Orange & Tums Brown & Tums Yellow \\
\hline Lot & 4D19 & 4D19 & 4D19 & 4D19 \\
\hline Time (min) & 9.9 & 7.8 & 8.6 & 7.1 \\
\hline Std Dev (min) & 0.4 & 0.0 & 0.2 & 0.2 \\
\hline
\end{tabular}

Table 24. Disintegration time for Tums calcium carbonate chewable tablets.

Of note is that this product is formulated to be used both as a calcium supplement and as an anti-acid tablet. In the use as an antacid, the goal is to achieve quick disintegration, meaning that products will break into fine powders in very short time and thus create more surface area to contact and absorb gastric acid. This explains its quick disintegration, less than ten (10) minutes, independent of being chewed.

\section{Dissolution tests}

All four flavored tablets were tested by both USP standard method and the optimized surfactant medium method. These chewable tablets were quick to dissolve. 
Our preliminary study showed their dissolution reached maximum in less than thirty (30) minutes at a stirring speed of $50 \mathrm{rpm}$ in a surfactant containing medium. The comparison of dissolution by the two methods is shown below:
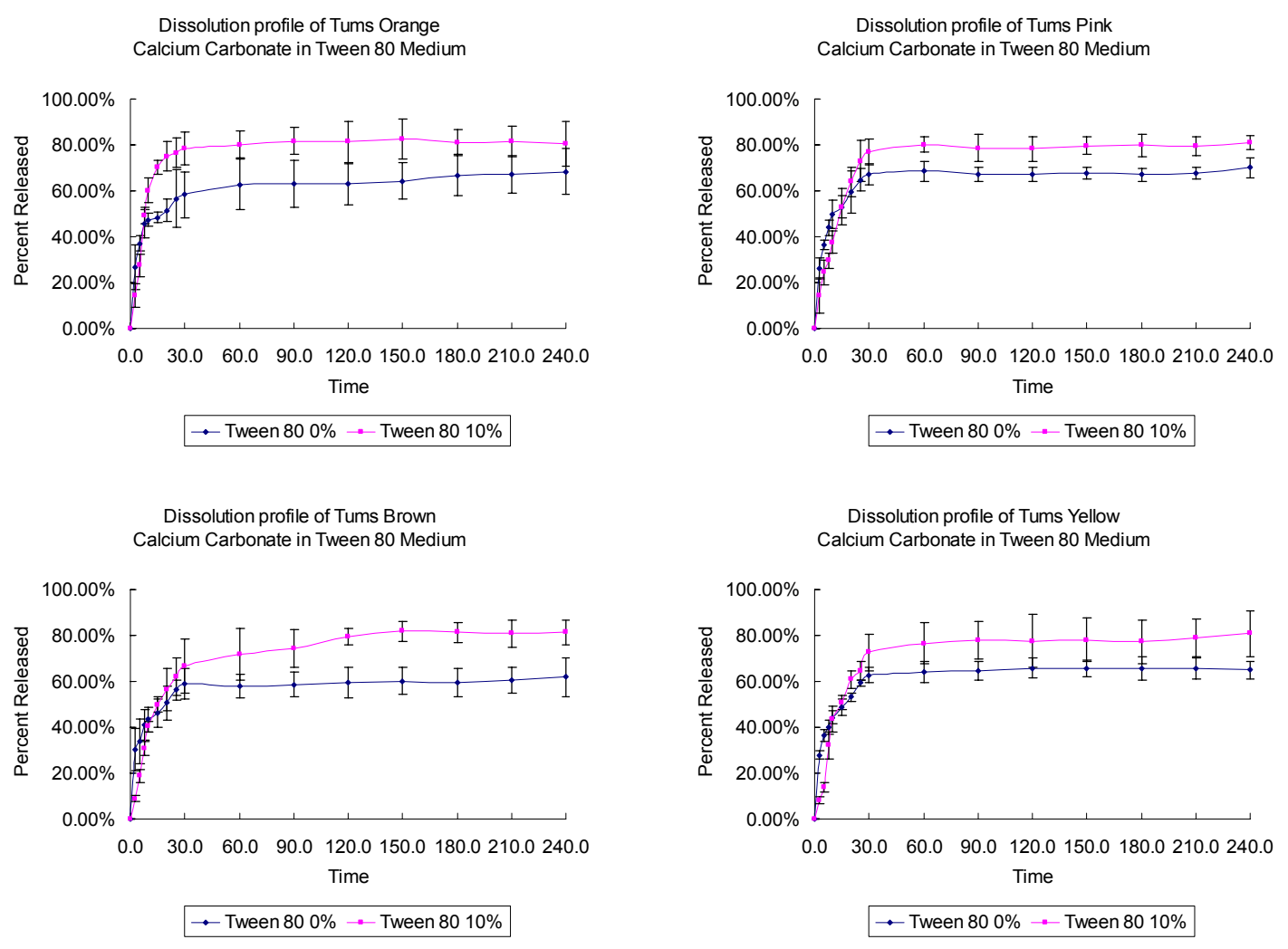

Figure 14. Dissolution profiles of Tums chewable tablets in USP and revised testing method.

The results show that in all four flavored products, the extent and rate of dissolution again appear limited by the poor solubility of calcium carbonate. The products cannot release over $70 \%$ calcium in USP standard method. When surfactant is added in high concentration, for all four flavored tablets, the calcium release can reach over $70 \%$ in 30 minutes. In this case, the addition of Tween 80 successfully makes the tolerance in USP become an attainable goal.

Because the drug, when used as an antacid, is supposed to have its effect in the 
stomach instead of being absorbed into the blood for a systemic effect, enhanced dissolution is not required. However, since this product is being recommended for use in the prevention of osteoporosis (i.e. systemic effect), complete dissolution would be desired.

4. The comparison of dissolution profiles using optimized and USP conditions.

The dissolution profiles of NatureMade, Major and PhosLo which were obtained by using both optimized and USP conditions were compared.

\section{Comparison of dissolution profiles for PhosLo calcium acetate}

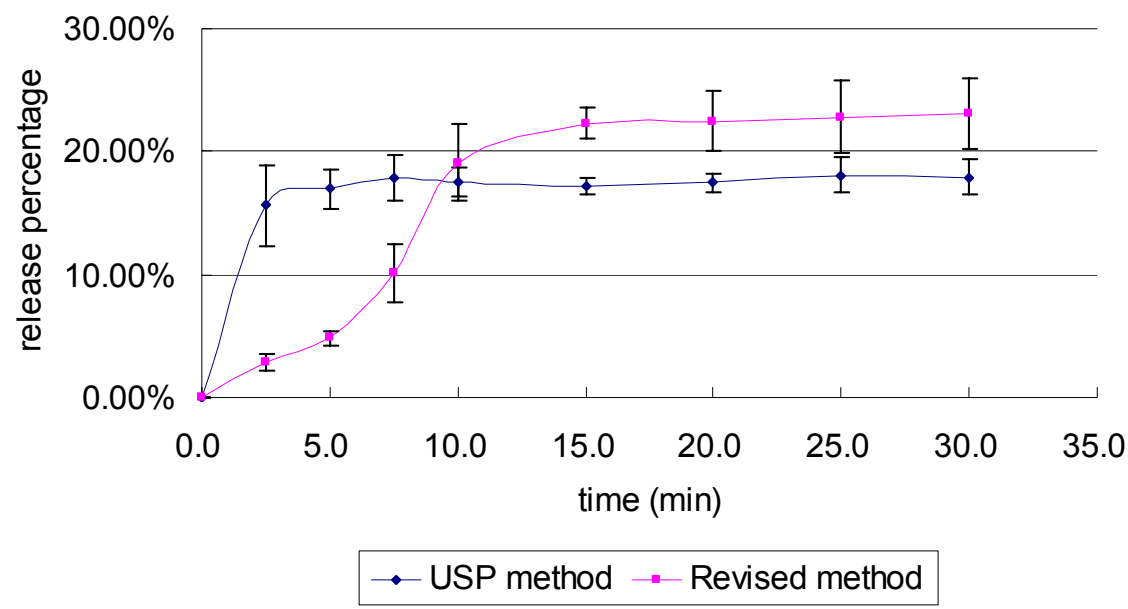




\section{Comparison of dissolution profiles for NatureMade calcium carbonate}

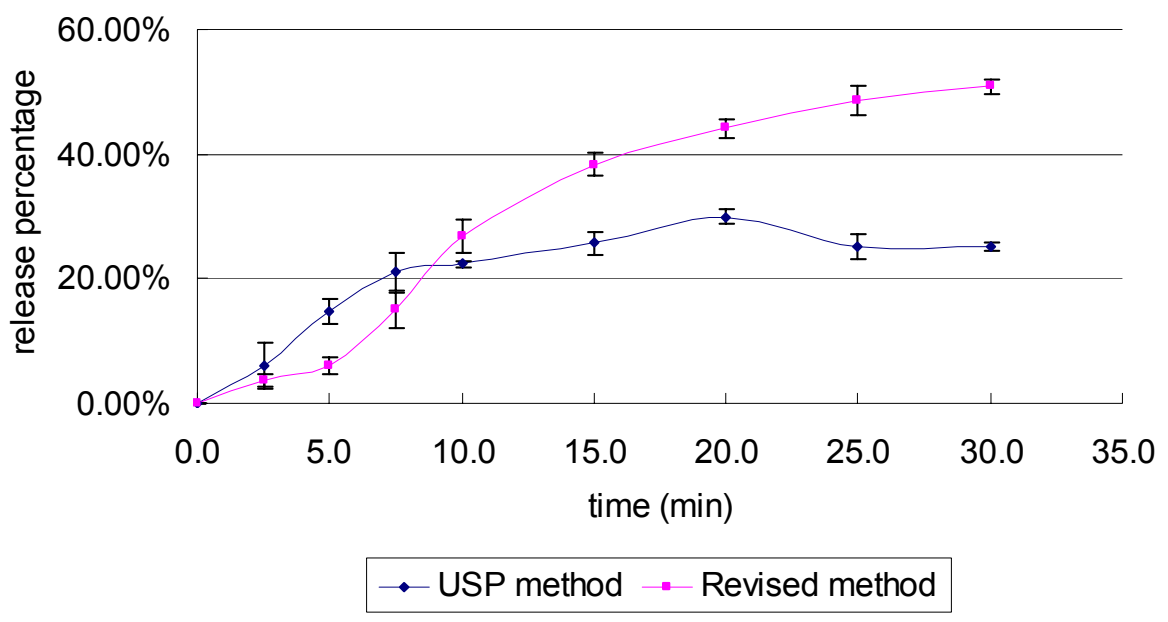

\section{Comparison of dissolution profiles for Major calcium carbonate}

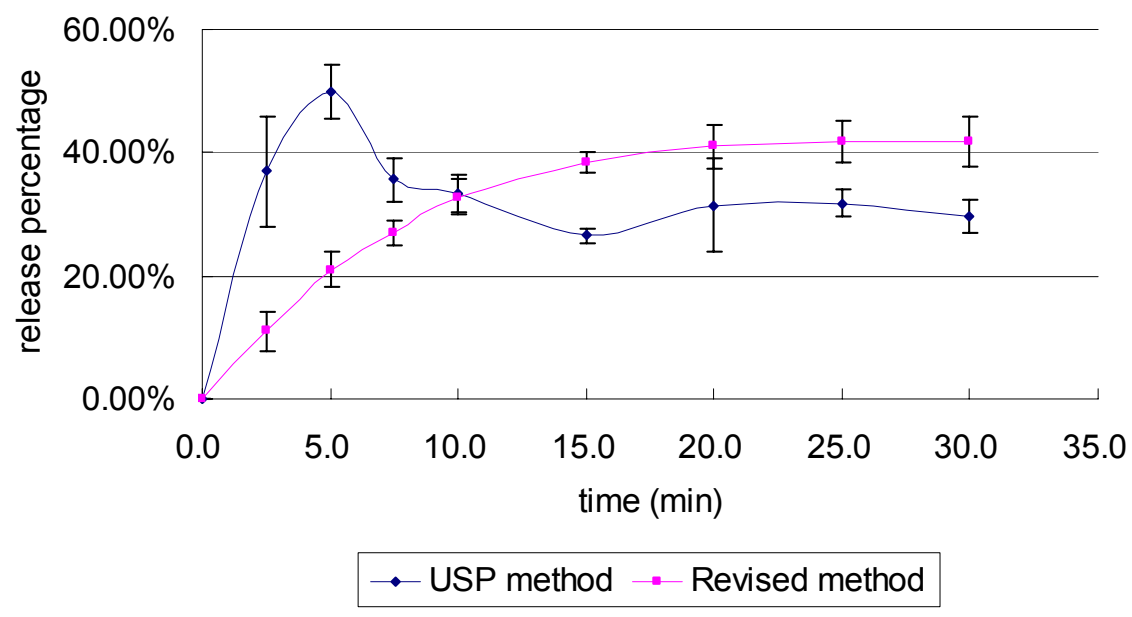

Figure 15. The comparison of dissolution profiles using optimized and USP conditions.

From the figures above, a significant improvement can be observed in the revised test. This result confirmed the optimized methodology was an improvement over USP, showing greater dissolution and increased sensitivity. 


\section{References for Chapter IV}

1. McGraw - Hill. Lange's Handbook of Chemistry $11^{\text {th }}$ Edition. P4-30-31 


\section{Chapter V}

\section{Summary and Conclusions}

With the increasing popularity of regularly using calcium supplements with the intention of health benefits, the quality of these products is coming under growing scrutiny. Concerns in their absorption and effectiveness call for a closer look at the current testing methods for them. In our research, the pharmaceutical quality of several commercially available calcium products was examined; a revised dissolution testing methodology was developed and proposed; and the testing of representative calcium supplements with the new method was performed.

The results showed that all products we tested can meet the USP guidelines in physical properties and disintegration requirement. Product disintegration times wee affected by $\mathrm{pH}$ effects, to some extent, with disintegration prolonged at more basic $\mathrm{pH}$. For dissolution, the current USP test is not sensitive for most calcium products. The limitations of the regular USP test resulted in limited dissolution (i.e. under 30\%), which may be related to the poor solubility of calcium salts in the dissolution medium. In order to develop a more sensitive testing method, different approaches to change the dissolution parameters were experimented so that a best testing criterion was eventually decided.

This revised testing methodology was based on the experiments of products in 
traditional tablet formulation. It was also then used in the test of some chewable calcium tablets. The results confirmed that this revised method also improved the sensitivity of USP dissolution test in chewable tablets.

The success of this revised test may not only be limited in the testing of calcium supplement. In recent years the use of surfactant in the dissolution test, as in this "optimized" method, has been included in more and more USP monograph. Similar approaches can be used in a number of other products with less soluble active ingredients.

For calcium supplements, more new formulations and new calcium salt forms have emerged in the past few years. Most came to the market with a self-claim of improved dissolution. Therefore more follow-up research in this field is needed to characterize these products' efficacy and satisfy the consumers' ability to make the right choice. 